\title{
The Renaissance of Non-Aqueous Uranium Chemistry
}

Stephen T. Liddle*

School of Chemistry, University of Nottingham, University Park, Nottingham, NG7 2RD, UK.

*Email: stephen.liddle@nottingham.ac.uk

\section{Summary}

Prior to the year 2000, non-aqueous uranium chemistry mainly involved metallocene and classical alkyl, amide or alkoxide compounds, and established carbene, imido, and oxo derivates. In the past 10-15 years, there has been a resurgence of the area and a dramatic expansion of supporting ligands, multiply bonded ligand types, small molecule activation, and magnetism. This review: (i) introduces the reader to some of the specialist theory of the area; (ii) covers all-important starting materials; (iii) surveys contemporary ligand classes installed at uranium including alkyls, aryls, arenes, carbenes, amides, imides, nitrides, alkoxides, aryloxides, and oxos; (iv) describes advances in single molecule magnetism; (v) summarises the coordination and activation of small molecules including carbon monoxide, carbon dioxide, nitric oxide, dinitrogen, white phosphorus, and alkanes. The review closes with a summary of progress and looking forward proposes remaining 'grand challenges'.

\section{Introduction}

Ever since the Manhattan Project, which sought to identify volatile compounds for the separation of fissionable isotopes for nuclear applications, there has been significant interest in actinide chemistry. ${ }^{[1]}$ In a nuclear age, it is critical to understand the fundamental chemistry and speciation of actinides because of the potential scientific and societal implications for processing nuclear fuels and weapons and radioactive waste clean-up. ${ }^{[2]}$ Given its prominent role in these technologies, and because it is one of the more amenable actinides to investigate, one of the most intensively researched actinide elements is uranium. ${ }^{[3]}$ For many years the majority of studies involved aqueous systems of direct relevance to nuclear fuel processes. However, under these conditions, systems are operating at, or close to, thermodynamic sinks (e.g. uranyl), or can only be supported by watercompatible ligands. Under non-aqueous conditions such restrictions are relaxed, giving opportunities to prepare uranium complexes that would not normally exist and thus gain glimpses of the 'hidden' and 'true' character of uranium. ${ }^{[4]}$ Researching non-aqueous systems, which we will 
define as complexes prepared in anhydrous organic solvents, permits the study of novel uraniumligand bonds and reactivity. This in turn enables us to address fundamental questions over the extent and nature ( $5 \mathrm{f}$ vs $6 \mathrm{~d}$ ) of covalency in uranium chemical bonding and how it impacts reactivity and physicochemical properties. This could impact on waste remediation where a key approach to minimize the volume of radioactive waste, and recycle useful components, is via separation technologies; these aim to deploy ligands that exploit the different levels of covalency in chemical bonding of the myriad of elements that are present in radioactive waste. ${ }^{[5]}$

Understanding the electronic structure of uranium complexes could impact on a number of areas in addition to waste remediation. For example, the magnetism of uranium is complex and only partly understood, yet novel phenomena such as single molecule magnetism have been discovered. The rich redox chemistry of uranium gives unique opportunities in small molecule activation. Also, the isolation of novel complexes provides opportunities to test theoretical models. Historically, the area was under-developed compared to the rest of the periodic table where, for example, textbook examples for the d-block - e.g. alkylidenes, carbynes, terminal nitride - are still, or until very recently were, unknown for uranium. Early work predominantly involved metallocene derivatives, and established first row multiply bonded ligand chemistry and static magnetism. In recent years, the renaissance of the area has seen a dramatic expansion of supporting ligands, post-first row multiply bonded ligand chemistry, small molecule activation, and dynamic magnetism. In addition to the synthetic challenges in this area, the historical lag is due to a relatively low level of research activity because of a combination of the difficulty in sourcing suitable uranium starting materials, and real, or perceived, safety constraints. Also, a significant factor has undoubtedly been the negative image of uranium from its association with nuclear weapons. However, as early as 1909 in the original Haber Bosch patent the chemical novelty and potential of uranium was revealed since it is a better promoter for ammonia formation than iron. ${ }^{[6]}$ Thus, from a chemical perspective uranium is an exciting element to work with. There are certainly still entry-barriers to working with this intriguing element, but a number of research groups now routinely work in this area and with modern synthetic methods and ever better analytical techniques the area has blossomed in recent years. This is evidenced by the fact that nearly half of all uranium entries in the Cambridge Structural Database have been added within the last decade alone. ${ }^{[7]}$

On the topic of safety, ${ }^{238} \mathrm{U}$, the principal uranium isotope in depleted uranium, is a relatively weak $\alpha$-emitter, and with a half life of ca. $4.47 \times 10^{9}$ years most research labs can be configured for this chemistry without needing the specialist equipment required for the more hazardous transuranics that require national facilities. The use of depleted, as opposed to natural abundance, uranium is 
particularly appealing because, in addition to the reduction of ${ }^{235} \mathrm{U}$ to ca. $0.2 \%$ in the former from $0.7 \%$ in the latter, its use in research finds utility for a 'waste' by-product of uranium isotope enrichment. So long as diligent monitoring is established, material use logged, containment of materials is ensured, safety protocols and assessments are implemented, and disposal is managed, then non-aqueous uranium chemistry can be routinely conducted on multi-gram scales.

Reflecting the burgeoning nature of the area after progress in the 1960s and 1970s, ${ }^{[8,11]}$ in the past three decades there have been a growing number of excellent review articles. ${ }^{[12-32]}$ Given that many areas (e.g. cyclopentadienyls, amides, alkoxides, halides, metal-ligand multiple bonding, metalmetal bonds, pentavalent uranium, uranyl, small molecule activation, magnetism, catalysis) have already been described in comprehensive detail elsewhere, this review adopts a different approach. Many readers may not be familiar with some of the specialist theory of uranium chemistry, so this review describes pertinent aspects to provide context for those new to the area before describing allimportant starting materials. Some key ligand-types of non-aqueous uranium chemistry are then described followed by aspects of single molecule magnetism and small molecule activation. In-line with the criteria for review articles, rather than a complete literature survey, a critical selection is presented, and discussions are limited to crystallographically authenticated compounds. The chemistry of uranium clusters, solid-state, extended lattices, and ionic liquids are beyond the scope

of this review. ${ }^{[33,34]}$ An extended discussion of uranyl chemistry, which represents a class in its own right, is also beyond the remit of this review. The review closes with a summary of the area and looking forward proposes 'grand challenges' that remain to be accomplished.

The following abbreviations are used throughout: $\mathrm{Ad}=$ adamantyl, Bipy $=2,2^{\prime}$-bipyridine, $\mathrm{dbabh}=$ 2,3:5,6-dibenzo-7-azabicyclo[2.2.1]hepta-2,5-diene, COT $=$ cyclooctatetrylene, $\operatorname{Dipp}=2,6$ diisopropylphenyl, Ditb $=$ 2,6-di-tert-butylphenyl, dmap $=4$-dimethylaminopyridine, DME $=1,2$ dimethoxyethane, Mes = 2,4,6-trimethylphenyl, Mes* = 2,4,6-tri-tert-butylphenyl, OTf = triflate, Py $=$ pyridine, tacn = triazacyclononane, $\mathrm{THF}=$ tetrahydrofuran, tmeda $=N, N, N^{\prime}, N^{\prime}-$ tetramethylethylenediamine, $\mathrm{SMM}=$ single molecule magnet, $\mathrm{TMS}=\mathrm{SiMe}_{3}, \mathrm{Tol}=$ para-tolyl, $\mathrm{Xy}$ = 3,5-dimethylphenyl, $12 \mathrm{C} 4=12$-crown-4 ether. 15C5 = 15-crown-5 ether, B15C5 = benzo-15crown ether, $18 \mathrm{C} 6=18$-crown- 6 ether.

\section{Periodicity and Physicochemical Properties}

Uranium was first isolated from pitchblende by Klaproth in 1789 and was named after Uranus, which had been discovered by Herschel in 1781. As the first f-element to be isolated, uranium was an anomaly for some time when the structure of the periodic table was yet to be determined. Indeed, 
for some time uranium was erroneously classified as a transition metal, being pseudo-isovalent to group 6 metals, until Seaborg recognized the existence of the $5 \mathrm{f}$ series so providing element 92 with its rightful place in the periodic table. However, it should be noted that uranium exhibits something of a Dr. Jekyll and Mr. Hyde character, ${ }^{[26 c]}$ not only in terms of the incongruous dichotomy of nuclear power and weapons applications, but also the fact that in some scenarios uranium behaves like transition metals but in others more like the lanthanides, so it is not surprising that uranium was originally mis-classified. The following sections describe some of the fundamental aspects of uranium chemistry that should be appreciated when contextualizing later sections.

\subsection{Periodicity}

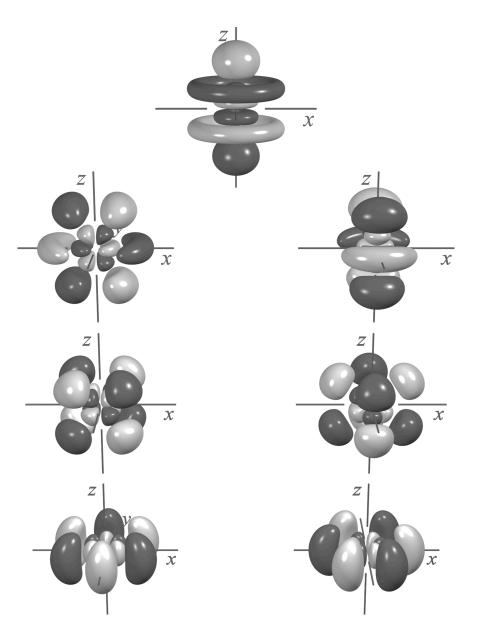

Figure 1. The seven 5 f-orbitals in the general setting. From top to bottom and left to right they are: $f_{z^{3}}, f_{x z}, f_{y z}, f_{x y z}, f_{z\left(x^{2}-y^{2}\right)}, f_{x\left(x^{2}-3 y^{2}\right)}$, and $f_{y\left(3 x^{2}-y^{2}\right)}$. Reproduced with kind permission of Prof. Mark Winter's Orbitron (University of Sheffield).

With principal quantum numbers $n=5, l=3, m_{l}= \pm 3, \pm 2, \pm 1$, and 0 (and for completeness $m_{s}=$ $\pm 1 / 2$ ), the seven 5 f-orbitals have large angular momentum. The projection of these orbitals is not as straightforward as the standard $\mathrm{d}_{\mathrm{z}^{2}}, \mathrm{~d}_{\mathrm{x} 2}-\mathrm{y}^{2}, \mathrm{~d}_{\mathrm{xy}}, \mathrm{d}_{\mathrm{xz}}$, and $\mathrm{d}_{\mathrm{yz}}$ orbitals for transition metals since there are the cubic $\left(\mathrm{f}_{\mathrm{z}} 3, \mathrm{f}_{\mathrm{y}} 3, \mathrm{f}_{\mathrm{x}} 3, \mathrm{f}_{\mathrm{xyz}}, \mathrm{f}_{\mathrm{z}\left(\mathrm{x}^{2}-\mathrm{y}^{2}\right)}, \mathrm{f}_{\mathrm{y}\left(\mathrm{z}^{2}-\mathrm{x}^{2}\right)}\right.$, and $\left.\mathrm{f}_{\mathrm{x}\left(\mathrm{y}^{2}-\mathrm{z}^{2}\right)}\right)$ and general $\left(\mathrm{f}_{\mathrm{z}^{3}}, \mathrm{f}_{\mathrm{xz}} \mathrm{z}^{2}, \mathrm{f}_{\mathrm{yz}}, \mathrm{f}_{\mathrm{xyz}}, \mathrm{f}_{\mathrm{z}\left(\mathrm{x}^{2}-\mathrm{y}^{2}\right)}, \mathrm{f}_{\mathrm{x}\left(\mathrm{x}^{2}-\right.}\right.$ $\left.3 y^{2}\right)$, and $\left.f_{y\left(3 x^{2}-y^{2}\right)}\right)$ setting representations. Since cubic symmetry is not so common in molecular uranium chemistry the general set are most appropriate generally (Figure 1). The notable difference to the $4 \mathrm{f}$ orbitals is the presence of an additional radial node due to the $n-l-1$ rule (total number of angular and radial nodes $=n-1$ ); this affects the pull that the 5 f-orbitals 'feel' from the effective nuclear charge which becomes important in the context of oxidation states and covalency.

\subsection{Relativistic Effects, Oxidation States, and Standard Potentials}




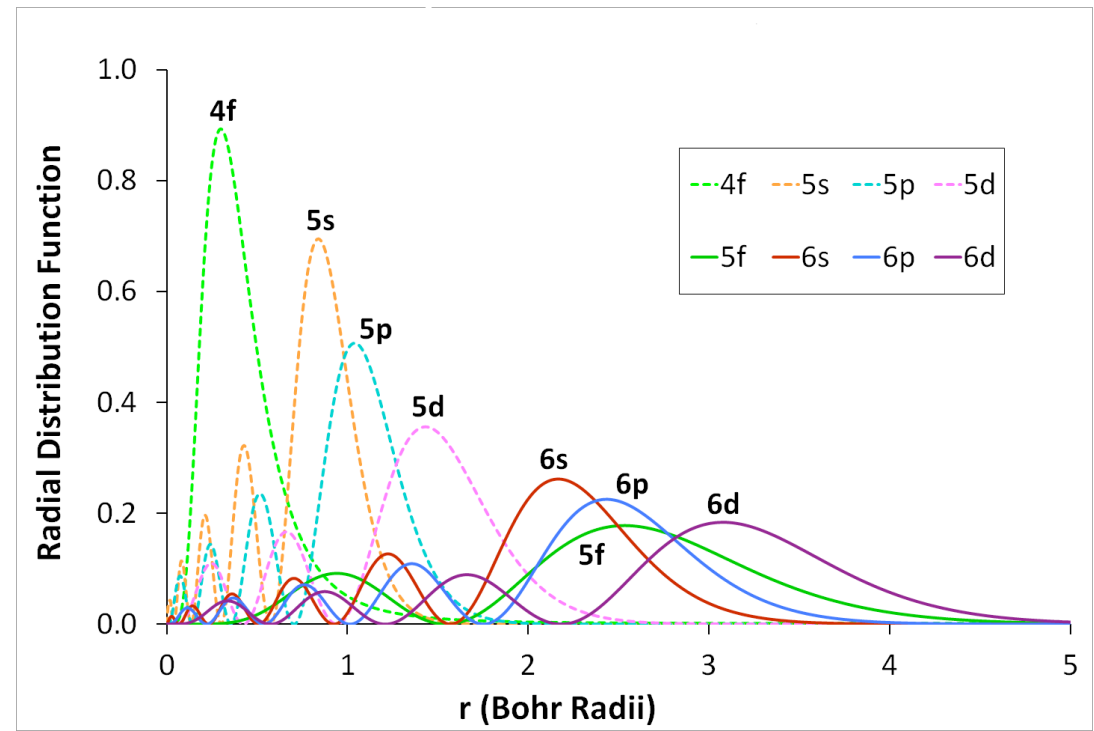

Figure 2. Illustrative radial distribution functions for $4 f, 5 s, 5 p, 5 d, 5 f, 6 s, 6 p$, and $6 d$ atomic orbitals.

At this point a discussion of relativistic effects is warranted. In principle, relativistic effects affect all elements in the periodic table, but in practice the effects are negligible for light elements. However, around platinum onwards relativistic effects begin to have tangible effects, such as the preference for linear coordination geometries in gold complexes. Einstein's Special Theory of Relativity states that objects moving towards the speed of light gain mass because of the equivalence of kinetic energy and mass from $\mathrm{E}=\mathrm{mc}^{2}$. Thus:

$$
\mathrm{m}=\mathrm{m}_{0} / \sqrt{ }\left(1-(\mathrm{v} / \mathrm{c})^{2}\right)
$$

[where $\mathrm{m}_{0}=$ rest mass, $\mathrm{v}=$ velocity, $\mathrm{c}=$ speed of light $]$

In atomic units the average radial velocity $<\mathrm{v}_{\text {rad }}>$ of a 1 s-electron is approximately $Z$, so for uranium:

$$
<\mathrm{V}_{\mathrm{rad}}>/ \mathrm{c}=92 / 137=0.67
$$

[where $\mathrm{c}$ is expressed in atomic units, hence the supposed limit of 137 for element atomic numbers]

Therefore, the mass increase is:

$$
\mathrm{m}=\mathrm{m}_{\text {electron }} / \sqrt{ }\left(1-(0.67)^{2}\right)=1.35 \mathrm{~m}_{\text {electron }}
$$

Thus, because the electron is travelling at an appreciable fraction of the speed of light the relativistic mass of the electron increases so the 1s-orbital contracts as do all other s-functions. A similar effect occurs for p-orbitals and this phenomenon is known as the direct relativistic orbital contraction. A consequence of this is that the $\mathrm{d}$ - and f-orbitals are more greatly shielded from the 
effective nuclear charge than they would otherwise have been and so undergo radial expansion; this is known as the indirect relativistic orbital expansion. The heavier the element the greater the effect, such that by uranium these effects are physically significant. Thus, the 5f-orbitals extend out from the atomic core into the valence region, an effect that can be obviously seen in the radial distribution plots in Figure 2. It is this phenomena which lies behind the increased covalency of $5 f-$ orbitals compared to $4 \mathrm{f}$, due to better overlap with ligand frontier orbitals; this underpins the ongoing debate over the levels of covalency that uranium exhibits compared to the essentially ionic lanthanides and transition metals which vary from electrostatic to covalent.

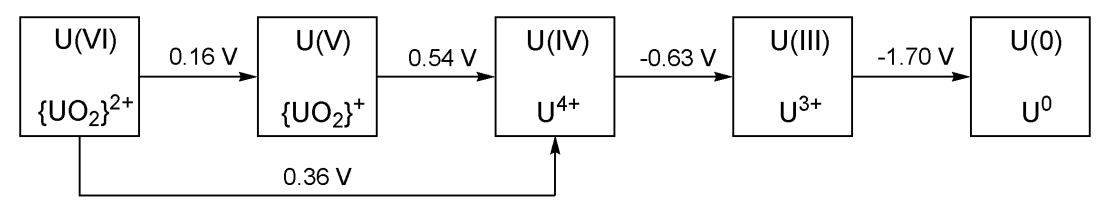

Scheme 1. Formal reduction potentials for uranium (V vs SHE in $1 \mathrm{M} \mathrm{HClO}_{4}$ at $298 \mathrm{~K}$ ).

Relativistic effects, and the concomitant radial extension of the 5 f-orbitals, are also responsible for the easily accessible range of oxidation states of uranium ( +3 to +6$)$; this behaviour is typically characteristic of transition metals, whereas transuranics, with 5 f-orbitals that become increasingly 'core-like' on increasing $Z$, increasingly favour the +3 oxidation state like the lanthanides. An illustration of the profound effect relativistic effects have is that a non-relativistic calculation yields a binding energy for a $5 \mathrm{f}$ electron to uranium of ca. $1665 \mathrm{~kJ} \mathrm{~mol}^{-1}$, but when relativistic effects are included the binding energy is essentially halved to $869 \mathrm{~kJ} \mathrm{~mol}^{-1}{ }^{[4]}$ Thus, ionization, and a range of accessible oxidation states, is easier to achieve in a relativistic regime. It should be noted that some oxidation states for uranium are more common than others. For example, uranium(III) may disproportionate into 0.75 equivalents of uranium(IV) and 0.25 equivalents of uranium( $(0)$. Uranium(III) is strongly reducing and can reduce substrates with low-lying $\pi$-systems to produce uranium(IV) complexes, whereas uranium(V) and (VI) can be very oxidizing. Uranium(V) is often unstable with respect to disproportionation to uranium(IV) and (VI) and so must be kinetically stabilized. Overall, uranium(IV) and (VI) are the most common oxidation states, with the latter most prevalent in the uranyl dication $\left\{\mathrm{UO}_{2}\right\}^{2+}$. This is all consistent with the $5 \mathrm{f}$ standard reduction potentials for uranium shown in Scheme $1 .^{[35]}$ 
a)

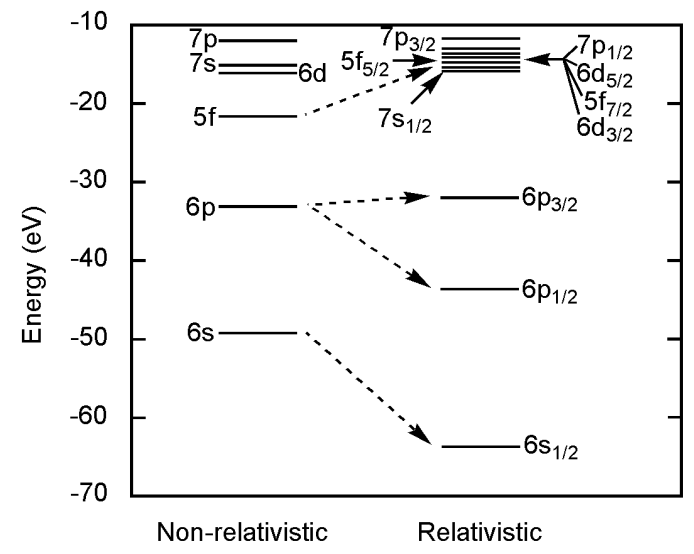

b)

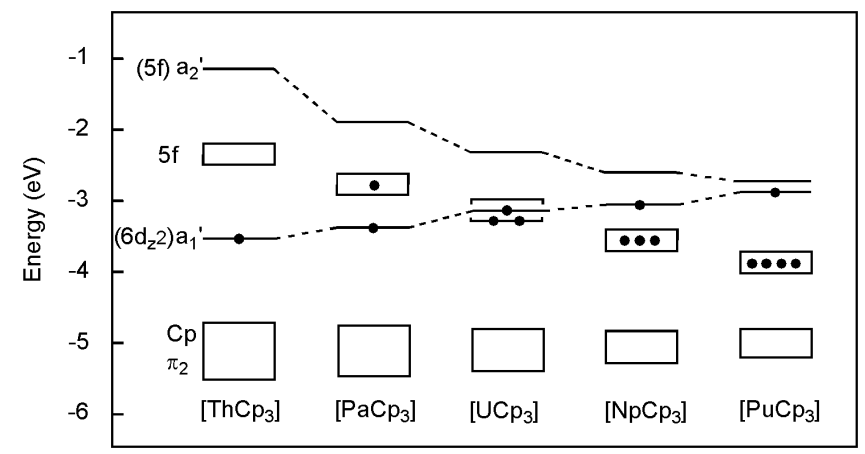

Figure 3. a) Variation of frontier uranium orbital energies with and without relativistic effects; the latter incorporates spin orbit coupling. Adapted from Handbook of Nuclear Chemistry, Volume 2, Dordrecht, 2003. b) Illustration of the variation of metal-based frontier orbital energies for the $5 \mathrm{f}^{\mathrm{n}-}$ ${ }^{1} 6 \mathrm{~d}^{1}$ electron configurations of $\mathrm{Cp}_{3} \mathrm{An}(\mathrm{An}=\mathrm{Th}, \mathrm{Pa}, \mathrm{U}, \mathrm{Np}, \mathrm{Pu})$ complexes; the frontier electrons are shown as black dots. Adapted from Bursten et al, J. Am. Chem. Soc. 1989, 111, 2756.

So far the discussion has focused on 5f-orbitals, but $6 \mathrm{~d}$-orbitals merit consideration. At the start of the actinide series the 5f-orbitals are higher in energy than the 6d-orbitals, but as the series is transversed the 5f-orbitals fall in energy and become increasingly 'core-like' (cf the small concentration of electron density close to the nucleus in Figure 2). At the same time the 6d-orbitals rise in energy. One consequence of relativistic effects is that the valence orbitals of uranium are compressed into a tighter energetic range than they would otherwise be (Figure 3a). ${ }^{[36]}$ Because the $5 \mathrm{f}$ - and 6d-orbitals start in relatively close proximity (ca. $1.5 \mathrm{eV}$ ), and the former falls in energy and the latter rises, at some point they cross over. It so happens that the cross-over point occurs at uranium $\left(\Delta 5 \mathrm{f} / 6 \mathrm{~d}=\sim 300 \mathrm{~cm}^{-1}\right),{ }^{[37]}$ which is demonstrated by the calculated frontier orbitals of $\mathrm{Cp}_{3} \mathrm{An}(\mathrm{An}=\mathrm{Th}, \mathrm{Pa}, \mathrm{U}, \mathrm{Np}, \mathrm{Pu})$ shown in Figure $3 \mathrm{~b} .{ }^{[38]}$ This provides uranium with a unique capacity to potentially hybridize $5 \mathrm{f}$ - and $6 \mathrm{~d}$-orbitals, which underpins the debate about the nature of uranium covalency in terms of $5 \mathrm{f}-$ and $6 \mathrm{~d}$-orbital contributions to chemical bonding. 
a)

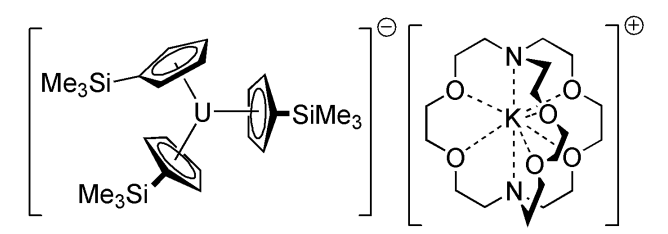

1

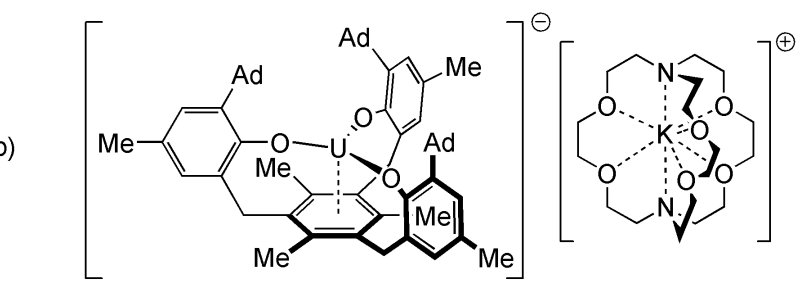

2

Figure 4. Landmark uranium(II) complexes. a) Structure of 1. b) Structure of 2.

It should be noted that the accessibility of oxidation states and energetic separation of $5 \mathrm{f}-$ and $6 \mathrm{~d}-$ orbitals can be greatly affected by the ligand environment. For example, until recently there were no molecular examples of uranium(II). Starting with an electronic configuration of $[R n] 5 \mathrm{f}^{3} 6 \mathrm{~d}^{1} 7 \mathrm{~s}^{2}$, uranium would be expected to easily ionize to form [Rn] $5 f^{3}$ uranium(III). [Rn] $5 f^{3} 6 d^{1}$ uranium(II) would be expected to be difficult to achieve. However, recent experimental studies carried out at $-45^{\circ} \mathrm{C}$ yielded the uranium(II) complex $\left[\mathrm{U}\left(\eta^{5}-\mathrm{C}_{5} \mathrm{H}_{4} \mathrm{SiMe}_{3}\right)_{3}\right][\mathrm{K}(2,2,2-\mathrm{crypt})](\mathbf{1})$, Figure $4 \mathrm{a}$, and the characterization data are consistent with a $[\mathrm{Rn}] 5 \mathrm{f}^{3} 6 \mathrm{~d}^{1}$ ground state. ${ }^{[39]}$ A demonstration that the ligand environment is key to the nature of the ground state was provided soon afterwards in another low temperature study that yielded the uranium(II) complex $\left[\mathrm{U}\left\{\eta^{6}-\mathrm{C}_{6} \mathrm{Me}_{3}\left(\mathrm{CH}_{2} \mathrm{C}_{6} \mathrm{H}_{2}-3-\mathrm{Me}-5-\mathrm{Ad}-6\right.\right.\right.$ $\left.\left.\mathrm{O}_{3}\right\}\right]\left[\mathrm{K}\left(2,2,2\right.\right.$-crypt)] (2) supported by $\delta$-backbonding, Figure 4b. ${ }^{[40]}$ Interestingly, in this complex the characterization data are consistent with a $[\mathrm{Rn}] 5 \mathrm{f}^{4}$ ground state. These two landmark complexes demonstrate how ligand design is crucial to stabilizing novel structural motifs and controlling the electronic structure of uranium.

\subsection{Spin Orbit, LS Russell-Saunders, and j-j Coupling}

Like relativistic effects, spin-orbit coupling affects all elements, but these effects become more pronounced for heavy elements. For the d-block, spin orbit coupling is relatively small $\left(\sim 200 \mathrm{~cm}^{-1}\right)$ and instead crystal field effects dominate $\left(\Delta_{0} \sim 15,000-25,000 \mathrm{~cm}^{-1}\right)$ so the orbital angular momenta $(L)$ is often quenched leaving the spin angular momenta $(S)$. For the lanthanides, crystal field effects are small $\left(\sim 100 \mathrm{~cm}^{-1}\right)$, spin orbit coupling is becoming significant $\left(\sim 1000 \mathrm{~cm}^{-1}\right)$ but inter-electronic repulsions dominate. In contrast, crystal field effects for uranium are appreciable $\left(\sim 1000 \mathrm{~cm}^{-1}\right)$ and inter-electronic repulsion is still greatest but spin orbit coupling is now relatively large $(\sim 2000$ $\mathrm{cm}^{-1}$ ). Therefore, for uranium the coupling of $S$ with $L$ to give the quantum number $J$, the total atomic angular momentum, must be considered. 
There are two principal ways of considering the construction of $J$. $L S$, or Russell-Saunders, coupling can be use in systems with relatively weak spin orbit coupling compared to interelectronic repulsion. Two assumptions are then made. Firstly, all electron spins couple amongst themselves to generate $S$; secondly, all electron orbital momenta couple amongst themselves to give $L$. $S$ and $L$ then couple together to give $J$. This gives rise to term symbols ${ }^{(2 S+1)} L_{J}$, which for uranium are ${ }^{5} \mathrm{I}_{4},{ }^{4} \mathrm{I}_{9 / 2},{ }^{3} \mathrm{H}_{4},{ }^{2} \mathrm{~F}_{5 / 2}$, and ${ }^{1} \mathrm{~S}_{0}$ for uranium(II) (assuming [Rn $] 5 \mathrm{f}^{4}$ not $[\mathrm{Rn}] 5 \mathrm{f}^{3} 6 \mathrm{~d}^{1}$ ), (III) ([Rn]5f $\mathrm{f}^{3}$ ), (IV) $\left([\mathrm{Rn}] 5 \mathrm{f}^{2}\right),(\mathrm{V})\left([\mathrm{Rn}] 5 \mathrm{f}^{1}\right)$, and (VI) ([Rn]), respectively. This method assumes that the ground state is well separated from excited states, i.e. there is no mixing of $J$ levels. The alternative method is $\mathrm{j}-\mathrm{j}$ coupling. This method is applicable where the spin orbit coupling is strong in relation to interelectronic repulsion. In this scheme the spin angular and orbital angular momenta combine to give a total angular momentum for each individual electron, $j$. The individual $j$ values are then coupled to give $J$. However, for uranium it is not straightforward to use $L S$ or $\mathrm{j}$-j coupling schemes because uranium sits in between the assumptions that underpin each approach. Additionally, because of the diffuse nature of $5 \mathrm{f}$-orbitals, compared to $4 \mathrm{f}$-orbitals, and their increased sensitivity to the ligand field, neither method is entirely appropriate for uranium because, unlike in lanthanides which have well separated $J$ levels, in uranium the $J$ levels mix; i.e. $J$ is no longer a reliable quantum number. However, it is useful to operate in a framework and the $L S$ coupling scheme provides a good first approximation on which to base uranium electronic structure and magnetism models.

\subsection{Electronic Absorption Spectroscopy}

Like any other metal complex, the electronic absorption spectra of uranium complexes may in principle exhibit LMCT, MLCT, and $\pi-\pi^{*}$ transitions, however the interpretation of uranium $\mathrm{UV} / \mathrm{Vis} / \mathrm{NIR}$ spectra in the context of $\mathrm{f}-\mathrm{f}$ and $\mathrm{f}-\mathrm{d}$ transitions is not always straightforward and it is instructive to set this in the context of transition metal and lanthanide optical absorption spectra. The bonding of lanthanides is essentially ionic and therefore lanthanide ions experience a very small crystal field. Therefore, their optical spectra are reminiscent of the free ions and essentially independent of the ligand environment; f-f absorption bands are consequently very sharp (little vibronic character) and weak, because they are Laporte forbidden (this and subsequent statements will assume a centrosymmetric molecule such as in $O_{\mathrm{h}}$ symmetry). f-d transitions usually occur well into the UV region because of large 4f-5d energy gaps, although this is of course oxidation statedependent. In contrast, transition metal optical spectra are often broad reflecting extensive vibronic coupling from strong crystal fields. $d$-d transitions are also Laporte forbidden, but d-orbital mixing with ligand frontier orbitals of opposite parity switches on transitions so appreciable intensities are observed, although they are still not of the magnitude of $\pi-\pi^{*}$ and LMCT/MLCT transitions. 
a)

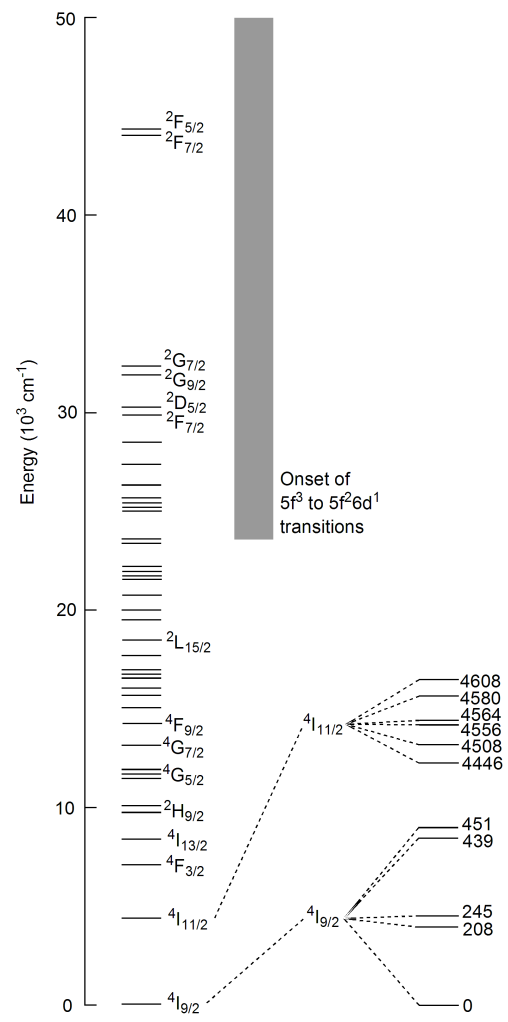

b)

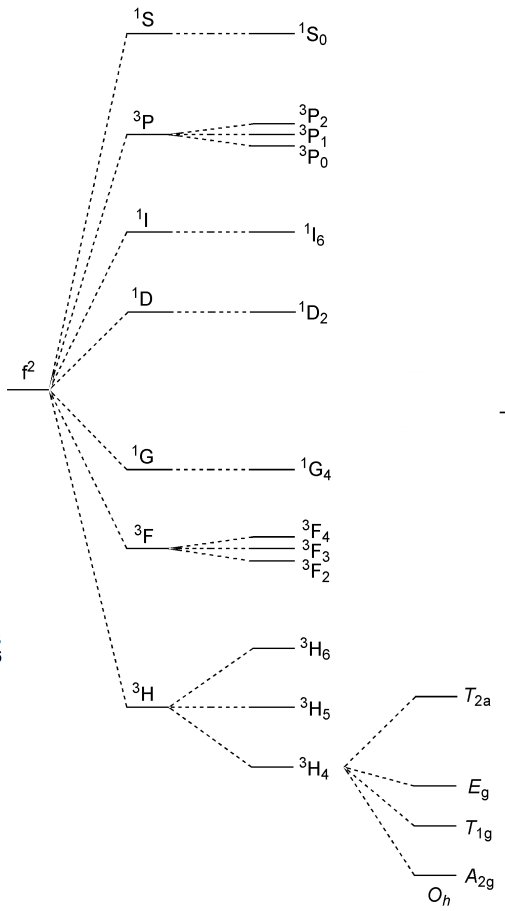

c)

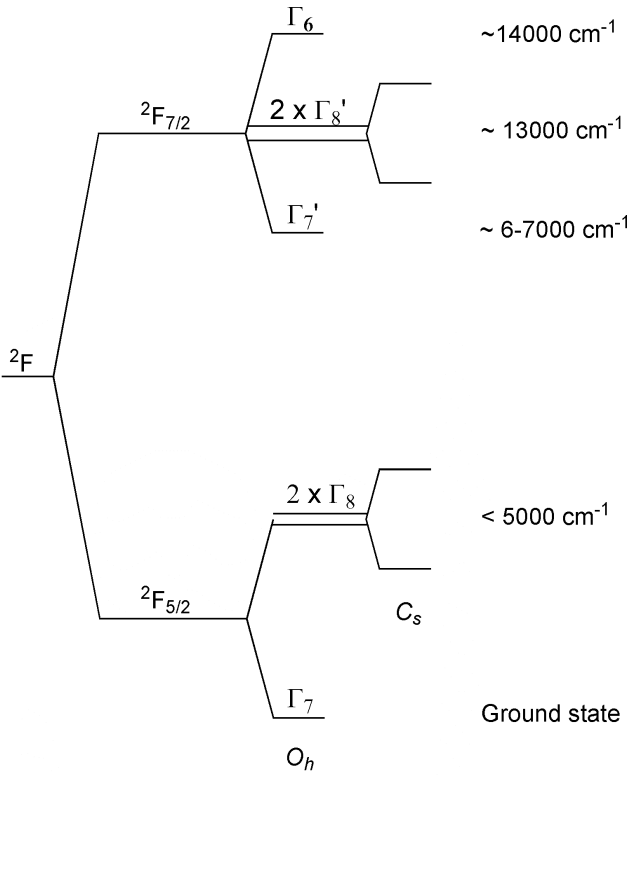

Figure 5. Diagrams showing the subsequent effects, where operating, of electrostatic repulsion, spin-orbit coupling and crystal field on: a) ${ }^{4}$ I uranium(III), b) ${ }^{3} \mathrm{H}$ uranium(IV), c) ${ }^{2} \mathrm{~F}$ uranium(V).

Uranium falls somewhere in between the above extremes and spectra are oxidation state-dependent. Vibronic coupling is greater than for the lanthanides, but $\mathrm{f}-\mathrm{f}$ transitions are still weak. However, greater covalency brings modest line-broadening and enhanced mixing with ligand orbitals, which increases the intensities of absorptions. In some instances the mixing is, by inference, so strong that significant intensities for $\mathrm{f}-\mathrm{f}$ transitions can be observed which is referred to as intensity-stealing. ${ }^{[41]}$ The 5f-6d energy gap is smaller than the corresponding 4f-5d gap, and thus, for uranium(III), Laporte allowed 5f-6d transitions are observed around 500-700 nm; for higher oxidation states the $5 f-6 d$ gap opens up and those transitions usually shift into the UV region. The optical spectra of uranium(III) and (IV) often exhibit weak $\left(\varepsilon \sim 5-100 \mathrm{M}^{-1} \mathrm{~cm}^{-1}\right)$ and numerous f-f transitions because of multiple states and crystal field sub-levels. For example, setting $5 \mathrm{f}-6 \mathrm{~d}$ transitions to one side, uranium(III) spectra contain 41 free-ion states (where inter-electronic repulsion and spin orbit coupling have been accounted for) and 182 crystal field sub-levels (each state is split into $(2 J+1) / 2$ levels). Uranium(V) is a special example of clarity, however, ${ }^{[10]}$ since because there is only one $5 f$ electron there is no inter-electronic repulsion and so the effects of spin orbit coupling and crystal field can be more straightforwardly treated. Assuming that spin orbit coupling is larger than the crystal field, the former splits the ${ }^{2} \mathrm{~F}$ term into ${ }^{2} \mathrm{~F}_{5 / 2}$ and ${ }^{2} \mathrm{~F}_{7 / 2}$ ground and excited states, respectively. Consideration of crystal field splits each of the ${ }^{2} \mathrm{~F}_{5 / 2}$ and ${ }^{2} \mathrm{~F}_{7 / 2}$ states into $(2 J+1) / 2$ levels. Because 
spin, a half-integer term, and orbital, an integer term, angular momenta have been combined double group theory needs to be used. This then generates the orbital manifold for uranium(V) (Figure 5). The labels change in different symmetries and the exact energetic spacings will vary as a function of the magnitudes of spin orbit coupling and crystal field. ${ }^{[42]}$ Uranium(V) thus usually exhibits a well-resolved manifold of $\mathrm{f}-\mathrm{f}$ transitions $\left(\varepsilon<500 \mathrm{M}^{-1} \mathrm{~cm}^{-1}\right)$ whose intensity can be indicative of the site symmetry at uranium: $O_{h}$ symmetry results in coupling to the $\mathrm{A}_{1 \mathrm{~g}}$ mode which reduces absorptivities to $\sim 50 \mathrm{M}^{-1} \mathrm{~cm}^{-1}$ but in low-symmetry systems higher molar extinction coefficients are known. ${ }^{[43]}$

\subsection{Magnetism}

The static magnetism of uranium (dynamic magnetism is discussed in Section 5) can be crucial to determining formal oxidation states where this assignment is in doubt. ${ }^{[31 \mathrm{c}]}$ For a d-block ion the magnetic moment $\mu_{\mathrm{eff}}$ is given by $\mu_{\mathrm{eff}}=\sqrt{ }[4 S(S+1)+L(L+1)]$. For many transition metals the orbital component can be ignored due to the crystal field and so the spin-only formula works well. For lanthanides, the orbital moment is not quenched and since $S$ and $L$ weakly couple $J$ must be considered which gives rise to the Landé formula:

$$
\begin{gathered}
\mu_{\text {eff }}=\mathrm{g}_{\mathrm{J}} \sqrt{ } J(J+1) \\
{\left[\text { where } \mathrm{g}_{\mathrm{J}}=3 / 2+((S(S+1)-L(L+1)) / 2 J(J+1))\right]}
\end{gathered}
$$

The Landé formula does a good job of predicting the magnetic moments of the lanthanides in complexes, which are like the free ions and by-and-large independent of the ligand environment; it fails in only two instances where the fundamental assumption of good separation of ground and first excited state is not obeyed (for Sm and Eu low-lying paramagnetic states contribute to their magnetic moments). 
a)

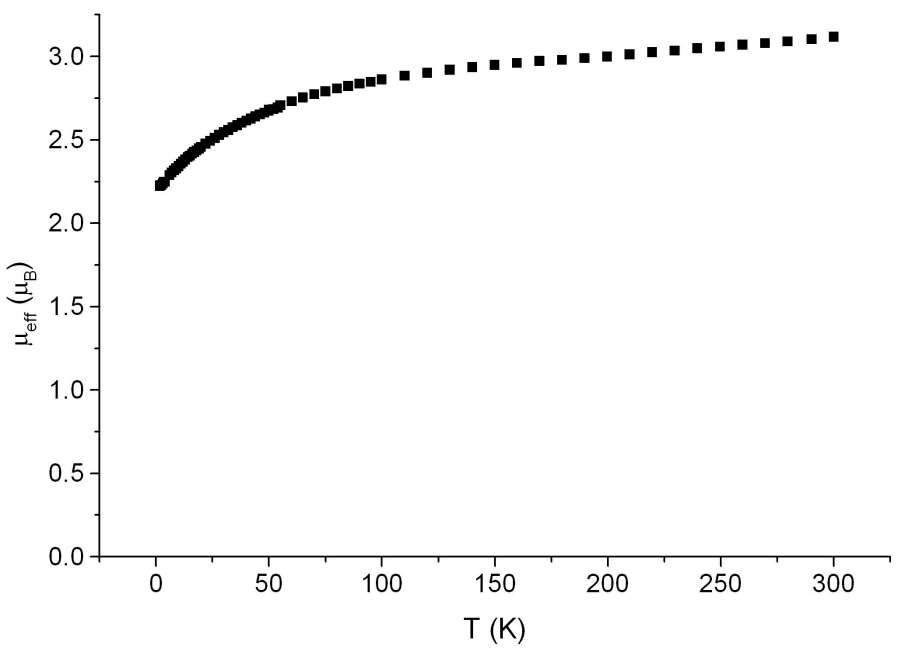

b)

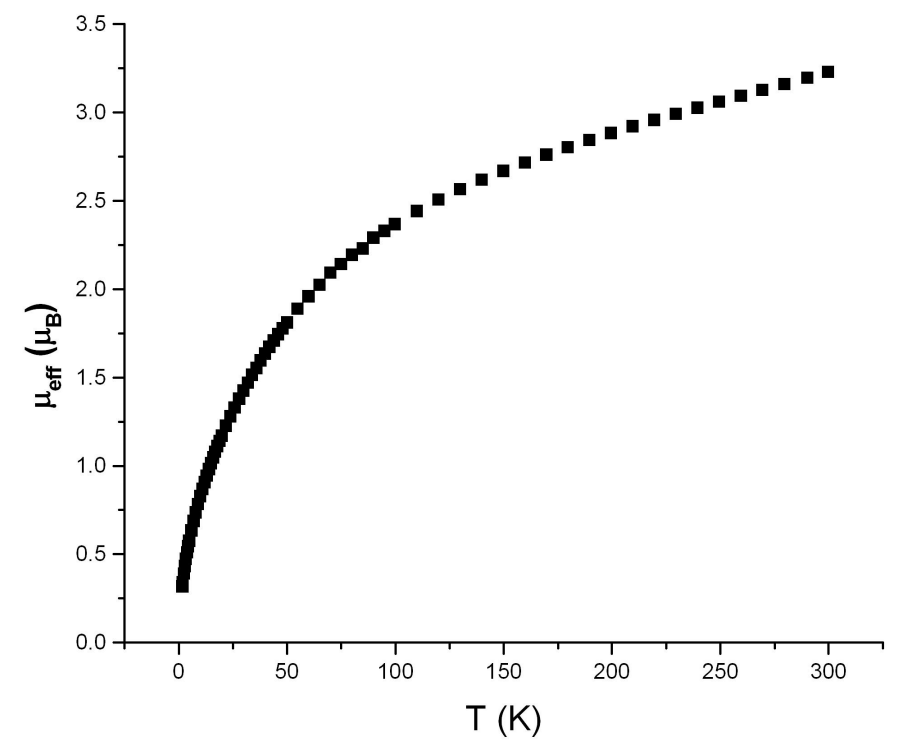

c)

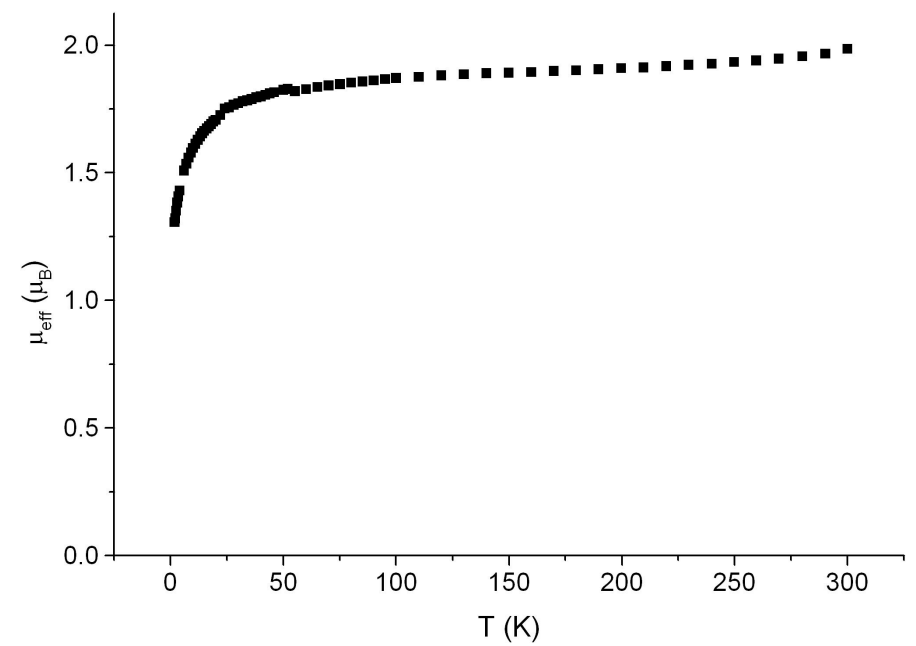

Figure 6. Typical $\mu_{\mathrm{eff}}\left(\mu_{\mathrm{B}}\right)$ vs temperature (K) plots for: (a) uranium(III), ${ }^{[44 \mathrm{a}]}$ (b) uranium(IV), ${ }^{[44 b]}$ (c) $\operatorname{uranium}(\mathrm{V}) \cdot{ }^{[44 \mathrm{a}]}$ 
In principle, the magnetism of uranium might not be expected to be well modelled by the Landé formula because as established in Section $2.3 J$ is not a good quantum number. However, the Landé formula does a good job of predicting the magnetic moments of uranium in various oxidation states. ${ }^{[44]}$ Representative plots of $\mu_{\text {eff }}\left(\mu_{\mathrm{B}}\right)$ against temperature (K) for uranium(III), (IV), and (V) are shown in Figure 6. The theoretical magnetic moments of uranium(III) and (IV) at room temperature are 3.62 and $3.58 \mu_{\mathrm{B}}$, which is not a sufficient difference to assign a formal oxidation state if there is any ambiguity. ${ }^{[31 \mathrm{c}]}$ However, the variable temperature behaviour are distinct and revealing, and the exact shape of the magnetization response can be quite informative about crystal field effects. ${ }^{[45]}$ A typical uranium(III) magnetic moment will decrease only slowly until at low temperature a drop in moment occurs as low-lying states are depopulated and the uranium ion adopts an orbital doublet ground state. Notably, however, the magnetic moment is usually higher than would be expected for the equivalent on one unpaired electron because some low-lying states are not completely depopulated, even at low temperature. In contrast, uranium(IV) usually presents a monotonous decrease in magnetic moment and the curve tends to zero because at the low temperature limit uranium(IV) is an orbital singlet in $O_{h}$ symmetry (Figure 5b), which most complexes approximate to. At $2 \mathrm{~K}$ there is usually a residual magnetic moment of $\sim 0.3-0.5 \mu_{\mathrm{B}}$ due to temperature independent paramagnetism. The magnetism of uranium(V) tends to present a flat line with little variation in magnetic moment from room temperature (calculated moment of 2.54 $\mu_{\mathrm{B}}$ ) to ca. $50 \mathrm{~K}$, below this temperature there is a rapid drop-off of magnetic moment due to depopulation of low-lying states but an appreciable moment $\left(\sim 1.1 \mu_{\mathrm{B}}\right)$ tends to remain because uranium(V) is always an orbital doublet, but the moment is lower than for uranium(III) because there is less mixing with excited states. It should be noted that experimentally observed magnetic moments of uranium complexes frequently deviate below ideal behaviour; note in Figure 6 the magnetic moments at $298 \mathrm{~K}$ for uranium(III) and (IV) are $\sim 3 \mu_{\mathrm{B}}$ whereas for uranium(V) it is $\sim 2 \mu_{\mathrm{B}}$. It is tempting to attribute this to partial quenching of $L$ by the crystal field, which invokes covalency, but numerous factors contribute to the observed magnetism in each case and their inter-relationships are complex and non-linear so dogmatically invoking covalency is too simplistic. ${ }^{[26 f]}$

\subsection{Bond Energetics and Chemical Bonding}

Thermochemical studies have shown uranium-carbon bond disruption enthalpies to be ca. 70-90 kcal mol ${ }^{-1}$. ${ }^{[4]}$ Therefore, it can be concluded that there is nothing thermodynamically unstable about uranium-ligand linkages. However, because of the predominantly electrostatic bonding many of these linkages are labile for kinetic reasons. 
The oxidation state of uranium profoundly affects the level of covalency in any uranium-ligand bond, and this will also be dependent on the type of ligand, but broadly speaking it can be said that uranium(III) will be the most ionic and uranium(VI) the most covalent. Electrostatics dominate the bonding, but there can be appreciable covalency and this is the source of much debate; although theoretical calculations are invaluable in providing models for the electronic manifolds of uranium complexes there is a need to experimentally validate them and this is an area that is beginning to show promise in terms of XANES studies. ${ }^{[47]}$

One consequence of the greater radial expansion of $5 \mathrm{f}$-orbitals vs their $4 \mathrm{f}$ cousins is the capability to engage in polarized-covalent multiple bonding with terminal $\pi$-donor ligands ${ }^{[27 \mathrm{a}, 30 \mathrm{e}]}$ and to engage in backbonding to $\pi$-acceptor ligands such as carbon monoxide and arenes. This is a burgeoning area of non-aqueous uranium research, and contrasts to the more ionic lanthanides that rarely engage in bonding to $\pi$-acceptor ligands or need constrained ligand frameworks to stabilize terminal multiply bonded ligands. Therefore, a great deal of attention needs to be given to ligand-design in non-aqueous uranium chemistry to support novel and potentially reactive uranium-ligand linkages. If uranium and ligand frontier orbitals are appropriately arranged with respect to each other uranium can engage in $\sigma, \pi, \delta$, and, uniquely to the actinides it would seem, $\phi$ bonding, although the latter tends to be limited to special cases such as uranocene ${ }^{[48]}$ and perhaps uranium-arene interactions. ${ }^{[40]}$

Since the bonding is electrostatic, most ligand combinations with uranium arrange themselves to minimize steric clashing. However, one structural motif that deserves special mention here is the rigorously trans-uranyl unit. In d-block chemistry, especially group 6 dioxos, the oxo groups would be anticipated to arrange themselves mutually cis to avoid these strong donors from competing with common d-orbitals, i.e. a manifestation of the trans-influence. The situation is clearly the opposite for uranyl. Specifically, when the parity of the highest occupied core orbitals (p, ungerade) is opposite to the lowest unoccupied metal orbitals ( $\mathrm{d}$, gerade) then dipolar polarization occurs and charge accumulation occurs in a trans position thus destabilizing the trans bond so a cis arrangement is favoured. However, when the parities are the same ( $\mathrm{p}$ and $\mathrm{f}$, ungerade) then the polarization is quadrupolar and thus cis positions are destabilized and trans is favoured. An alternative way of explaining this is that the semi-core $6 \mathrm{p}$-orbitals transfer electron density to vacant 5 f orbitals leaving a $6 \mathrm{p}$-hole directed to the trans position so trans-bonded ligands reinforce each other (pushing from below). This is a complex and not fully understood phenomena but is referred to as the inverse-trans-influence (ITI). ${ }^{[30 b, 49]}$ Interestingly, there is growing evidence for an ITI effect in certain uranium(V) complexes which hints that this phenomena may be more widespread than is currently appreciated. ${ }^{[50]}$ 


\subsection{Principal Reaction Types}

With predominantly ionic bonds, uranium-ligand linkages are often labile and therefore amenable to a range of reactivity. ${ }^{[51]}$ Salt, amine, and alkane elimination reactions are common. Migratory insertion reactions are also well known. $\beta$-Hydride elimination, like for early d-block metals, is an accessible decomposition pathway and needs to be avoided by using alkyls that are void of $\beta$ hydrogens or by steric blocking/saturation. In contrast to transition metals, classical single-metal two-electron oxidative addition is unknown, and the reverse reductive elimination is incredibly rare. ${ }^{[52]}$ However, the redox chemistry of uranium tends to be dominated by one-electron redox events so bimetallic oxidative additions have extensive precedent. ${ }^{[53]}$ Multi-electron reductions are known, ${ }^{[23 f]}$ but tend to involve metal redox coupled with non-innocent ligand reactivity, and twoelectron oxidations are known but rare, for example reactivity with azides or oxygen-transfer reagents to make terminal imido or oxo complexes, respectively. ${ }^{[27 \mathrm{a}, 30 \mathrm{e}]}$ Low valent uranium is very reducing, and accordingly reduction of substrates with low-lying $\pi$-systems to give coupled organics is well known, whereas uranium(V) and (VI) can be very oxidizing.

\section{Commonly Used Uranium Halide Starting Materials}

The start point for essentially all molecular non-aqueous uranium chemistry is halide derivatives, and consequently significant effort has been spent in producing reliable starting materials that can be made 'in-house' since there are very few commercial sources; the recent acceleration of the area can be correlated to contributions to improved starting materials. The following sections describe key advances that have supported the renaissance of non-aqueous chemistry.

\subsection{Uranium(III)}

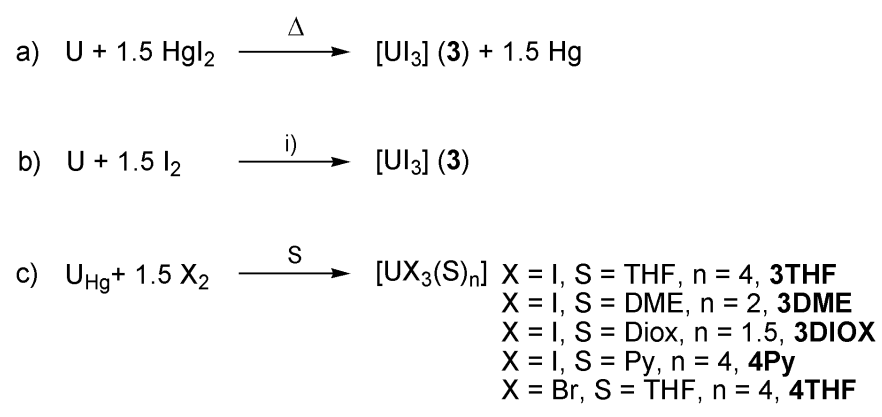

d) $\left[\mathrm{UCl}_{4}\right]+\mathrm{xs} \mathrm{Mg} \stackrel{\text { ii) }}{\longrightarrow}\left[\mathrm{UCl}_{3}(\mathrm{Py})_{4}\right](5 \mathrm{Py})$

Scheme 2. a) - d): synthesis of uranium(III) halides. Specific reagents and conditions: i) Solid state or diethyl ether; ii) Dioxane, then hexane/pyridine.

Several routes to uranium(III) halide starting materials are known, Scheme 2. Although the direct reaction of uranium and mercury diiodide is a proven method to prepare $\left[\mathrm{UI}_{3}\right](3),{ }^{[54]}$ the synthesis 
involves harsh conditions using specialist equipment and produces mercury as a by-product. Reaction of uranium with iodine has also been reported but involves heating the uranium to red heat. ${ }^{[55]}$ A major advance, which opened up the area, was the report in 1989 of a robust synthesis of $\left[\mathrm{UI}_{3}(\mathrm{THF})_{4}\right]$ (3THF) from uranium ( $\sim 5 \%$ mercury-amalgamated) and iodine in THF. ${ }^{[56]}$ This method is quite flexible, and $\left[\mathrm{UI}_{3}(\mathrm{DME})_{2}\right]$ (3DME) and $\left[\mathrm{UI}_{3}(\mathrm{Py})_{4}\right](\mathbf{3 P y})$ can be prepared by changing the solvent to DME or Py, respectively, ${ }^{[56 \mathrm{~b}]}$ and iodine can be substituted by bromine to produce $\left[\mathrm{UBr}_{3}(\mathrm{THF})_{4}\right](\mathbf{4 T H F}) .{ }^{[56 \mathrm{~b}]}$ Compound $\mathbf{3 T H F}$ has proven to be the foundation of numerous experimental uranium studies in the last 25 years, but there are still occasions when solvent-free $\mathbf{3}$ is required. In order to avoid solid state methods a solution-based method was reported in 2008 where uranium is reacted with 1.5 equivalents of $\mathrm{I}_{2}$ in diethyl ether with occasional sonication. ${ }^{[57]}$ Elemental analysis of the dark purple powder prepared by this method shows minimal hydrocarbon inclusion (ca. $1 \% \mathrm{C}, 0.5 \% \mathrm{H}$ ) and since this method avoids the need to prepare mercuryamalgamated uranium, as reported in the 1989 method, ${ }^{[56]}$ soxhlet extraction using THF can be used to purify 3 to produce $\mathbf{3 T H F}$ leaving behind a residual $2 \%$ impurity by weight whose composition remains unknown. In 2011 an improved synthesis of solvated 3 was reported, ${ }^{[58]}$ namely that reaction of uranium with 1.35 equivalents of $\mathrm{I}_{2}$ in 1,4-dioxane affords [ $\mathrm{UI}_{3}(1,4 \text {-dioxane })_{1.5}$ ] (3DIOX) in excellent yield, and this complex exhibits higher thermal stability than 3THF. One uranium(III) trihalide that eluded unambiguous preparation for a number of years was [ $\left.\mathrm{UCl}_{3}\right](\mathbf{5}) .{ }^{[59]}$ This was often prepared by an in situ reduction of $\left[\mathrm{UCl}_{4}\right](\mathbf{6})$ with sodium naphthalenide but the resulting compound was ill-defined and derivatives were often obtained in low yield suggesting a complex reaction. However, it was not until as recently as 2014 that a robust synthesis of solvated $\mathbf{5}$ complexes was reported. ${ }^{[60]}$ Reduction of a 1,4-dioxane suspension of 6 with magnesium turnings at $100{ }^{\circ} \mathrm{C}$ for 3 days produces a blue powder, and after separation from excess magnesium and dissolution in pyridine and work-up $\left[\mathrm{UCl}_{3}(\mathrm{Py})_{4}\right]_{2}(\mathbf{5 P y})$ is isolated in good yield as a purple/black crystalline solid. 


\subsection{Uranium(IV)}
a) $\mathrm{UO}_{3}+\mathrm{xs} \mathrm{Cl}_{3} \mathrm{CC}(\mathrm{Cl})=\mathrm{CCl}_{2} \stackrel{\Delta}{\longrightarrow}\left[\mathrm{UCl}_{4}\right](6)$
b) $6 \stackrel{\mathrm{THF}}{\longrightarrow}\left[\mathrm{UCl}_{4}(\mathrm{THF})_{3}\right](6 \mathrm{THF})$
c) $6+x s \mathrm{Me}_{3} \mathrm{Sil} \stackrel{\mathrm{MeCN}}{\longrightarrow}\left[\mathrm{UI}_{4}(\mathrm{NCMe})_{4}\right](7 \mathrm{MeCN})$
d) $7 \mathrm{MeCN} \stackrel{\mathrm{Py}}{\longrightarrow}\left[\mathrm{UI}_{4}(\mathrm{Py})_{3}\right](7 \mathrm{Py})$
e) $\mathrm{U}+2 \mathrm{I}_{2} \longrightarrow\left[\mathrm{UI}_{4}(\mathrm{~S})_{n}\right] \mathrm{S}=\mathrm{PhCN}, \mathrm{n}=4,7 \mathrm{PhCN}$
$\mathrm{S}=\mathrm{OEt}_{2}, \mathrm{n}=2,70 \mathrm{Et}_{2}$

Scheme 3. a) - e): synthesis of uranium(IV) halide starting materials.

Uranium(IV) is a common oxidation state for uranium and hence there are a number of tetravalent halide precursors, Scheme 3. Uranium tetrachloride has been prepared by a number of methods over the years, ${ }^{[61]}$ but perhaps the most popular method is to react $\mathrm{UO}_{3}$ with hexachloropropene to produce $\left[\mathrm{UCl}_{4}\right](6)$ as an emerald green solid in essentially quantitative yield; this can be easily converted to $\left[\mathrm{UCl}_{4}(\mathrm{THF})_{3}\right](\mathbf{6 T H F})$ if solubility is an issue in subsequent chemistry. ${ }^{[62]}$ The reaction requires high temperature (ca. $200{ }^{\circ} \mathrm{C}$ ) and hexachloropropene is highly toxic and the reaction initiates with a violent exotherm so modifications including slow addition of $\mathrm{UO}_{3}$ to hot hexachloropropene have been devised, ${ }^{[61 \mathrm{~d}]}$ but despite some drawbacks $\mathrm{UCl}_{4}$ represents the most commonly used uranium halide starting material apart from 3THF and uranyl derivatives. Chloride is not always the optimal halide for salt elimination reactions and often, although a small number of $\mathrm{UBr}_{4}$ derivatives are known, ${ }^{[63]}$ the tetraiodides have received most attention since iodide is an excellent halide to eliminate, especially as $\mathrm{KI}$. However, $\left[\mathrm{UI}_{4}\right](7)$ is known to be unstable at room temperature and decomposes to $\mathrm{UI}_{3}$ and $\mathrm{I}_{2}{ }^{[64]}$ Although pyridine or nitrile adducts such as $\left[\mathrm{UI}_{4}(\mathrm{~S})_{\mathrm{n}}\right]$ $(\mathrm{S}=\mathrm{Py}, \mathrm{n}=3$, 7Py; $\mathrm{S}=\mathrm{MeCN}, \mathrm{n}=4, \mathbf{7 M e C N} ; \mathrm{S}=\mathrm{PhCN}, \mathrm{n}=4, \mathbf{7 P h C N})$ are known, ${ }^{[65]}$ the latter are inevitably of limited utility because of the unsaturated nitrile linkage, but they have found application in, for example, the synthesis of nitrido-azide clusters. ${ }^{[66]}$ However, in the same 2008 report of the synthesis of $\mathrm{UI}_{3},{ }^{[57]}$ it was reported that when uranium is treated with 2 equivalents of $\mathrm{I}_{2}$ in diethyl ether with occasional sonication $\left[\mathrm{UI}_{4}\left(\mathrm{OEt}_{2}\right)_{2}\right](\mathbf{7 O E t})$ is formed as a red powder in good yield. Complex 70Et $\mathbf{2}_{2}$ is sensitive to loss of diethyl ether, however in 2011 the synthesis of more robust uranium halides were reported utilizing 1,4 -dioxane,${ }^{[58]}$ which although a weak ligand seems to stabilize thermally robust adducts and is resistant to ring-opening reactions that can plague THF complexes. Thus, reacting uranium with 2.05 equivalents of $\mathrm{I}_{2}$ in 1,4-dioxane affords [UI ${ }_{4}(1,4-$ 
dioxane) $)_{2}$ ] (7DIOX), which can be converted to $\mathbf{7 O E t}_{2}$ by treatment with diethyl ether or $\left[\mathrm{UCl}_{4}(1,4-\text { dioxane })\right]_{2}(\mathbf{6 D I O X})$ by treatment with $\mathrm{HCl} / 1,4$-dioxane.

\subsection{Uranium(V) and (VI)}

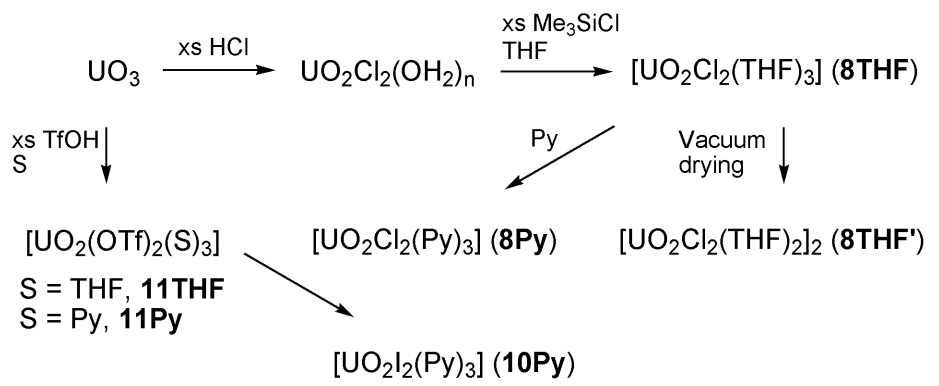

Scheme 4. Synthesis of uranyl(VI) halides.

The synthesis of uranium(V) chloride is known but it seems to be a rarely used starting material, ${ }^{[67]}$ presumably because of disproportionation and/or reduction reactions when salt elimination reactions are attempted. Although hexahalides of uranium(VI) are known they are very oxidizing and of limited synthetic utility. The most common uranium(VI) starting materials are uranyl derivatives, Scheme 4. Following aqueous $\mathrm{HCl}$ treatment of $\mathrm{UO}_{3}, \mathrm{UO}_{2} \mathrm{Cl}_{2}\left(\mathrm{OH}_{2}\right)_{\mathrm{n}}$ is treated with a six-fold excess of $\mathrm{Me}_{3} \mathrm{SiCl}$ in THF. After concentration and addition of hexane anti-solvent $\left[\mathrm{UO}_{2} \mathrm{Cl}_{2}(\mathrm{THF})_{3}\right](\mathbf{8 T H F})$ is isolated as a yellow powder. ${ }^{[68]}$ Importantly, it should be noted that one THF molecule is labile and drying under vacuum affords $\left[\mathrm{UO}_{2} \mathrm{Cl}_{2}(\mathrm{THF})_{2}\right]_{2}(\mathbf{8}$ THF' $)$. Although 8 is arguably the most important halide-coligand combination from a practical experimental perspective, a number of useful permutations have been prepared including $\left[\mathrm{UO}_{2} \mathrm{Cl}_{2}(\mathrm{Py})_{3}\right](\mathbf{8 P y})$, $\left[\mathrm{UO}_{2} \mathrm{Br}_{2}(\mathrm{THF})_{3}\right](\mathbf{9 T H F})$, and $\left[\mathrm{UO}_{2} \mathrm{I}_{2}(\mathrm{Py})_{3}\right](\mathbf{1 0 P y}) .{ }^{[69]}$ Uranyl triflates have also been prepared directly from $\mathrm{UO}_{3}$, to give $\left[\mathrm{UO}_{2}(\mathrm{OTf})_{2}(\mathrm{~S})_{3}\right](\mathrm{S}=\mathrm{THF}, \mathbf{1 1 T f} ; \mathrm{S}=\mathrm{Py}, \mathbf{1 1 P y}) .{ }^{[70]}$

$$
\left[\mathrm{Ul}_{3}(\mathrm{THF})_{4}\right](3 \mathrm{THF})+\mathrm{PyO}+\mathrm{H}_{2} \mathrm{O} \longrightarrow \mathrm{KI} \longrightarrow \cdots
$$

Scheme 5. Rational synthesis of the uranyl(V) halide precursor 12.

After initial studies in the $1960 \mathrm{~s},{ }^{[10]}$ pentavalent uranium chemistry has developed dramatically in recent years, ${ }^{[26 f]}$ after a lull of around 40 years great strides have in particular been made in pentavalent uranyl chemistry; although $\left\{\mathrm{UO}_{2}\right\}^{+}$derivatives can be prepared from hexavalent precursors the development of this area has been largely due to the development of new uranyl(V) starting materials. For example, treatment of $\mathbf{3 T H F}$ with pyridine- $N$-oxide and water afforded a compound formulated as $\left[\mathrm{UO}_{2} \mathrm{I}(\mathrm{Py})_{\mathrm{n}}\right]$ which could be treated with potassium iodide to produce the 
coordination polymer $\left[\left\{\mathrm{UO}_{2}(\mathrm{Py})_{5}\right\}\left\{\mathrm{KI}_{2}(\mathrm{Py})_{2}\right\}\right]_{\infty}(\mathbf{1 2})$, Scheme 5. ${ }^{[71]}$ Compound 12 can also be prepared from $\mathrm{UO}_{2} \mathrm{I}_{2}$ and potassium pentamethylcyclopentadienyl; indeed a range of pentavalent uranyl complexes of the general form $\left[\left\{\mathrm{UO}_{2}(\mathrm{~S})_{5}\right\}\left\{\mathrm{MX}_{2}(\mathrm{~S})_{\mathrm{n}}\right\}\right](\mathrm{S}=\mathrm{Py}, \mathrm{THF} ; \mathrm{M}=\mathrm{Li}, \mathrm{K} ; \mathrm{X}=\mathrm{OTf}, \mathrm{I})$ can be prepared from $\mathrm{UO}_{2} \mathrm{X}_{2}(\mathrm{X}=\mathrm{I}$, OTf $)$ and organo-lithium or -thallium reagents. ${ }^{[69 \mathrm{c}]}$

\section{Common Ligand Classes Supporting Non-Aqueous Uranium Chemistry}

The following sections describe non-aqueous uranium complexes supported by a range of more commonly deployed ligands. The sections are organized along the lines of donor atom-type that is central to the ligand in question, moving from group 14 to 16, and in a given group the order is top to bottom.

\subsection{Tetryl Donor Atom Ligands}

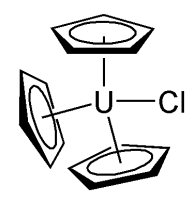

13

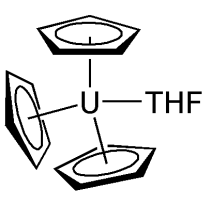

15

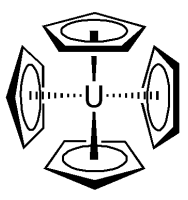

14

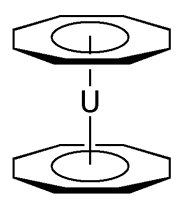

16

Figure 7. Progenitor organouranium complexes 13-16.

Organouranium chemistry was initiated in 1956, Figure 7, with the synthesis of $\left[\mathrm{U}\left(\eta^{5}-\mathrm{C}_{5} \mathrm{H}_{5}\right)_{3} \mathrm{Cl}\right]$ (13) which was structurally authenticated in 1965. ${ }^{[72]}$ In the intervening time $\left[\mathrm{U}\left(\eta^{5}-\mathrm{C}_{5} \mathrm{H}_{5}\right)_{4}\right]$ (14) was reported in $1962,{ }^{[73]}$ then subsequently in $1970\left[\mathrm{U}\left(\eta^{5}-\mathrm{C}_{5} \mathrm{H}_{5}\right)_{3}(\mathrm{THF})\right](\mathbf{1 5})$ was isolated. ${ }^{[74]}$ It is important to realize that these complexes have no counterparts in transition metal chemistry, which signalled the novelty of f-block organometallics. A landmark result for actinide chemistry was the report of uranocene $\left[\mathrm{U}\left(\eta^{8}-\mathrm{C}_{8} \mathrm{H}_{8}\right)_{2}\right](\mathbf{1 6})$ in 1968 and its structural confirmation in 1969 because this complex instigated the debate about f-electron participation in metal-ligand bonding that continues to this day. ${ }^{[75]}$ Uranium alkyl, cyclopentadienyl, and arene complexes have been recently reviewed in great detail, ${ }^{[30 \mathrm{c}, \mathrm{d}, 32 \mathrm{~b}, \mathrm{c}]}$ and the following section highlights key reports. 


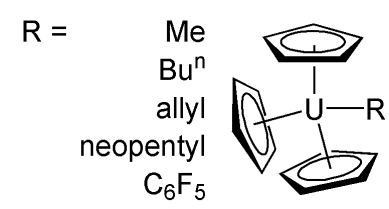

17

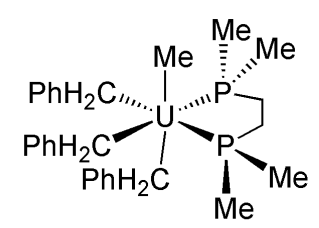

18

Figure 8. Stable uranium(IV) alkyls 17 and 18.

The aforementioned complexes are all $\pi$-organometallics, however there had been prior interest in homoleptic uranium $\sigma$-alkyls as volatile candidates for isotope-separation, ${ }^{[30 \mathrm{~d}]}$ but early efforts to prepare such species were thwarted by decomposition; indeed, the repeated failure to prepare homoleptic uranium alkyls led to the perception that they could not be made. ${ }^{[1]}$ This view was overturned in the $1970 \mathrm{~s}$, Figure 8 , when it was shown that $\left[\mathrm{U}\left(\eta^{5}-\mathrm{C}_{5} \mathrm{H}_{5}\right)_{3} \mathrm{R}\right](\mathbf{1 7}, \mathrm{R}=$ alkyl $)$ complexes could be prepared, ${ }^{[76]}$ and that steric saturation could impart stability to the U-R bond because this blocked the vacant site required for facilitate $\beta$-hydride elimination. An example of this approach is the synthesis of $\left[\mathrm{U}(\mathrm{Me})\left(\mathrm{CH}_{2} \mathrm{Ph}\right)_{3}\left(\mathrm{Me}_{2} \mathrm{PCH}_{2} \mathrm{CH}_{2} \mathrm{PMe}_{2}\right)\right](\mathbf{1 8}){ }^{[77]}$ Thus, it is a matter of sterically taming the linkage, ${ }^{[78]}$ and now uranium mono- and di-alkyl derivatives are well known when supported by suitable ancillary ligands. ${ }^{[32 b]}$

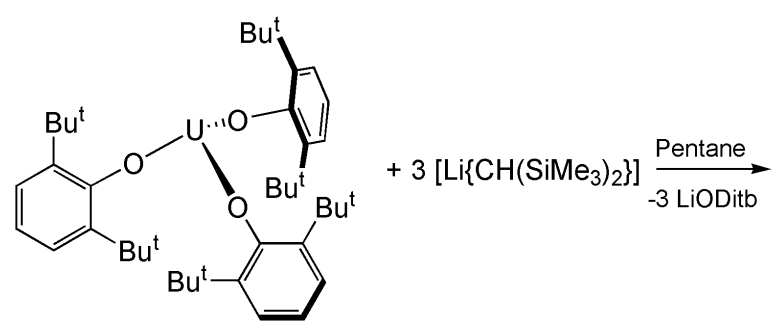

19

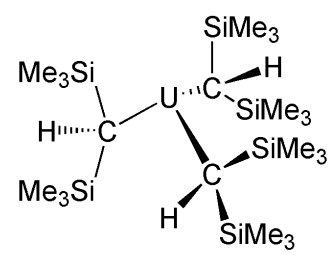

20

Scheme 6. Synthesis of the low-coordinate uranium(III) alkyl 20.

With the steric saturation approach homoleptic uranium alkyls were finally prepared, for example, utilizing the sterically demanding, $\beta$-hydrogen-free alkyl $\left\{\left(\mathrm{Me}_{3} \mathrm{Si}\right)_{2} \mathrm{HC}\right\}^{-}$. Reaction of $\left[\mathrm{U}(\mathrm{ODitb})_{3}\right]$ (19) and three equivalents of $\left[\mathrm{Li}\left\{\mathrm{CH}\left(\mathrm{SiMe}_{3}\right)_{2}\right]\right.$ to give the trigonal pyramidal uranium(III) complex $\left[\mathrm{U}\left\{\mathrm{CH}\left(\mathrm{SiMe}_{3}\right)_{2}\right\}_{3}\right](\mathbf{2 0})$ was reported in 1989, Scheme $6 .{ }^{[79]}$ Complex 20, a nine valence electron, three-coordinate complex, is stabilized by agostic-type $\mathrm{CH} \cdot \cdots \mathrm{U}$ interactions and demonstrates the kinetically stabilizing effect of the $\left\{\left(\mathrm{Me}_{3} \mathrm{Si}\right)_{2} \mathrm{HC}\right\}^{-}$alkyl groups. 


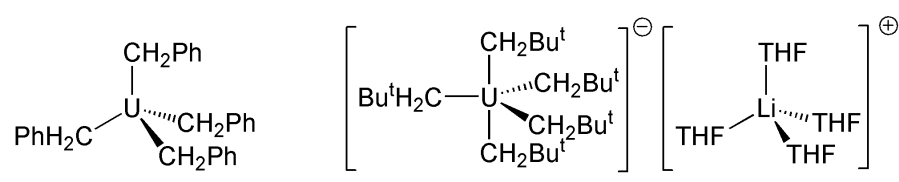

21

22
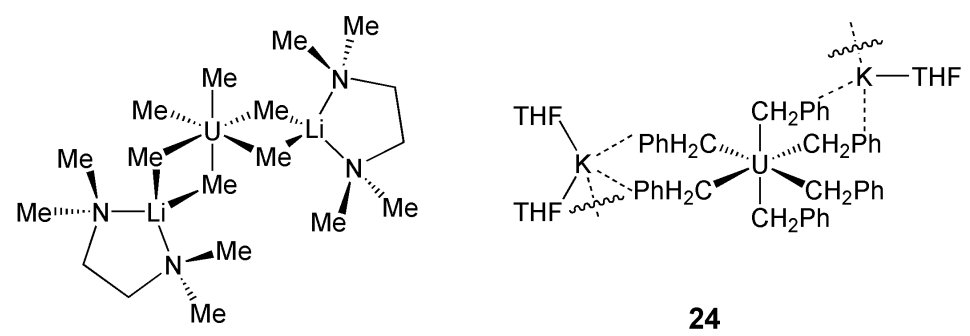

23

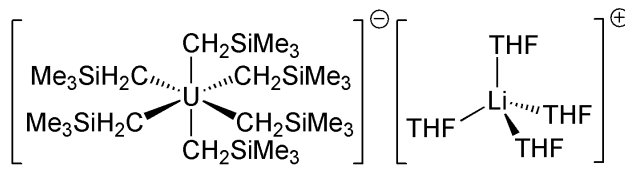

25

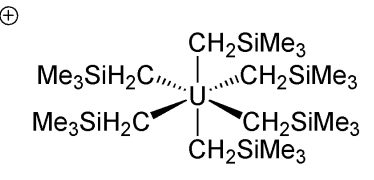

26

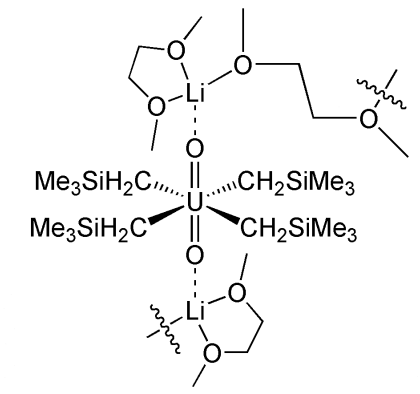

27

Figure 9. Uranium(IV), (V), and (VI) alkyls 21-27.

More recently, Figure 9, the steric saturation approach has been successfully applied to the preparation of higher valent homoleptic uranium alkyls with reports between 2009-2012 including

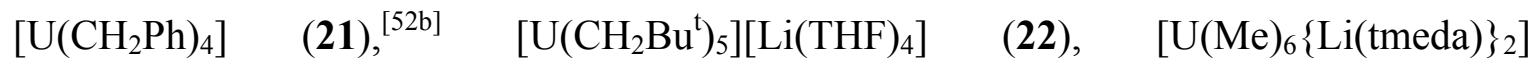
(23),

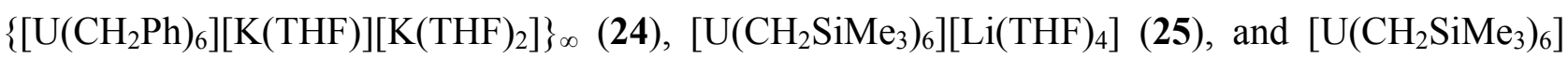
(26), although the latter, despite being apparently sterically saturated, is reported to be only stable below $-25^{\circ} \mathrm{C} .{ }^{[80]}$ The highly reactive nature of uranium(VI)-alkyls, evidenced by the sensitivity of 26, is further highlighted when considering the chemistry of uranyl-dialkyls. In 1982 it was shown that treatment of $\mathrm{UO}_{2} \mathrm{Cl}_{2}$ with two equivalents of alkyl lithiums resulted in transient uranyl-dialkyls which decompose, by a mixture of reductive elimination and homolytic scission/ $\beta$-hydride elimination, to give $\mathrm{UO}_{2}$ and organics. ${ }^{[52 \mathrm{a}]}$ However, again exploiting the steric saturation approach, in 2013 it was shown that treating $\mathrm{UO}_{2} \mathrm{Cl}_{2}$ with four equivalents of $\left[\mathrm{Li}\left(\mathrm{CH}_{2} \mathrm{SiMe}_{3}\right)\right]$ at $-25{ }^{\circ} \mathrm{C}$ gives $\left[\mathrm{UO}_{2}\left(\mathrm{CH}_{2} \mathrm{SiMe}_{3}\right)_{4}\left\{\mathrm{Li}(\mathrm{DME})_{1.5}\right\}\right](\mathbf{2 7}),{ }^{[81]}$ although like 26 complex 27 is stable only at low temperature and decomposes at room temperature in a few hours. 


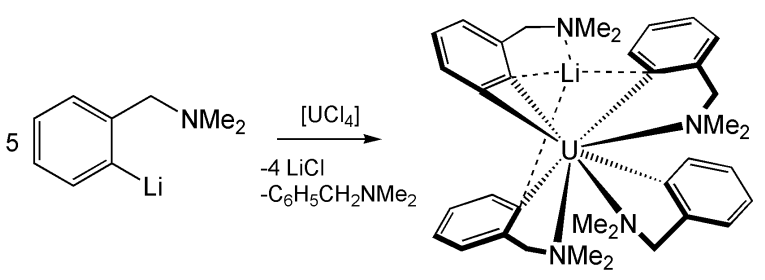

28

Scheme 7. Synthesis of the uranium benzyne complex 28.

Like their alkyl cousins, uranium aryl complexes are fairly rare and tend to be thermally unstable or require chelating stabilization and hence they are reactive. An example of this was reported in 2013, whereby reaction of five equivalents of ortho-lithiated $N, N$-dimethylbenzylamine with $\mathrm{UCl}_{4}$ was found to produce the uranium benzyne complex $\left[\mathrm{U}\left(\mathrm{C}_{6} \mathrm{H}_{4}-2-\mathrm{CH}_{2} \mathrm{NMe}_{2}\right)_{3}\left(\mathrm{C}_{6} \mathrm{H}_{3}-2-\mathrm{CH}_{2} \mathrm{NMe}_{2}\right) \mathrm{Li}\right](\mathbf{2 8})$, Scheme $7 .^{[82]}$ Complex 28 is the only example of an isolable f-block benzyne complex, although uranium-benzyne complexes have been previously invoked as reactive intermediates, ${ }^{[83]}$ and a theoretical study concluded that the 5 f-orbitals play a significant role in stabilizing the uraniumbenzyne interaction.

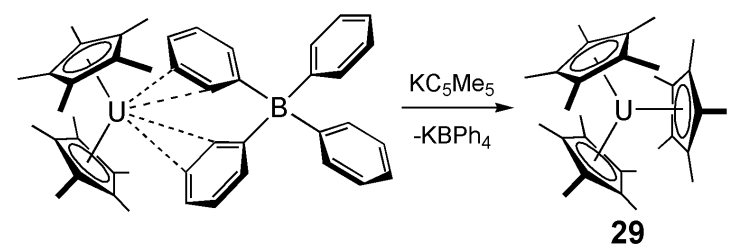

Scheme 8. Synthesis of the tris(pentamethylcyclopentadienyl) uranium(III) complex 29.

Returning to metallocenes, it was long thought that it was impossible to assemble three pentamethylcyclopentadienyl ligands at one metal center because the cone angle of this ligand exceeds $120^{\circ}$. However, in 1997 it was shown that by carefully choosing the strategy and reagents $\left[\mathrm{U}\left(\eta^{5}-\mathrm{C}_{5} \mathrm{Me}_{5}\right)_{3}\right]$ (29) can be prepared, Scheme 8. ${ }^{[84]}$ Although small cylindrical molecules can coordinate to uranium in $\mathbf{2 9},{ }^{[85]}$ (Figures 12, 17, and 37) the complex is evidently sterically compressed as exemplified by a range of sterically induced reduction chemistry which this molecule exhibits. ${ }^{[23 f]}$ This class of complex also demonstrates that to ameliorate the cone angle issue the uranium to cyclopentadienyl centroid distance simply lengthens, showing that distortions of such metrics is facile, i.e. in a shallow potential energy well, which reflects the predominantly electrostatic uranium-ligand bonding. 


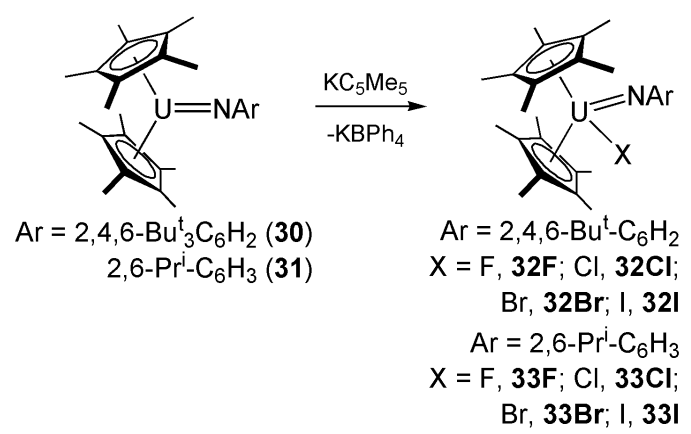

Scheme 9. Synthesis of uranium(V) complexes in a metallocene environment.

Metallocenes have also proven to be an excellent platform from which to access the less-common uranium(V) oxidation state. Complexes of the form $\left[\mathrm{U}\left(\eta^{5}-\mathrm{C}_{5} \mathrm{Me}_{5}\right)_{2} \mathrm{NAr}\right]\left(\mathrm{Ar}=2,4,6-\mathrm{Bu}_{3}^{\mathrm{t}}-\mathrm{C}_{6} \mathrm{H}_{2}, \mathbf{3 0}\right.$; $\left.\mathrm{Ar}=2,6-\operatorname{Pr}_{2}{ }_{2}^{\mathrm{i}}-\mathrm{C}_{6} \mathrm{H}_{3}, 31\right)$ are amenable to one-electron oxidation by copper(I/II) halide reagents to afford $\left[\mathrm{U}\left(\eta^{5}-\mathrm{C}_{5} \mathrm{Me}_{5}\right)_{2}(\mathrm{NAr}) \mathrm{X}\right]\left(\mathrm{X}=\mathrm{F}, \mathrm{Cl}, \mathrm{Br}, \mathrm{I}, \mathbf{3 2 F}-\mathbf{I}\right.$ or 33F-I, respectively), ${ }^{[86]}$ Scheme 9, which could be converted to a range of $\left[\mathrm{U}\left(\eta^{5}-\mathrm{C}_{5} \mathrm{Me}_{5}\right)_{2}(\mathrm{NAr}) \mathrm{Y}\right](\mathrm{Y}=\mathrm{OTf}, \mathrm{SPh}, \mathrm{CCPh})$ derivatives. These essentially isostructural complexes, except for the variation of the $\mathrm{X}$ or $\mathrm{Y}$ group, proved to be excellent vehicles to probe the ${ }^{2} \mathrm{~F}$ electronic manifold of uranium(V), enabling the crystal field effects of the $\mathrm{X}$ and $\mathrm{Y}$ groups to be probed.

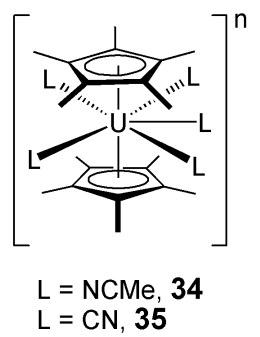

Figure 10. The linear metallocene anion portion of $\mathbf{3 4}$ and $\mathbf{3 5}\left(\mathrm{L}=\mathrm{MeCN}, \mathrm{n}=+2\right.$ and $\mathrm{CN}^{-}, \mathrm{n}=-3$, respectively).

A notable feature of most metallocene complexes that do not involve divalent d-block metals is that they are bent, unless very bulky substituents are installed on the cyclopentadienyl ligands. In a divergence from the overwhelming number of metallocene derivatives right across the periodic table, it was shown in 2006 and 2007 that donor ligands such as acetonitrile and cyanide can displace iodide and triflate ligands from $\left[\mathrm{U}\left(\eta^{5}-\mathrm{C}_{5} \mathrm{Me}_{5}\right)_{2} \mathrm{X}_{2}\right]$ complexes $(\mathrm{X}=\mathrm{I}$, OTf $){ }^{[87]}$ The resulting separated ion pair complexes contain a linear metallocene unit $\left[\mathrm{U}\left(\eta^{5}-\mathrm{C}_{5} \mathrm{Me}_{5}\right)_{2} \mathrm{~L}_{5}\right]^{\mathrm{n}}(\mathrm{L}=$ $\mathrm{MeCN}, \mathrm{n}=+234 ; \mathrm{L}=\mathrm{CN}, \mathrm{n}=-3,35)$ with five nitrile or cyanide ligands around the equatorial girdle, Figure 10. 


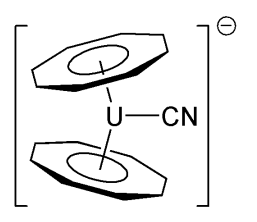

36

Figure 11. Structure of the bent uranocene(IV) adduct 36.

In contrast to the prevalence of bent metallocenes, molecules such as uranocene are always considered to be linear, and fairly unreactive. This lack of reactivity arises from the fact the uranium center in uranocene is well shielded from external ligands, but also because the adoption of a rigorously linear coordination geometry maximizes symmetry allowed overlap between uranium and ligand frontier orbitals. Therefore, any deviation from this ideal geometry would be thermodynamically uphill and, indeed, uranocene often represents a thermodynamic sink where decomposition reactions of uranium-COT complexes are concerned. However, in 2008 it was found that coordination of cyanide to uranocene could be accomplished to generate a bent uranocene anion $\left[\mathrm{U}\left(\eta^{8}-\mathrm{C}_{8} \mathrm{H}_{8}\right)_{2}(\mathrm{CN})\right]^{-}(\mathbf{3 6})$, Figure 11. ${ }^{[88]}$ However, examples of bent uranocene are few and far between, but a significant number of bent thorocene derivatives are now known which has been attributed to the more Lewis acidic nature of Th vs $U$, which may have its origins in the differences of covalency of the bonding in thorocene and uranocene. ${ }^{[89]}$

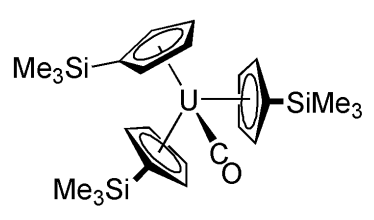

37

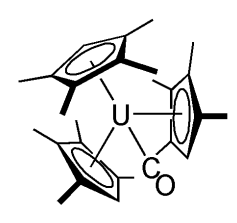

38

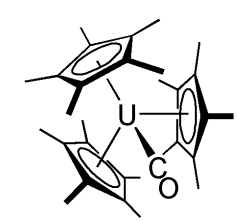

39

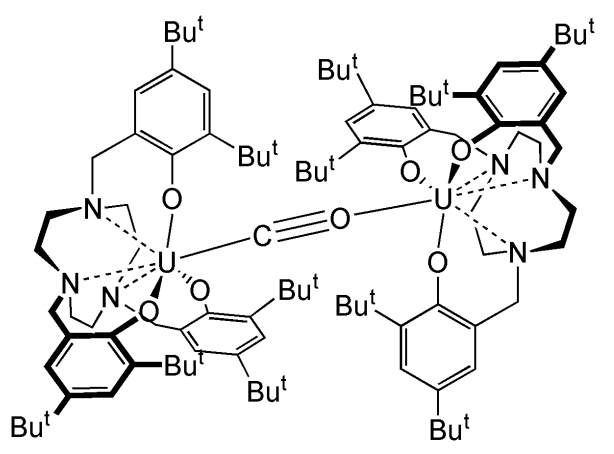

40

Figure 12. Terminal (37-39) and bridging (40) carbon monoxide complexes of uranium.

Carbon monoxide is a classical ligand in transition metal chemistry and there are hundreds of crystallographically characterized. The bonding model of $\mathrm{CO}$ is well understood, and electron-rich transition metals are well suited to partaking in the back-bonding model under ambient conditions. Under ambient conditions there are no stable lanthanide carbonyl compounds because of the ionic 
bonding and core-like nature of the f-orbitals that precludes back-bonding which is the dominant part of the synergic metal-carbonyl bond. ${ }^{[90]}$ With some covalency uranium might be expected to be different, and indeed a handful of uranium-CO complexes are known, but they remain very rare because the bonding of uranium is after all predominantly ionic, Figure 12. Uranium carbonyl has been spectroscopically observed in matrix isolation experiments. ${ }^{[90]}$ In an ambient molecular setting, the uranium carbonyl complex $\left[\mathrm{U}\left(\eta^{5}-\mathrm{C}_{5} \mathrm{H}_{4} \mathrm{SiMe}_{3}\right)_{3}(\mathrm{CO})\right](37)$ was reported in $1986 ;{ }^{[91]}$ this complex was not structurally characterized, but exposure of $\left[\mathrm{U}\left(\eta^{5}-\mathrm{C}_{5} \mathrm{H}_{4} \mathrm{SiMe}_{3}\right)_{3}\right]$ to a $\mathrm{CO}$ atmosphere resulted in the green solution turning burgundy and a $v_{\mathrm{CO}}$ band at $1976 \mathrm{~cm}^{-1}$ was observed in the IR spectrum which shifts to $1935 \mathrm{~cm}^{-1}$ when ${ }^{13} \mathrm{CO}$ is used. Structural evidence for a uranium carbonyl complex was obtained in 1995 by the synthesis and structure of $\left[\mathrm{U}\left(\eta^{5}-\mathrm{C}_{5} \mathrm{Me}_{4} \mathrm{H}\right)_{3}(\mathrm{CO})\right](38),{ }^{[92]}$ which exhibits a $v_{\mathrm{CO}}$ band at $1880 \mathrm{~cm}^{-1}$ in the solid state. The rarity of uranium carbonyl complexes is underscored by the fact the only other structurally characterized terminal uranium carbonyl complex, $\left[\mathrm{U}\left(\eta^{5}-\mathrm{C}_{5} \mathrm{Me}_{5}\right)_{3}(\mathrm{CO})\right](39),{ }^{[93]}$ was not reported until 2003; the IR spectrum for this complex exhibits a $v_{\mathrm{CO}}$ band at $1922 \mathrm{~cm}^{-1}$ which shifts to $1877 \mathrm{~cm}^{-1}$ for the ${ }^{13} \mathrm{CO}$ isotopomer. Only one other structurally authenticated $\mathrm{CO}$ adduct of uranium is known, which is a bridging radical in $\left[\left\{\mathrm{U}\left(\operatorname{tacn}\left[\mathrm{CH}_{2} \mathrm{C}_{6} \mathrm{H}_{2}-2-\mathrm{O}-3,5-\mathrm{Bu}_{2}^{\mathrm{t}}\right]_{3}\right)\right\}_{2}(\mathrm{CO})\right](\mathbf{4 0})$ reported in 2005. This complex was prepared from $\mathrm{CO}$ derived from the reductive cleavage of $\mathrm{CO}_{2} \cdot{ }^{\left[{ }^{[9]}\right.}$ The IR spectrum of $\mathbf{4 0}$ exhibits a $v_{\mathrm{CO}}$ band at $2092 \mathrm{~cm}^{-1}$ that is consistent with the bridging mode of CO. Since complexes 37-40 exhibit carbonyl bands with $v_{\mathrm{CO}}$ bands substantially below the value for free $\mathrm{CO}\left(2143 \mathrm{~cm}^{-1}\right)$, this suggests that the $\pi^{*}$ orbital of $\mathrm{CO}$ is being populated by electron density, which implies back-bonding is operating in these complexes. However, theoretical calculations have shown that whilst back-bonding does occur, there is a crucial difference to the classical metal [pure] d-orbital to $\pi^{*}$ back-bond model of transition metals; for uranium-carbonyl complexes that are supported by cyclopentadienyl ligands the frontier orbital that is involved in the back-bonding has metal and ligand character. ${ }^{[95]}$ 


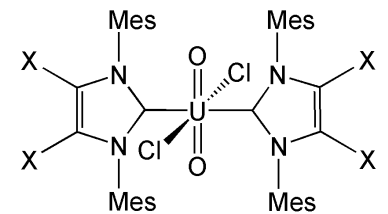

$\mathrm{X}=\mathrm{H}, 41 \mathrm{H}$ $\mathrm{X}=\mathrm{Cl}, \mathbf{4 1 \mathrm { Cl }}$

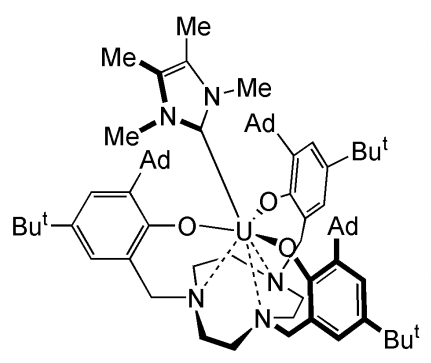

43

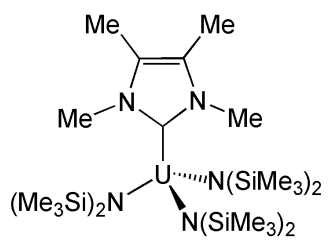

42

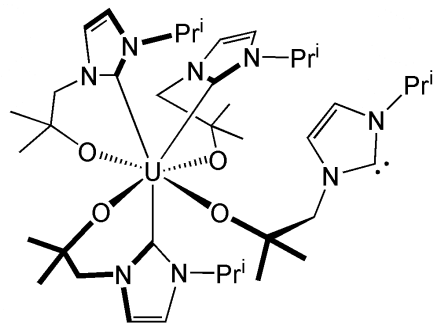

44

Figure 13. $N$-heterocyclic carbene complexes (41-44) of uranium(III)-(VI).

In 2001 the burgeoning field of $N$-heterocyclic carbenes (NHCs) combined with uranium chemistry, Figure 13. Specifically, the bis-NHC uranyl complexes $\left[\mathrm{UO}_{2} \mathrm{Cl}_{2}\left\{\mathrm{C}(\mathrm{NMesCX})_{2}\right\}\right](\mathrm{X}=\mathrm{H}, \mathbf{4 1 H} ; \mathrm{X}=$ $\mathrm{Cl}, \mathbf{4 1 C l}$ ) were reported, ${ }^{[96]}$ and these represent the first examples of actinyl-carbon bonds. In 2004 this area extended to encompass low-valent uranium(III) including $\left[\mathrm{U}\left\{\mathrm{C}(\mathrm{NMeCMe})_{2}\right\}\left\{\mathrm{N}\left(\mathrm{SiMe}_{3}\right)_{2}\right\}_{3}\right](\mathbf{4 2})$ and $\left[\mathrm{U}\left\{\operatorname{tacn}\left(\mathrm{CH}_{2} \mathrm{C}_{6} \mathrm{H}_{2}-2-\mathrm{O}-3-\mathrm{Ad}-5-\mathrm{Bu}{ }^{t}\right)_{3}\right\}\left\{\mathrm{C}(\mathrm{NMeCMe})_{2}\right\}\right]$ (43). ${ }^{[97]}$ The latter was investigated with theoretical calculations which revealed a $\pi$-bond involving a singularly occupied f-type orbital and the vacant p-orbital of the carbene carbon atom. From 2004 onwards a range of increasingly sophisticated uranium-NHC complexes have been reported for uranium(III), (IV), and uranyl(VI) utilizing pincer or amide- or alkoxy-tethered NHCs, such as the alkoxy-NHC complex $\left[\mathrm{U}\left\{\mathrm{OCH}_{2} \mathrm{CMe}_{2} \mathrm{C}(\mathrm{NCHCHNPr})\right\}_{4}\right](\mathbf{4 4 )}),{ }^{[23 \mathrm{~h}, 24 \mathrm{~b}, 98]}$ where three NHCs are coordinated but one remains pendant.

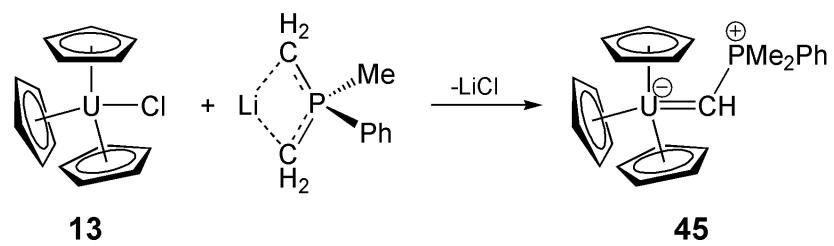

Scheme 10. Synthesis of the uranium(IV) carbene complex 45.

NHCs bind to metal centers datively through the carbene lone pair of electrons and may or may not engage in back-bonding depending on the requirements of the metal. However, covalent uranium carbenes - i.e. $\mathrm{U}=\mathrm{C}$ double bonds - have been known for over thirty years. In 1981 it was reported that treatment of $\mathbf{1 3}$ with $\left[\mathrm{Li}\left\{\left(\mathrm{CH}_{2}\right)_{2} \mathrm{PMePh}\right\}\right]$ afforded the uranium carbene complex $\left[\mathrm{U}\left(\eta^{5}-\right.\right.$ $\left.\left.\mathrm{C}_{5} \mathrm{H}_{5}\right)_{3}\left\{\mathrm{C}(\mathrm{H}) \mathrm{PMe}_{2} \mathrm{Ph}\right\}\right]\left(\right.$ (45), ${ }^{[99]}$ Scheme 10, that exhibits a short $\mathrm{U}=\mathrm{C}$ distance of 2.29(3) $\AA$. The 
reactivity of complex $\mathbf{4 5}$ was examined with a wide range of substrates, ${ }^{[100]}$ demonstrating bondmetathesis chemistry, and a notable product of one of these reactions is the first uranium imido complex (Scheme 18). The $\mathrm{U}=\mathrm{C}$ bond is clearly more polarized than transition metal analogues, and it is important to note that no true alkylidene $\mathrm{U}=\mathrm{CR}_{2}$ bond has yet been reported; all examples of $\mathrm{U}=\mathrm{C}$ bonds feature at least one phosphorus(V)-substituent to stabilize the carbene and there are still few examples of $\mathrm{U}=\mathrm{C}$ bonds. Indeed, after an initial flurry of activity the area fell into a lull spanning nearly thirty years and $\mathrm{U}=\mathrm{C}$ bonds were for many years limited to uranium(IV). However, much success has been achieved recently with $\left\{\mathrm{C}\left(\mathrm{PPh}_{2} \mathrm{NR}\right)_{2}\right\}^{2-}\left(\mathrm{BIPM}^{\mathrm{R}}, \mathrm{R}=\mathrm{SiMe}_{3}(\mathrm{TMS}), \mathrm{Mes}\right.$, Dipp) and $\left\{\mathrm{C}\left(\mathrm{PPh}_{2} \mathrm{~S}\right)_{2}\right\}^{2-}$ (SCS) ligands in terms of expanding the range of complexes and securing $\mathrm{U}=\mathrm{C}$ double bonds with different oxidation states of uranium. ${ }^{[30 \mathrm{~g}]}$

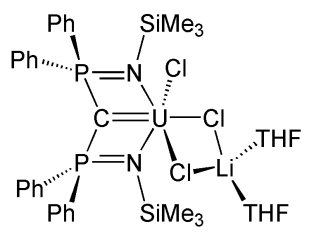

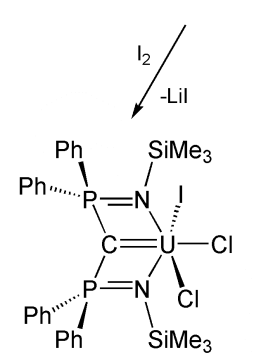

47
46
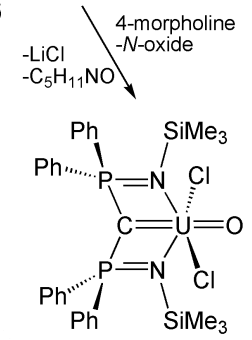

48

Scheme 11. Synthesis of the uranium(V) and (VI) carbene complexes 47 and 48 from the uranium(IV) carbene complex 46.

In 2011 it was reported that the uranium(IV)-carbene complex $\left[\mathrm{U}\left(\mathrm{BIPM}^{\mathrm{TMS}}\right)(\mathrm{Cl})_{3} \mathrm{Li}(\mathrm{THF})_{2}\right](\mathbf{4 6})$ can be straightforwardly prepared from $\mathrm{UCl}_{4}$ and $\left[\mathrm{Li}_{2}\left(\mathrm{BIPM}^{\mathrm{TMS}}\right)\right]_{2}$, and is readily oxidized by $\mathrm{I}_{2}$ to afford the uranium(V)-carbene $\left[\mathrm{U}\left(\mathrm{BIPM}^{\mathrm{TMS}}\right)(\mathrm{Cl})_{2}(\mathrm{I})\right](47)$, Scheme 11. ${ }^{[101]}$ In related work, in 2012 it was found that oxidation of $\mathbf{4 6}$ with 4 -morpholine- $N$-oxide affords the uranium(VI)-carbene $\left[\mathrm{U}\left(\mathrm{BIPM}^{\mathrm{TMS}}\right)(\mathrm{Cl})_{2}(\mathrm{O})\right](\mathbf{4 8})^{[102]}$ which features a trans $\left[\mathrm{R}_{2} \mathrm{C}=\mathrm{U}=\mathrm{O}\right]^{2+}$ linkage that is analogous to the uranyl $[\mathrm{O}=\mathrm{U}=\mathrm{O}]^{2+}$ unit, Scheme 11. The progression of uranium(IV) to (V) to (VI) can be nicely seen in complexes $\mathbf{4 6 - 4 8}$, where the $U=C$ bond falls from $2.310(4)$ to 2.268(10) to 2.184(3) $\AA$; the latter is the shortest U-C distance yet reported. This observation, along with computational studies, suggests that an ITI effect may operating in the trans $\left[\mathrm{R}_{2} \mathrm{C}=\mathrm{U}=\mathrm{O}\right]^{2+}$ linkage, as in uranyl, and that their electronic structures are similar. A salient point to note is that 5 f-orbital contributions to the $\mathrm{U}=\mathrm{C}$ bond dominate over $6 \mathrm{~d}$. Covalency in these $\mathrm{U}=\mathrm{C}$ bonds can be inferred from their reactivity; they react, like cerium(IV)-carbon multiple bonds, with carbonyl compounds to give 
metallo-Wittig alkene products $\mathrm{RC}(\mathrm{H})=\mathrm{C}\left(\mathrm{PPh}_{2} \mathrm{NSiMe}_{3}\right)_{2}(\mathrm{R}=$ phenyl, 9-anthracene $)$, whereas ionic yttrium-BIPM complexes activate $\mathrm{C}-\mathrm{H}$ bonds. ${ }^{[103]}$

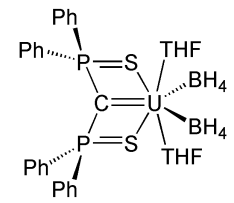

49

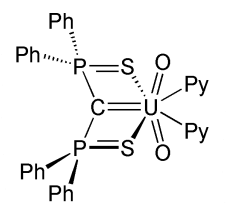

51

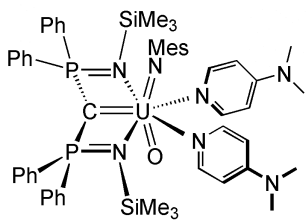

53

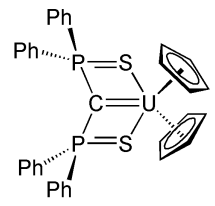

50

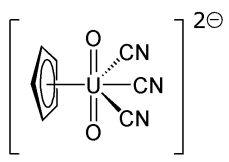

52

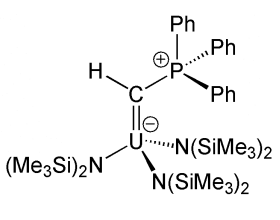

54

Figure 14. Uranium(IV) carbenes 49 and 50, the uranyl(VI) carbene complex 51, the cyclopentadienyl complex of uranyl(VI) 52, the uranium(VI) carbene imido oxo complex 53, and the uranium(IV) carbene complex 54.

Uranium(IV)-carbene complexes $\left[\mathrm{U}(\mathrm{SCS}) \mathrm{L}_{2} \mathrm{~S}_{\mathrm{n}}\right]\left(\mathrm{e} . \mathrm{g} . \mathrm{L}=\mathrm{BH}_{4}, \mathrm{~S}=\mathrm{THF}, \mathrm{n}=2,49 ; \mathrm{L}=\mathrm{C}_{5} \mathrm{H}_{5}, \mathrm{n}=0\right.$, 50) have been prepared in the past 5 years, ${ }^{[104]}$ and a notable addition in 2011 was the uranyl(VI)carbene complex $\left[\mathrm{UO}_{2}(\mathrm{SCS})(\mathrm{Py})_{2}\right](\mathbf{5 1})$ from $\mathbf{1 1 P y}$ and the parent methane $\mathrm{SCS}(\mathrm{Li})_{2}$, Figure 14. ${ }^{[105]}$ This result is notable because covalent uranyl-organometallics remain rare. ${ }^{[44 b, 102,106]}$ Indeed, for example, for many years a curious omission from the literature was a cyclopentadienyl complex of uranyl, but in 2007 it was shown that the linear metallocene anion $\mathbf{3 5}$ could be converted to the uranyl complex $\left[\mathrm{UO}_{2}\left(\eta^{5} \mathrm{C}_{5} \mathrm{H}_{5}\right)(\mathrm{CN})_{3}\right]^{2-}(\mathbf{5 2})$ by careful treatment with pyridine- $N$-oxide, Figure 14. ${ }^{[107]}$ The $\mathrm{U}=\mathrm{C}$ bond in $\mathbf{5 1}$ was found to be highly polar and close to single-bond character, and long at 2.430(6) $\AA$, which reflects the strong bonding in the trans $[\mathrm{O}=\mathrm{U}=\mathrm{O}]^{2+}$ linkage at the expense of the $\mathrm{U}=\mathrm{C}$ bond. A similar effect was found in the mixed uranium(VI)-carbene-imido-oxo complex $\left[\mathrm{U}\left(\mathrm{BIPM}^{\mathrm{TMS}}\right)(\mathrm{NMes})(\mathrm{O})(\mathrm{dmap})_{2}\right](\mathbf{5 3})^{[108]}$ which contains a trans $[\mathrm{MesN}=\mathrm{U}=\mathrm{O}]^{2+}$ unit, Figure 14 , where the bonding in this unit is clearly strongest at the expense of the $\mathrm{U}=\mathrm{C}$ bond as reflected by calculated Nalewajski-Mrozek bond orders of 1.23, 2.34, and 2.68 for the $U=C, U=N$, and $U=O$ bonds, respectively. Exactly 30 years after the first $\mathrm{U}=\mathrm{C}$ bond, the closely related uranium(IV)carbene complex $\left[\mathrm{U}\left\{\mathrm{N}\left(\mathrm{SiMe}_{3}\right)_{2}\right\}_{3}\left(\mathrm{CHPPh}_{3}\right)\right](\mathbf{5 4})$ was prepared, ${ }^{[109]}$ Figure 14. When solutions of the trivalent ylide $\left[\mathrm{U}\left\{\mathrm{N}\left(\mathrm{SiMe}_{3}\right)_{2}\right\}_{3}\left(\mathrm{CH}_{2} \mathrm{PPh}_{3}\right)\right](\mathbf{5 4 H})$ are allowed to stand in diethyl ether $\mathbf{5 4}$ is formed along with $\left[\mathrm{U}\left\{\mathrm{N}\left(\mathrm{SiMe}_{3}\right)_{2}\right\}_{3}\left(\mathrm{CH}_{3}\right)\right]$ and $\mathrm{PPh}_{3}$. Notably, the $\mathrm{U}=\mathrm{C}$ bond in $\mathbf{5 4}$ is short at 
2.278(8) $\AA$ and comparable to $\mathbf{4 5}$ and longer only than 48. Lastly, it should be noted that molecules such as UC, CUC, and CUO have been prepared in argon matrices at ca. $10 \mathrm{~K}$, and the knowledge that such molecules can be prepared has helped to spur carbene chemistry forward. ${ }^{[110]}$

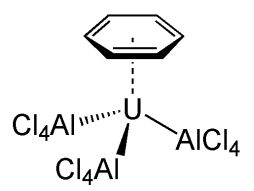

55

Figure 15. The benzene uranium(III) complex 55.

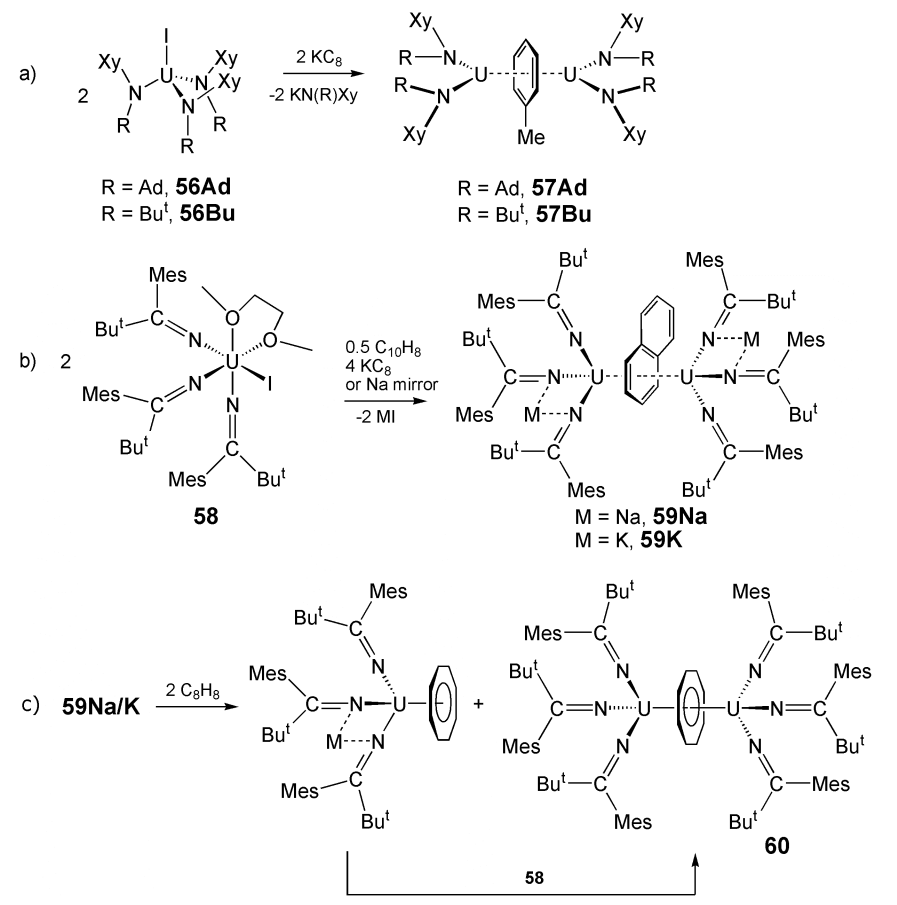

Scheme 12. a) - c): synthesis of the inverted sandwich diuranium arene complexes 57Ad/Bu and $\mathbf{5 9 N a / K}$, and conversion of the latter into the inverted cyclooctatetraenyl complex $\mathbf{6 0}$.

After the synthesis of arene complexes $\mathbf{1 3}\left(\mathrm{C}_{5}\right)$ and $\mathbf{1 6}\left(\mathrm{C}_{8}\right), \mathrm{C}_{6}$ benzene derivatives were somewhat conspicuous by their absence until in 1971 the uranium(III) complex $\left[\mathrm{U}\left(\eta^{6}-\mathrm{C}_{6} \mathrm{H}_{6}\right)\left(\mathrm{AlCl}_{4}\right)_{3}\right](\mathbf{5 5})$ was reported, ${ }^{[111]}$ Figure 15. A number of complexes followed, ${ }^{[32 c]}$ which exploited either the electron richness of hexamethylbenzene or cationic formulations. However, in 2000 a new type of uraniumarene was introduced. ${ }^{[112]}$ Reduction of $\left[\mathrm{U}(\mathrm{I})\{\mathrm{N}(\mathrm{Xy})(\mathrm{R})\}_{3}\right]\left(\mathrm{R}=\mathrm{Ad}, \mathbf{5 6} \mathbf{A d} ; \mathrm{R}=\mathrm{Bu}^{\mathrm{t}}, \mathbf{5 6 B u}\right)$ by $\mathrm{KC}_{8}$ resulted in formation of the inverted sandwich complex $\left[\left\{\mathrm{U}[\mathrm{N}(\mathrm{Xy})(\mathrm{R})]_{2}\right\}_{2}\left(\mu: \eta^{6}-\eta^{6}-\mathrm{C}_{6} \mathrm{H}_{5} \mathrm{Me}\right)\right](\mathrm{R}=$ Ad, 57Ad; $\mathrm{R}=\mathrm{Bu}^{\mathrm{t}}, \mathbf{5 7} \mathbf{B u}$ ), Scheme 12 . The $\mathrm{C}-\mathrm{C}$ bond lengths of the bridging arene were modestly extended compared to free toluene and together with theoretical calculations suggested $\delta$-backbonding between uranium and the arene. The formulation of oxidation state could either be uranium(II)-neutral arene, uranium(III)-dianionic arene, or uranium(IV)-tetraanionic arene; the 
weight of spectroscopic and theoretical characterization evidence favours the uranium(III)-dianionic arene formulation, but 57 react as divalent synthons to, for example, cleave $\mathrm{PhN}=\mathrm{NPh}$ or $\mathrm{PhS}-\mathrm{SPh}$ to give dinuclear uranium(IV) $\mu$-imido or -thiolate derivatives, respectively. Two years after the report of $\mathbf{5 7 A d} / \mathbf{B u}$, reduction of the uranium tris(ketimide) complex [U(NCBu $\left.{ }^{t} \mathrm{Mes}\right)_{3}(\mathrm{I})(\mathrm{DME})$ ] (58) with sodium mirror or potassium graphite was reported to afford the inverted sandwich naphthalene complexes $\left[\left\{\mathrm{U}\left(\mathrm{NCBu}{ }^{\mathrm{t}} \mathrm{Mes}\right)_{3}\right\}_{2}\left(\mu: \eta^{6}-\eta^{6}-\mathrm{C}_{10} \mathrm{H}_{8}\right)(\mathrm{M})_{2}\right](\mathrm{M}=\mathrm{Na}, \mathbf{5 9 N a} ; \mathrm{M}=\mathrm{K}, \mathbf{5 9 K})$,

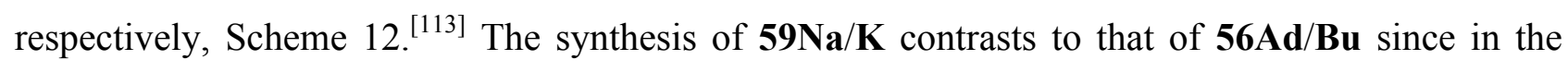
former all ketimide ligands are retained at uranium whereas in the latter an amide ligand is lost during reduction. The $\mu: \eta^{6}-\eta^{6}$-bridging mode of the naphthalene is notable since in lanthanide analogues each six-membered ring bonds to a separate metal on opposite sides of naphthalene, which reflects the increased covalency in the uranium-naphthalene interactions. Complexes $59 \mathrm{Na} / \mathbf{K}$ spawned a range of arene-bridged diuranium complexes which exhibit a rich redox chemistry towards a range of reducible substrates, for example allowing access to the only example to date of a symmetrically bridging COT ligand in uranium chemistry, namely $\left[\left\{\mathrm{U}\left(\mathrm{NCBu}{ }^{\mathrm{t}} \mathrm{Mes}\right)_{3}\right\}_{2}\left(\mu: \eta^{8}-\eta^{8}-\right.\right.$ $\left.\left.\mathrm{C}_{8} \mathrm{H}_{8}\right)\right]$ (60), Scheme 12.

a)
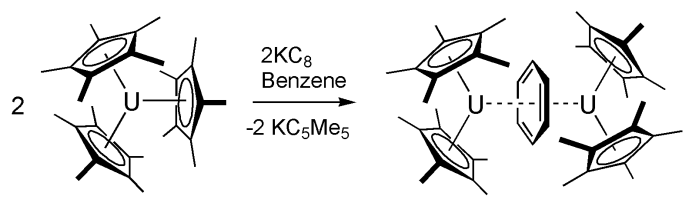

61

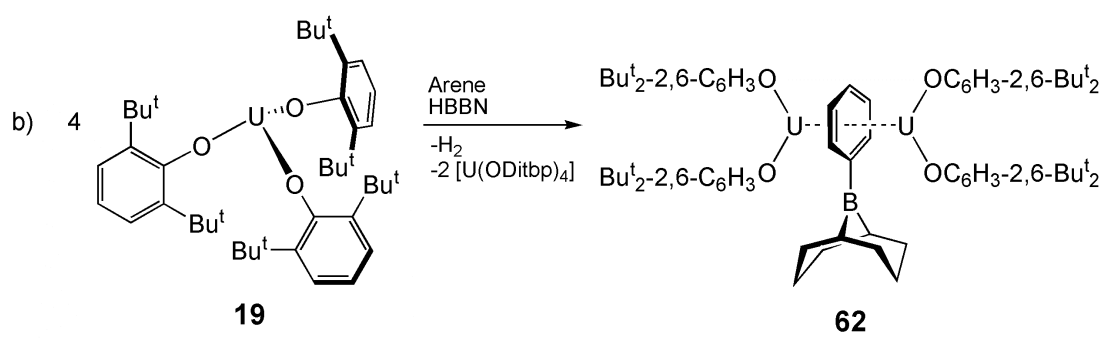

Scheme 13. a) - b): synthesis of the inverted sandwich diuranium(III) arene complexes 61 and 62.

In 2004, an inverted sandwich complex related to 56Ad/Bu was reported exploiting the steric crowding of 29 . Treatment of $\mathbf{2 9}$ with $\mathrm{KC}_{8}$ in the presence of benzene afforded [ $\left\{\mathrm{U}\left(\eta^{5}\right.\right.$ $\left.\left.\left.\mathrm{C}_{5} \mathrm{Me}_{5}\right)_{2}\right\}_{2}\left(\mu: \eta^{6}-\eta^{6}-\mathrm{C}_{6} \mathrm{H}_{6}\right)\right]$ (61), Scheme 13. ${ }^{[14]}$ In this study it was determined that, like for 56Ad/Bu, the most appropriate description of 61 invokes uranium(III) centers with an arene dianion. This implies that the best $\pi$-acceptor arenes should be the most favoured ligands, displacing poorer $\pi$-acceptor ligands and this was confirmed experimentally where para-methyltoluene is displaced by benzene. In this regard, the bonding is distinctly different to transition metal analogues where the arenes are principally acting as $\pi$-donors. Complex $\mathbf{6 1}$ was found to be effective for multi-electron 
reduction reactions with a range of substrates. Notable other examples in this area include a diuranium arene SMM (Section 5.10), and reduction and $\mathrm{C}-\mathrm{H}$ borylation of arenes mediated by uranium(III) disproportionation to afford $\left[\{\mathrm{U}(\mathrm{ODitbp})\}_{2}(\mathrm{PhBBN})\right](62)$ from 19 with sacrificial elimination of $\left[\mathrm{U}(\mathrm{ODitbp})_{4}\right](\mathbf{6 3}) .^{[115]}$
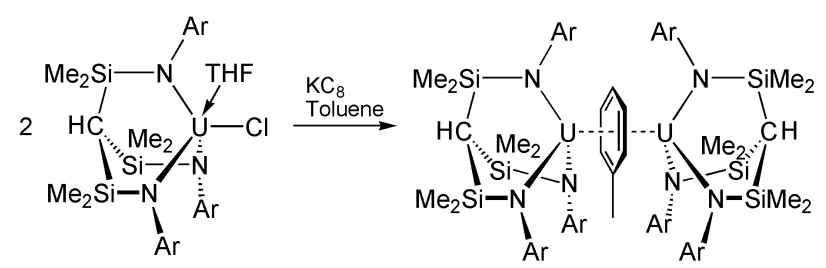

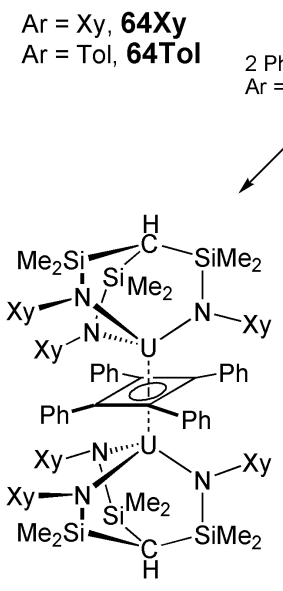

66

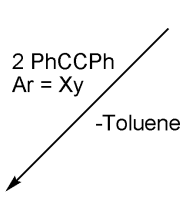

$\mathrm{Ar}=\mathrm{Xy}, 65 \mathrm{Xy}$ $\mathrm{Ar}=\mathrm{Tol}, 65 \mathrm{Tol}$
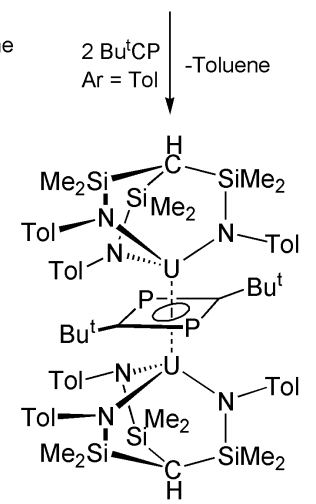

67

Scheme 14. Synthesis of the inverted sandwich diuranium(V) arene complexes $65 \mathrm{Xy} / \mathrm{Tol}$ and their conversion to the diuranium(IV) cyclobutadienyl complex $\mathbf{6 6}$ and diphosphacyclobutadienyl complex 67.

For the first 11 years of diuranium inverted sandwich arene chemistry all examples conformed to the uranium(III) arene dianion description. However, in 2011 a new class of diuranium arene emerged. Reduction of the uranium triamide chloride complexes [ $\left.\mathrm{U}\left\{\mathrm{HC}\left(\mathrm{SiMe}_{2} \mathrm{NAr}\right)_{3}\right\}(\mathrm{Cl})(\mathrm{THF})\right]$ $(\mathrm{Ar}=\mathrm{Xy}, \mathbf{6 4 X y} ; \mathrm{Ar}=\mathrm{Tol}, \mathbf{6 4 T o l})$ with $\mathrm{KC}_{8}$ afforded $\left[\left\{\mathrm{U}\left[\mathrm{HC}\left(\mathrm{SiMe}_{2} \mathrm{NAr}\right)_{3}\right]\right\}_{2}\left(\mu: \eta^{6}-\eta^{6}-\mathrm{C}_{6} \mathrm{H}_{5} \mathrm{Me}\right)\right]$ $(\mathbf{6 5 X y} / \mathbf{T o l})$, Scheme $14 .{ }^{[116]}$ In contrast to $\mathbf{5 7 A d} / \mathbf{B u}$, there are three amide donors in $\mathbf{6 5 X y} / \mathbf{T o l}$, but unlike $\mathbf{5 9 N a / K}$ there are no alkali metal cations present. Surprisingly, of the three formulations, namely a neutral arene and uranium(III), an arene dianion and uranium(IV), or an arene tetraanion and uranium(V), the characterization data confirm the latter combination, but the $\delta$-bonding in these complexes renders this a formalism. Although the pairing of formal [and oxidizing] uranium(V) centers with an arene tetraanion may seem unlikely, $\delta$-bonding will stabilize this interaction, and the toluene tetraanions in $\mathbf{6 5 X y} / \mathbf{T o l}$ are $10 \pi$-electron systems that satisfy Hückel's $4 n+2 \pi$-electron rule giving stability. However, these molecules are very reactive and, for example, effect reductive $[2+$ 2]-cycloadditions to assemble the first examples of f-block cyclobutadienyl 
$\left[\left\{\mathrm{U}\left[\mathrm{HC}\left(\mathrm{SiMe}_{2} \mathrm{NAr}\right)_{3}\right]\right\}_{2}\left(\mu: \eta^{5}-\eta^{5}-\mathrm{C}_{4} \mathrm{Ph}_{4}\right)\right] \quad(66, \quad \mathrm{Ar}=\mathrm{Xy})^{[117]}$ and diphosphacyclobutadienyl $\left[\left\{\mathrm{U}\left[\mathrm{HC}\left(\mathrm{SiMe}_{2} \mathrm{NAr}\right)_{3}\right]\right\}_{2}\left(\mu: \eta^{4}-\eta^{4}-\mathrm{C}_{2} \mathrm{P}_{2} \mathrm{Bu}_{2}^{\mathrm{t}}\right)\right](\mathbf{6 7}, \mathrm{Ar}=\mathrm{Tol})$ derivatives, Scheme 14. ${ }^{[118]}$

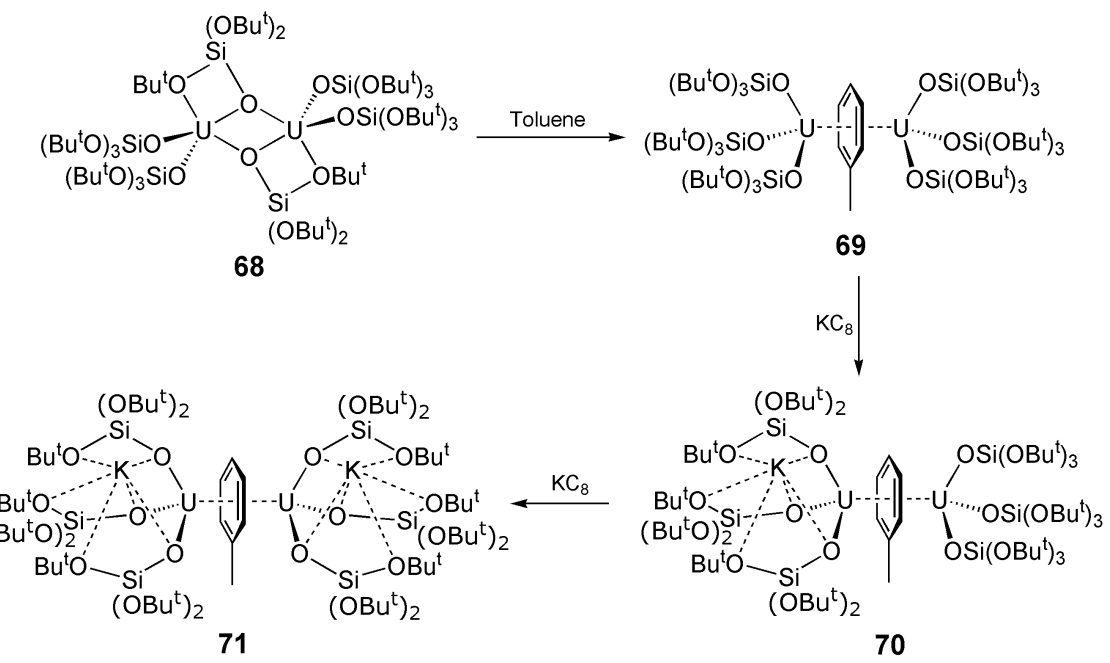

Scheme 15. Synthesis of the inverted sandwich diuranium(V/V), (V/VI), and (IV/IV) arene complexes 69-71 from 68 .

In 2012 another complex assignable as a diuranium(V) arene tetraanion was reported. Reaction of $\left[\left\{\mathrm{U}\left(\mathrm{OSi}\left[\mathrm{OBu}^{\mathrm{t}}\right]_{3}\right)_{3}\right\}_{2}\right](\mathbf{6 8})$ with toluene afforded $\left[\left\{\mathrm{U}\left(\mathrm{OSi}\left[\mathrm{OBu}^{\mathrm{t}}\right]_{3}\right)_{3}\right\}_{2}\left(\mu: \eta^{6}-\eta^{6}-\mathrm{C}_{6} \mathrm{H}_{5} \mathrm{Me}\right)\right](\mathbf{6 9}) .{ }^{[119]}$ The uranium oxidation states were not assigned in the preliminary report, but in 2013 a fuller study found that 69 could be sequentially reduced to monoanionic $\left[\left\{\mathrm{U}\left(\mathrm{OSi}\left[\mathrm{OBu}^{t}\right]_{3}\right)_{3}\right\}_{2}\left(\mu: \eta^{6}-\eta^{6}-\right.\right.$ $\left.\left.\mathrm{C}_{6} \mathrm{H}_{5} \mathrm{Me}\right)(\mathrm{K})\right](\mathbf{7 0})$ and dianionic $\left[\left\{\mathrm{U}\left(\mathrm{OSi}\left[\mathrm{OBu}^{\mathrm{t}}\right]_{3}\right)_{3}\right\}_{2}\left(\mu: \eta^{6}-\eta^{6}-\mathrm{C}_{6} \mathrm{H}_{5} \mathrm{Me}\right)(\mathrm{K})_{2}\right]$ (71), which are diuranium(IV/V) arene tetraanion and diuranium(IV/IV) arene tetraanion formulations, respectively, Scheme 15 . The changes in electronic structure could be observed by monitoring the change in U-C bond distances from $2.689(3)$ to $2.695(3) \AA$ (69) to $2.602(9)$ to $2.674(13) \AA$ (70) to $2.589(4)$ to 2.621(3) $\AA$ (71). DFT calculations revealed that as electrons are injected into the molecules they occupy non-bonding f-orbitals since the arene at $10 \pi$-electrons is already electronically saturated and the remaining $\psi_{6}$ orbital is too high-lying to accept electrons.

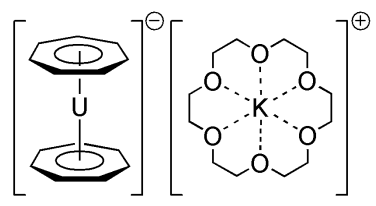

72

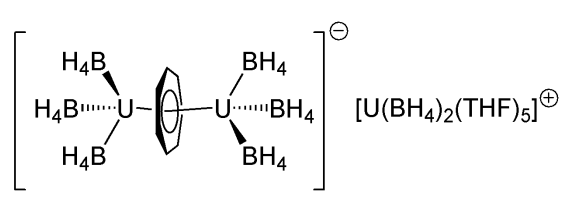

73

Figure 16. The cycloheptatrienyl complexes 72 and 73.

Lastly, although there are a fairly large number of reports of transition metal cycloheptatrienyl complexes, ${ }^{[120]}$ it is interesting to note that uranium analogues are exceptionally rare and therefore 
the only two known examples reported in the mid-1990s merit a mention. Aside from the sandwich complex $\left[\mathrm{U}\left(\eta^{7}-\mathrm{C}_{7} \mathrm{H}_{7}\right)_{2}\right]\left[\mathrm{K}\left(\mathrm{C}_{12} \mathrm{H}_{24} \mathrm{O}_{6}\right)\right](\mathbf{7 2})$, which is a $5 \mathrm{f}^{1}$ analogue of uranocene, the only other example of a uranium cycloheptatrienyl complex is that of the inverse sandwich separated ion pair complex $\left[\left(\mathrm{H}_{4} \mathrm{~B}\right)_{3} \mathrm{U}\left(\mu: \eta^{7}-\eta^{7}-\mathrm{C}_{7} \mathrm{H}_{7}\right) \mathrm{U}\left(\mathrm{BH}_{4}\right)_{3}\right]\left[\mathrm{U}\left(\mathrm{BH}_{4}\right)_{2}(\mathrm{THF})_{5}\right]$ (73), Figure 16. ${ }^{[121]}$ Although no theoretical studies of $\mathbf{7 3}$ have been reported it seems likely that $\delta$-bonding will dominate the bonding of the inverse sandwich unit, as has been suggested for the bonding scheme of $\mathbf{7 2}^{[122]}$ which would be consistent with the planar $\mathrm{C}_{7} \mathrm{H}_{7}$ rings observed in X-ray diffraction studies. The formulations for $\mathbf{7 2}$ and $\mathbf{7 3}$ are consistent with uranium(V) and (IV) centers, respectively, which suggests the cycloheptatrienyl ligands bear -3 charges in both complexes.

\subsection{Pnictide Donor Atom Ligands}

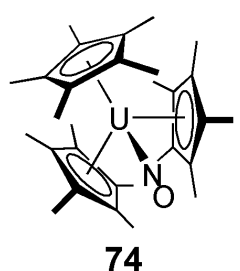

Figure 17. The nitrosyl complex of uranium 74.

In analogy to the small number of uranium-carbon monoxide adducts, the isolation of a uraniumnitrosyl complex is of fundamental importance. Only one such complex exists, reported as recently as 2012, namely $\left[\mathrm{U}\left(\eta^{5}-\mathrm{C}_{5} \mathrm{Me}_{4} \mathrm{H}\right)_{3}(\mathrm{NO})\right]$ (74), prepared from trivalent 29 and $\mathrm{NO}$ gas. ${ }^{[123]}$ Interestingly, the U-NO linkage is linear, which is typical for $\mathrm{NO}^{+}$when bonded to a d-block metal. However, the U-N bond length is short (2.013(4) $\AA$ ) and more in keeping with a U(IV)-N distance rather than $\mathrm{U}(\mathrm{III})$, and the $\mathrm{N}-\mathrm{O}$ distance is consistent with a $\mathrm{NO}^{-}$charge state (1.231(5) $\AA$ ). It would seem from the characterization data that this complex is best formulated as U(IV) with a significant back-bonding interaction between uranium $5 \mathrm{f}$ and $\mathrm{NO} \pi^{*}$ orbitals. Indeed, a linear binding of NO to uranium was theoretically predicted in $1989 .{ }^{[124]}$

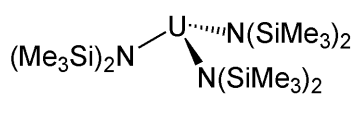

75

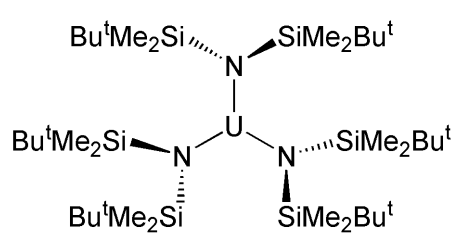

76

Figure 18. The trigonal pyramidal and trigonal planar uranium(III) amides $\mathbf{7 5}$ and $\mathbf{7 6 .}$

Amides play a central role in coordination and organometallic chemistry and the amide chemistry of uranium is no exception. Although the amide chemistry of uranium can be considered to be mature, it is notable that, like for alkyl derivatives, heteroleptic variants dominate and there are 
relatively few homoleptic variants. One of the most utilized and perhaps iconic homoleptic amides is the uranium(III) complex $\left[\mathrm{U}\left\{\mathrm{N}\left(\mathrm{SiMe}_{3}\right)_{2}\right\}_{3}\right]$ (75) reported in $1981,{ }^{[125 \mathrm{a}, \mathrm{b}]}$ which can be easily prepared from 3THF and three equivalents of sodium or potassium bis(trimethylsilyl)amide and purified by sublimation or careful recrystallization. The low formal coordination number of 3 in $\mathbf{7 5}$ and substituted variants ${ }^{[125 c]}$ is potentially useful for reactivity studies, and this platform has supported the activation of a number of small molecules, installation of novel ligand linkages and oxidation to give uranium(V) derivatives, ${ }^{[126]}$ and even SMM behaviour (Section 5.1). In the solid state 75 adopts a trigonal pyramidal geometry which is in contrast to most transition metal analogues that adopt trigonal planar geometries, but this was recently shown to be surmountable by the use of larger silyl substituents in $\left[\mathrm{U}\left\{\mathrm{N}\left(\mathrm{SiMe}_{2} \mathrm{Bu}^{\mathrm{t}}\right)_{2}\right\}_{3}\right](\mathbf{7 6}) .{ }^{[127]}$

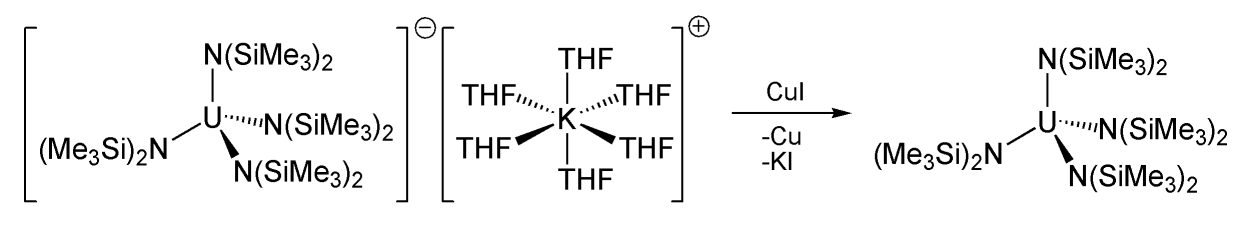

77

78

Scheme 16. Synthesis of the uranium(IV) amide complex 78 from 77.

For many years it was thought that the bis(trimethylsilyl)amide ligand was too sterically demanding to have four of them accommodated at uranium(IV), although $\left[\mathrm{U}\left\{\mathrm{N}\left(\mathrm{SiMe}_{3}\right)_{2}\right\}_{4}\right]\left[\mathrm{K}(\mathrm{THF})_{6}\right](77),{ }^{[128]}$ which contains the larger uranium(III), had been prepared from trivalent 3THF and four equivalents of potassium bis(trimethylsilyl)amide. Treating 6 with four equivalents of alkali metal bis(trimethylsilyl)amides produces the cyclometallated complex $\left[\mathrm{U}\left\{\mathrm{N}\left(\mathrm{SiMe}_{3}\right)_{2}\right\}_{2}\left(\mathrm{CH}_{2} \mathrm{SiMe}_{2} \mathrm{NSiMe}\right)\right]$, which further reinforced the steric overload notion. ${ }^{[129]}$ However, in 2013 it was finally determined that oxidation of 77 with copper(I) iodide gives $\left[\mathrm{U}\left\{\mathrm{N}\left(\mathrm{SiMe}_{3}\right)_{2}\right\}_{4}\right]$ (78) in excellent yield. ${ }^{[130]}$ Although the synthesis of $\mathbf{7 8}$ is a recent development, given the extensive chemistry of $\mathbf{7 5}$ it is likely that $\mathbf{7 8}$ will find interesting uses in the future. 


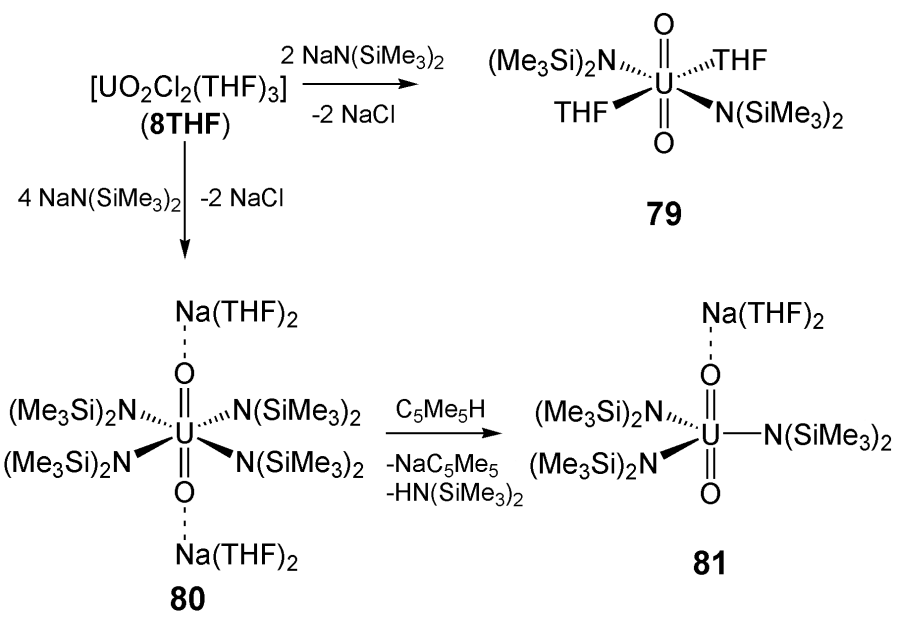

Scheme 17. Synthesis of $\left\{\left(\mathrm{Me}_{3} \mathrm{Si}\right)_{2} \mathrm{~N}\right\}^{-}$uranyl(VI) derivatives 79-81.

The $\left\{\left(\mathrm{Me}_{3} \mathrm{Si}\right)_{2} \mathrm{~N}\right\}^{-}$ligand finds utility over a wide range of uranium oxidation states. Exemplifying this, as well as stabilizing uranium(III) and (IV), uranyl(VI) derivatives have been prepared, Scheme 17. For example, from 1979 it was known that treatment of 8THF with two equivalents of sodium bis(trimethylsilyl)amide produced $\left[\mathrm{UO}_{2}\left\{\mathrm{~N}\left(\mathrm{SiMe}_{3}\right)_{2}\right\}_{2}(\mathrm{THF})_{2}\right](\mathbf{7 9}),{ }^{[131]}$ which is an efficient reagent to introduce uranyl to pro-ligands via protonolysis chemistry. Alternatively, it was shown in 2000 that treatment of $\mathbf{8 T H F}$ with four equivalents of sodium bis(trimethylsilyl)amide produces $\left[\mathrm{UO}_{2}\left\{\mathrm{~N}\left(\mathrm{SiMe}_{3}\right)_{2}\right\}_{4}\right]\left[\mathrm{Na}(\mathrm{THF})_{2}\right]_{2}(\mathbf{8 0}),{ }^{[132]}$ which when treated with $\mathrm{C}_{5} \mathrm{Me}_{5} \mathrm{H}$ eliminates $\left(\mathrm{Me}_{3} \mathrm{Si}\right)_{2} \mathrm{NH}$ and $\left[\mathrm{Na}\left(\mathrm{C}_{5} \mathrm{Me}_{5}\right)\right]$ to give $\left[\mathrm{UO}_{2}\left\{\mathrm{~N}\left(\mathrm{SiMe}_{3}\right)_{2}\right\}_{3}\right]\left[\mathrm{Na}(\mathrm{THF})_{2}\right](\mathbf{8 1}){ }^{[133]}$

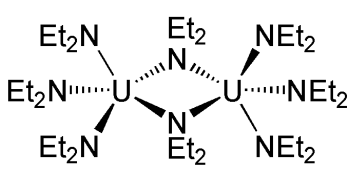

82

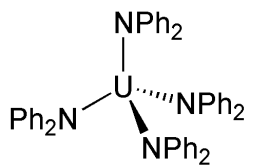

83

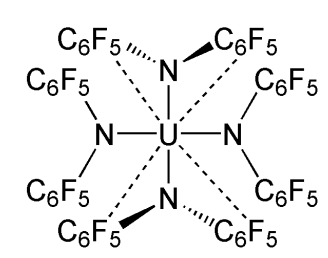

84

Figure 19. The uranium(IV) amide complexes 82-84.

Although 78 was reported very recently, homoleptic uranium(IV) amides have been known for decades. ${ }^{[134]}$ The dimeric diethylamide complex $\left[\left\{\mathrm{U}\left(\mathrm{NEt}_{2}\right)_{4}\right\}_{2}\right](\mathbf{8 2})$ was reported in 1976 and was the first five-coordinate f-block complex, Figure $19 .^{[134 \mathrm{~b}]}$ The complex is straightforwardly prepared from 6 and lithium diethylamide, and so is in principle an excellent starting material, but the compound must be carefully sublimed during purification since thermal decomposition is facile. Reported in 1977, [U(NPh$\left.)_{4}\right](83)$ illustrates the importance of steric effects in uranium 
chemistry, ${ }^{[135]}$ Figure 19, inasmuch as making the amide more sterically demanding now enforces a monomeric, four-coordinate formulation. More recently, in 2013 the synthesis of the homoleptic uranium(IV) complex $\left[\mathrm{U}\left\{\mathrm{N}\left(\mathrm{C}_{6} \mathrm{~F}_{5}\right)_{2}\right\}_{4}\right](\mathbf{8 4})$ was reported, ${ }^{[136]}$ Figure 19. In contrast to 83, which adopts a tetrahedral geometry, complex 84 notably adopts a pseudo-square planar geometry, that is usually the preserve of $\mathrm{d}^{8}$ group 9 or 10 metals, which underscores the important effect subtle and weak bonding interactions, in this case $\mathrm{F} \cdot \cdot \mathrm{U}$, can have on complex geometry.
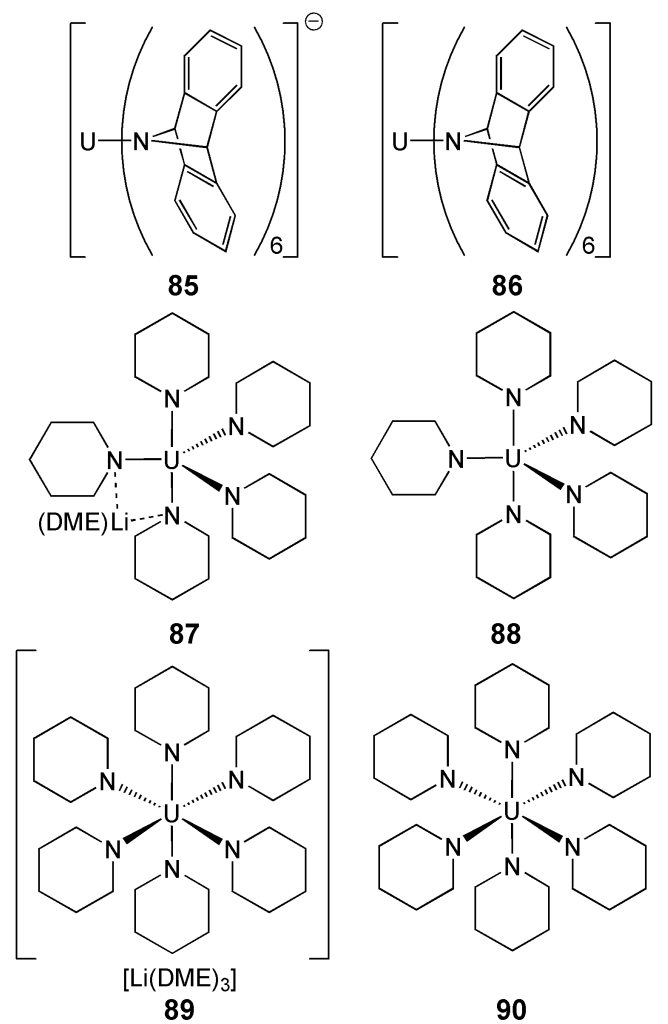

Figure 20. Homoleptic uranium(V) and (VI) amides 85-90.

In 2000, homoleptic uranium(V) and (VI) hexaamide complexes were reported, ${ }^{[137]}$ Figure 20. Reaction of 3THF with [Li(dbabh) $\left.\left(\mathrm{OEt}_{2}\right)\right]$, a potential nitride delivery reagent, afforded $\left[\mathrm{U}(\mathrm{dbabh})_{6}\right]^{-}(\mathbf{8 5})$ as its lithium salt with elimination of lithium iodide and anthracene, and this complex was crystallographically authenticated as its tetraphenylphosphonium salt. The uranium(V) center is well shielded by the six dbabh ligands, and therefore can be straightforwardly oxidized with AgOTf to afford [U(dbabh) 6 (86). In 2011, a related pair of uranium(V) and (VI) complexes were reported using the piperidide ligand, ${ }^{[138]}$ Figure 20. Treatment of $\mathbf{6}$ with five equivalents of $\left[\mathrm{Li}\left(\mathrm{NC}_{5} \mathrm{H}_{10}\right)\right]$ affords $\left[\mathrm{U}\left(\mathrm{NC}_{5} \mathrm{H}_{10}\right)_{5} \mathrm{Li}(\mathrm{DME})\right](87)$ which can be oxidized with iodine

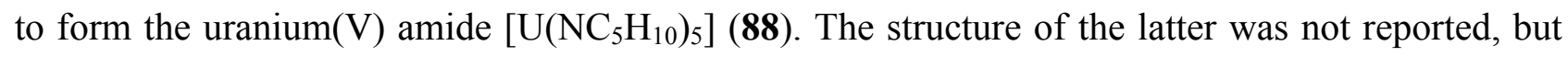
addition of one equivalent of $\left[\mathrm{Li}\left(\mathrm{NC}_{5} \mathrm{H}_{10}\right)\right]$ afforded the 'ate' complex $\left[\mathrm{U}\left(\mathrm{NC}_{5} \mathrm{H}_{10}\right)_{6}\right]\left[\mathrm{Li}(\mathrm{DME})_{3}\right]$ (89), which could then be oxidized by iodine again to afford the uranium(VI) amide [U(NC $\left.\left.\mathrm{NH}_{10}\right)_{6}\right]$ 
(90). Analogously to uranium-alkyls and -amides, although uranium-ketimides are known, most are heteroleptic and few homoleptic variants are reported. Known homoleptic variants follow the methodology used for 85-90. ${ }^{[139]}$

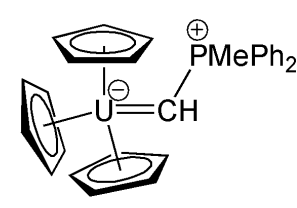

91

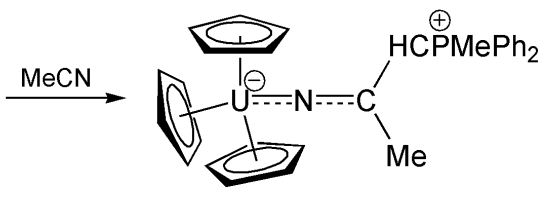

92

Scheme 18. Synthesis of the uranium imido complex 92 from the carbene complex 91.

The first uranium-imido complex was reported in 1984, Scheme 18. Treatment of the uraniumcarbene complex $\left[\mathrm{U}\left(\eta^{5}-\mathrm{C}_{5} \mathrm{H}_{5}\right)_{3}\left\{\mathrm{C}(\mathrm{H}) \mathrm{P}(\mathrm{Me}) \mathrm{Ph}_{2}\right\}\right](\mathbf{9 1})$, a close analogue of 45, with acetonitrile afforded the 1,2-migratory insertion product $\left[\mathrm{U}\left(\eta^{5}-\mathrm{C}_{5} \mathrm{H}_{5}\right)_{3}\left\{\mathrm{NC}(\mathrm{Me}) \mathrm{C}(\mathrm{H}) \mathrm{P}(\mathrm{Me}) \mathrm{Ph}_{2}\right\}\right](\mathbf{9 2}) .{ }^{[140]} \mathrm{The}$ bond lengths within the $\mathrm{UNC}(\mathrm{Me}) \mathrm{C}(\mathrm{H}) \mathrm{P}$ fragment, as determined by X-ray crystallography, suggested some delocalization but the short U-N distance of 2.06(1) $\AA$ is consistent with a $U=N$ double bond.

a)

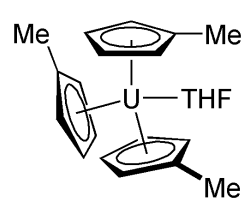

93

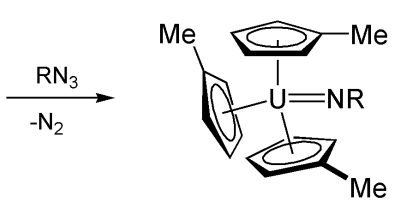

$\mathrm{R}=\mathrm{Ph}, \mathbf{9 4} \mathrm{Ph}$

$\mathrm{R}=\mathrm{SiMe}_{3}, 94 \mathrm{TMS}$

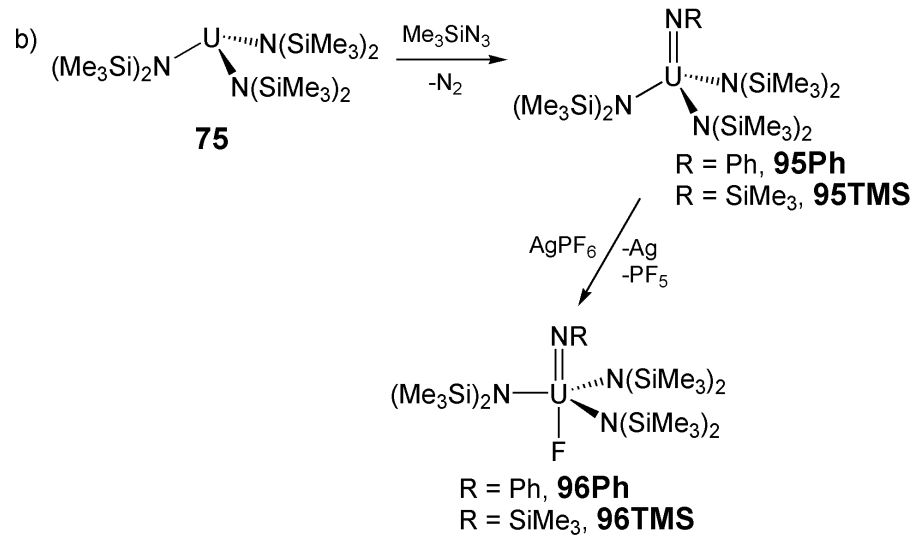

Scheme 19. a) - b): synthesis of the uranium(V) and (VI) imido complexes 94Ph/94TMS to 96Ph/96TMS.

Complex 92 was prepared by insertion chemistry, and in 1985 a new 2-electron oxidative route to an imido complex was reported, Scheme 19. Treatment of the uranium(III) complex [U( $\eta^{5}$ $\left.\left.\mathrm{C}_{5} \mathrm{H}_{4} \mathrm{Me}\right)_{3}(\mathrm{THF})\right](\mathbf{9 3})$ with one equivalent of an organic azide produced the uranium(V) complexes 
$\left[\mathrm{U}\left(\eta^{5}-\mathrm{C}_{5} \mathrm{H}_{4} \mathrm{Me}\right)_{3} \mathrm{NR}\right]\left(\mathrm{R}=\mathrm{Ph}, 94 \mathrm{Ph} ; \mathrm{R}=\mathrm{SiMe}_{3}\right.$, 94TMS $) .{ }^{[141]}$ The phenyl derivative was crystallographically characterized revealing a $\mathrm{U}=\mathrm{N}$ bond length of $2.019(6) \AA$ which at that time was the shortest U-N distance ever reported. The generality of this route was later shown in 1988 with the reaction of $\mathrm{PhN}_{3}$ or $\mathrm{Me}_{3} \mathrm{SiN}_{3}$ with 75 to afford the uranium(V) imido complexes $\left[\mathrm{U}\left\{\mathrm{N}\left(\mathrm{SiMe}_{3}\right)_{2}\right\}_{3} \mathrm{NR}\right]\left(\mathrm{R}=\mathrm{Ph}, \mathbf{9 5 P h} ; \mathrm{R}=\mathrm{SiMe}_{3}, 95 \mathrm{TMS}\right),{ }^{[142]}$ Scheme 19 , which for the latter exhibits an even shorter $\mathrm{U}=\mathrm{N}$ distance of 1.910(16) $\AA$ compared to 94Ph. Complex 95 provided a platform from which to prepare the first uranium(VI) imido complexes which were reported in 1990. Treatment of 95Ph or 95TMS with $\mathrm{AgPF}_{6}$ effected oxidation. Working the reactions up within 6-8 hours to avoid extensive by-product formation afforded the uranium(VI) imido complexes $\left[\mathrm{U}\left\{\mathrm{N}\left(\mathrm{SiMe}_{3}\right)_{2}\right\}_{3}(\mathrm{NR})(\mathrm{F})\right]\left(\mathrm{R}=\mathrm{Ph}, 96 \mathrm{Ph} ; \mathrm{R}=\mathrm{SiMe}_{3}, 96 \mathrm{9MS}\right) .{ }^{[143]}$ The solid state structures revealed the fluoride to reside trans to the imido group in each case, and the $\mathrm{U}=\mathrm{N}$ distances were found to be very short at 1.979(8) and 1.854(23) $\AA$, the former for the phenyl imido group where delocalization into the aromatic ring might be expected.

a)

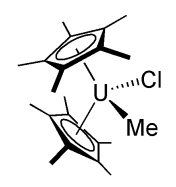

97

b)
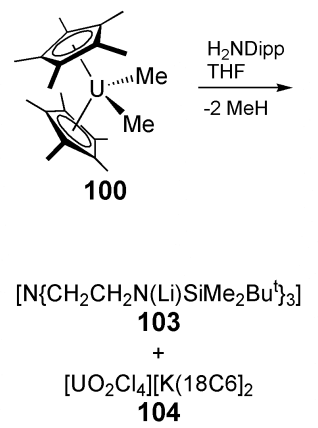

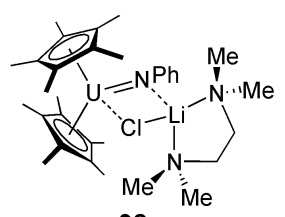

98

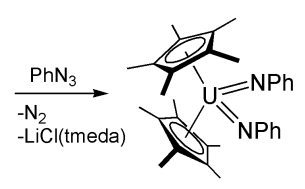

99
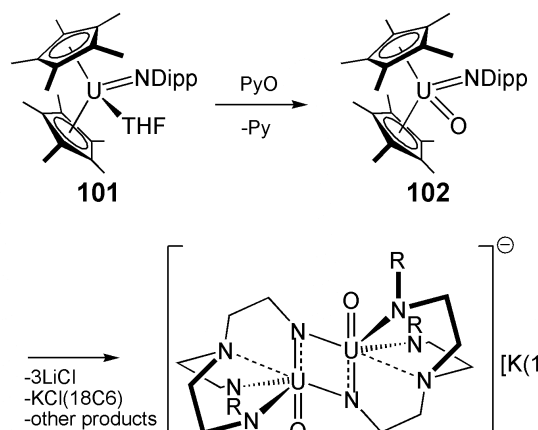

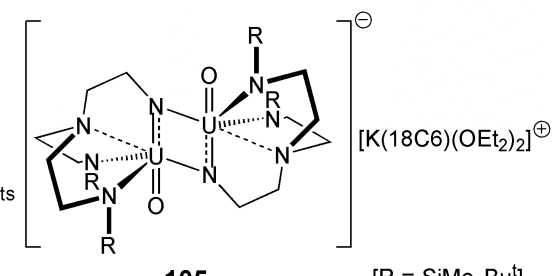

105

$\left[\mathrm{R}=\mathrm{SiMe}_{2} \mathrm{Bu}^{\mathrm{t}}\right]$

Scheme 20. a) - c): synthesis of high valent uranium imido complexes 99, 102, and 105.

An alternative route to uranium(IV) imido complexes was disclosed in 1992. Treatment of [U( $\eta^{5}$ $\left.\left.\mathrm{C}_{5} \mathrm{Me}_{5}\right)_{2}(\mathrm{Me})(\mathrm{Cl})\right]$ (97) with lithium phenyl amide and tmeda afforded the LiCl occluded imido complex $\left[\mathrm{U}\left(\eta^{5}-\mathrm{C}_{5} \mathrm{Me}_{5}\right)_{2}(\mathrm{NPh})\{\mathrm{ClLi}(\right.$ tmeda $\left.)\}\right]$ (98), thus demonstrating that acid-base chemistry, driven by methane elimination, could construct $\mathrm{U}=\mathrm{N}$ double bonds. Interestingly, 98 is quite reactive, and although uranium(IV) is in principle not very oxidizing, further reaction with phenyl azide afforded the first organometallic uranium(VI) complex $\left[\mathrm{U}\left(\eta^{5}-\mathrm{C}_{5} \mathrm{Me}_{5}\right)_{2}(\mathrm{NPh})_{2}\right](\mathbf{9 9}){ }^{[144]}$ Scheme 20. Complex 99 is also notable for being the first example of a uranium bis(imido) complex, i.e. an isoelectronic analogue of $[\mathrm{O}=\mathrm{U}=\mathrm{O}]^{2+}$, and remained so for some time until a new route to 
these species was eventually discovered (Scheme 24). This chemistry also served to spur the synthesis of the first mixed imido-oxo complex which was reported in 1993, Scheme 20; conversion of 97 to $\left[\mathrm{U}\left(\eta^{5}-\mathrm{C}_{5} \mathrm{Me}_{5}\right)_{2}(\mathrm{Me})_{2}\right]$ (100), followed by treatment with DippNH$H_{2}$ afforded the uranium(IV) imido complex $\left[\mathrm{U}\left(\eta^{5}-\mathrm{C}_{5} \mathrm{Me}_{5}\right)_{2}(\mathrm{NDipp})(\mathrm{THF})\right](\mathbf{1 0 1}$, note the Mes* variant is solventfree ${ }^{[144,145]}$ which was subsequently oxidized by pyridine- $N$-oxide to give $\left[\mathrm{U}\left(\eta^{5}\right.\right.$ $\left.\left.\mathrm{C}_{5} \mathrm{Me}_{5}\right)_{2}(\mathrm{NDipp})(\mathrm{O})\right]$ (102). Another example of a mixed oxo-imido dimer was reported in 2001, Scheme 20; reaction of $\left[\mathrm{N}\left\{\mathrm{CH}_{2} \mathrm{CH}_{2} \mathrm{~N}(\mathrm{Li}) \mathrm{SiMe}_{2} \mathrm{Bu}^{t}\right\}_{3}\right]$ (103) with $\left[\mathrm{UO}_{2} \mathrm{Cl}_{4}\right][\mathrm{K}(18 \mathrm{C} 6)]_{2}$ (104) afforded the mixed valent uranium(V/VI) oxo-imido dimer complex $\left[\left\{\mathrm{U}(\mathrm{O})\left[\mathrm{N}\left(\mathrm{CH}_{2} \mathrm{CH}_{2} \mathrm{NSiMe}_{2} \mathrm{Bu}^{\mathrm{t}}\right)_{2}\left(\mathrm{CH}_{2} \mathrm{CH}_{2} \mathrm{~N}\right)\right\}_{2}\right]\left[\mathrm{K}(18 \mathrm{C} 6)\left(\mathrm{OEt}_{2}\right)_{2}\right](\mathbf{1 0 5}) .{ }^{[146]}\right.$

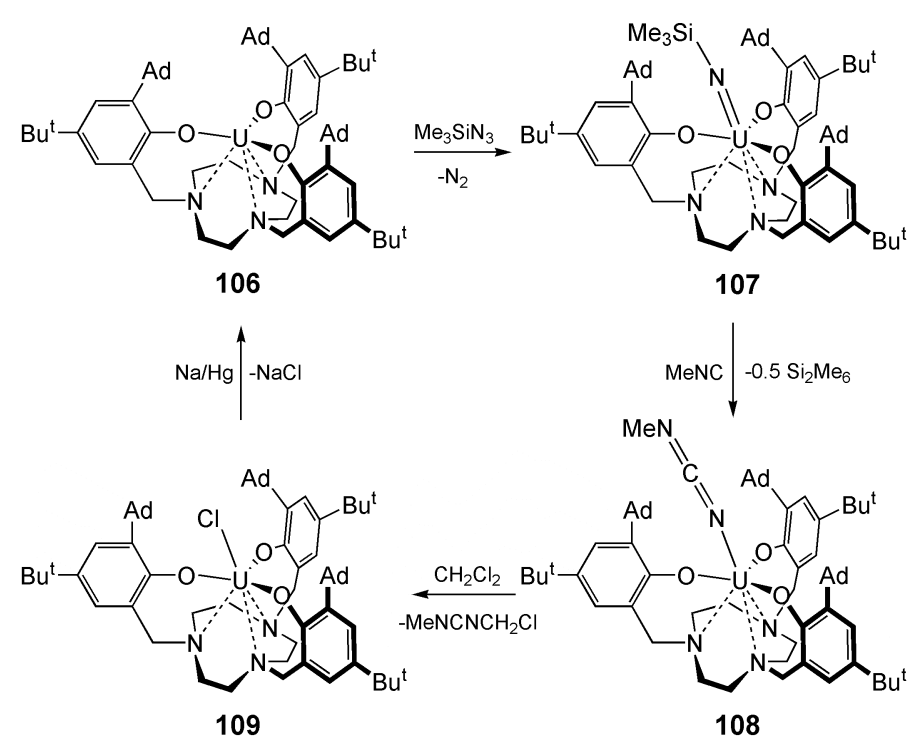

Scheme 21. Bond metathesis and group transfer at a sterically pressurised uranium complex.

Like transition metal imido compounds, uranium-imido complexes might be expected to engage in bond metathesis chemistry and this expectation has been met, Scheme 21. ${ }^{[147]}$ In 2006 it was shown that the sterically encumbered uranium(III) complex $\left[\mathrm{U}\left\{\operatorname{tacn}\left(\mathrm{CH}_{2} \mathrm{C}_{6} \mathrm{H}_{2}-3-\mathrm{Bu}^{\mathrm{t}}-5-\mathrm{Ad}-6-\mathrm{O}\right)_{3}\right\}\right]$ (106) reacted with $\mathrm{Me}_{3} \mathrm{SiN}_{3}$, analogously to 75, to give [ $\mathrm{U}\left\{\operatorname{tacn}\left(\mathrm{CH}_{2} \mathrm{C}_{6} \mathrm{H}_{2}-3-\mathrm{Bu}-5-\mathrm{Ad}-6-\mathrm{O}\right)_{3}\right\} \mathrm{NSiMe}_{3}$ ] (107). Because of the steric overload the $U=N$ distance is long at 2.1219(18) $\AA$, which leads to facile reactivity with $\mathrm{MeNC}$ to liberate half an equivalent of $\mathrm{Me}_{6} \mathrm{Si}_{2}$ to give an isocyanate derivative $\left[\mathrm{U}\left\{\operatorname{tacn}\left(\mathrm{CH}_{2} \mathrm{C}_{6} \mathrm{H}_{2}-3-\mathrm{Bu}^{\mathrm{t}}-5-\mathrm{Ad}-6-\mathrm{O}\right)_{3}\right\} \mathrm{NCNMe}\right](\mathbf{1 0 8})$. Complex 108 reacts with dichloromethane to give $\left[\mathrm{U}\left\{\operatorname{tacn}\left(\mathrm{CH}_{2} \mathrm{C}_{6} \mathrm{H}_{2}-3-\mathrm{Bu}^{\mathrm{t}}-5-\mathrm{Ad}-6-\mathrm{O}\right)_{3}\right\} \mathrm{Cl}\right]$ (109) which can be reductively converted to 106, thus closing a cyclic reaction pathway. Interestingly, $\mathbf{1 0 7}$ also reacts with $\mathrm{CO}$ to afford the cyanate complex $\left[\mathrm{U}\left\{\operatorname{tacn}\left(\mathrm{CH}_{2} \mathrm{C}_{6} \mathrm{H}_{2}-3-\mathrm{Bu}^{\mathrm{t}}-5-\mathrm{Ad}-6-\mathrm{O}\right)_{3}\right\} \mathrm{NCO}\right]$. 


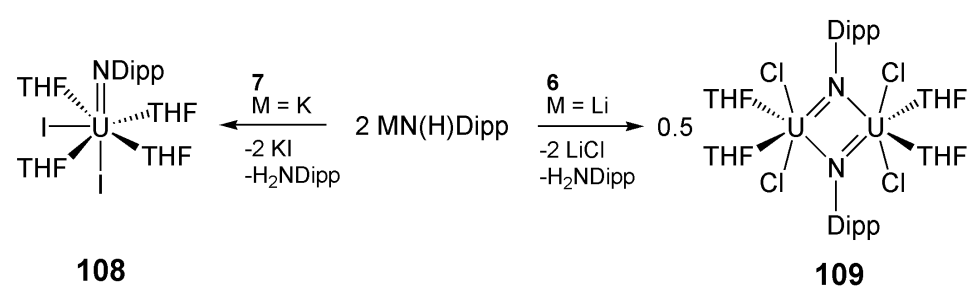

Scheme 22. Divergent outcomes in the preparation of uranium(IV) imido complexes.

For many years terminal uranium imido complexes had been supported by a fairly bulky ligandcombination, but in 2011 it was shown that sterically demanding co-ligands are not necessarily a mandatory requirement, even for uranium(IV), Scheme $22 .{ }^{[148]}$ For example, treatment of 7 with two equivalents of $\mathrm{KN}(\mathrm{H})$ Dipp affords $\left[\mathrm{UI}_{2}(\mathrm{NDipp})(\mathrm{THF})_{4}\right]$ (108). However, the synthesis of such species is evidently sensitive to reagents and conditions since the analogous reaction between $\mathbf{6}$ and LiN(H)Dipp affords dimeric $\left[\left\{\mathrm{UCl}_{2}(\mathrm{NDipp})(\mathrm{THF})_{2}\right\}_{2}\right](\mathbf{1 0 9})$.

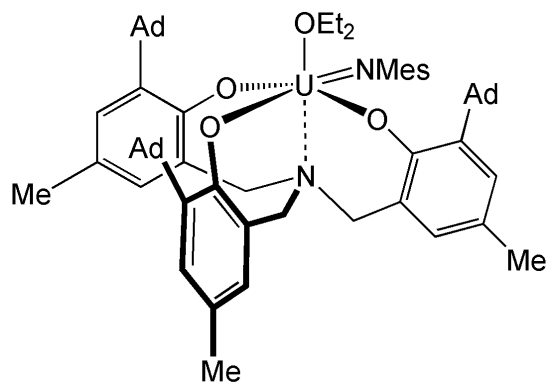

110

Figure 21. A uranium(V) imido complex 110 that exhibits an ITI effect.

In 2012 the synthesis of the uranium(V)-imido complex [ $\mathrm{U}\left\{\mathrm{N}\left(\mathrm{CH}_{2} \mathrm{C}_{6} \mathrm{H}_{2}-3-\mathrm{Bu}^{\mathrm{t}}-5-\mathrm{Ad}-6-\mathrm{O}\right)_{3}\right\} \mathrm{NMes}$ ] (110) from the trivalent precursor and $\mathrm{MesN}_{3}$ was reported, Figure 21. ${ }^{[50 \mathrm{a}]}$ Whereas the predicted structure would be a $C_{3}$ symmetric complex with the imido group trans to the amine, in fact the structure adopts a $C_{s}$ structure with the imido group trans to an aryloxide oxo group. In contrast, the silyl imido congener adopts the anticipated $C_{3}$ geometry. The structure of $\mathbf{1 1 0}$ shows a relatively short $\mathrm{U}=\mathrm{N}$ distance of 1.950(3) $\AA$ and the oxo trans is the shortest of the three U-O distances at 2.145(2) $\AA$ ( cis U-O = av. 2.175(2) $\AA$ ). This was taken as evidence of an ITI effect like in uranyl and was the first observation of this with a uranium(V) center. 

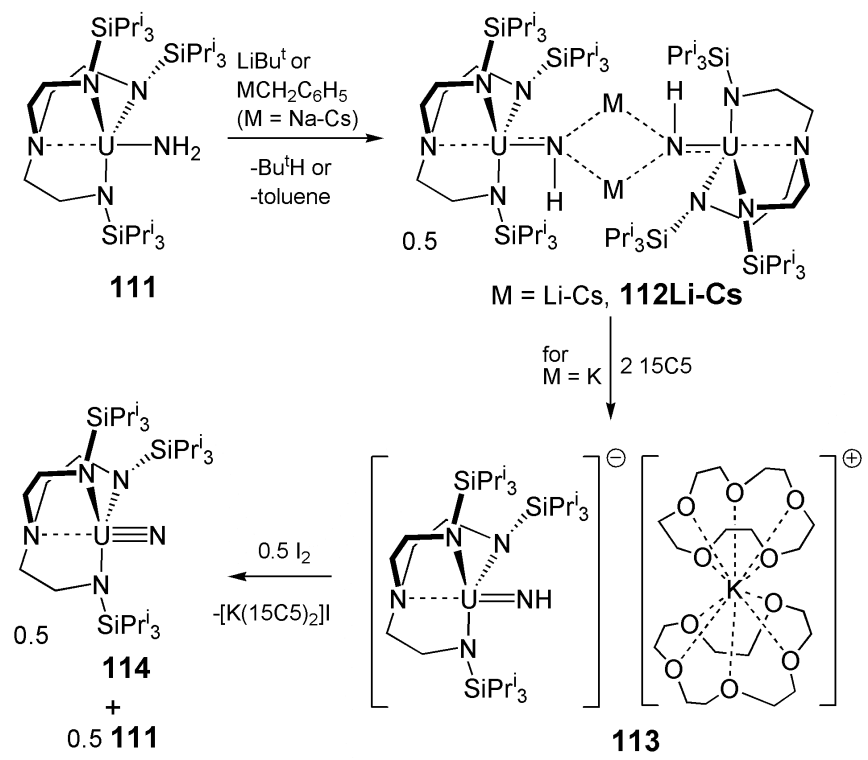

Scheme 23. Synthesis of bridging and terminal parent uranium(IV) imido complexes $112 \mathrm{Li} / \mathbf{N a} / \mathbf{K} / \mathbf{R b} / \mathbf{C s}$ and 113 .

A notable feature of most metal-imido complexes is the presence of a bulky $N$-R group which stabilizes the $U=N$ linkage. The stabilization of a $U=N-R$ linkage with a small $R$ group, especially $R$ $=\mathrm{H}$, would be expected to be challenging because of the large size of uranium. However, in 2014 the synthesis of the parent $\mathrm{U}=\mathrm{NH}$ linkage was reported, ${ }^{[149]}$ Scheme 23. Deprotonation of $\left[\mathrm{U}\left(\operatorname{Tren}^{\mathrm{TIPS}}\right) \mathrm{NH}_{2}\right]$ (111, Tren $\left.^{\text {TIPS }}=\mathrm{N}\left(\mathrm{CH}_{2} \mathrm{CH}_{2} \mathrm{NSiPr}_{3}{ }_{3}\right)_{3}\right]$ with alkali metal bases produces $\left[\left\{\mathrm{U}\left(\operatorname{Tren}^{\mathrm{TIPS}}\right)(\mathrm{NHM})\right\}_{2}\right](\mathrm{M}=\mathrm{Li}-\mathrm{Cs}, \mathbf{1 1 2} \mathbf{L i} / \mathbf{N a} / \mathbf{K} / \mathbf{R b} / \mathbf{C s})$, and for $\mathrm{M}=\mathrm{K}$ abstraction with two equivalents of $15 \mathrm{C} 5$ afforded $\left[\mathrm{U}\left(\operatorname{Tren}^{\mathrm{TIPS}}\right) \mathrm{NH}\right]\left[\mathrm{K}(15 \mathrm{C} 5)_{2}\right](\mathbf{1 1 3})$. The bulky Tren $^{\text {TIPS }}$ and anionic charge on the uranium component seem to stabilize the $U=\mathrm{NH}$ linkage; attempts to oxidize 113 resulted in disproportionation to give 111 and $\left[\mathrm{U}\left(\operatorname{Tren}^{\mathrm{TIPS}}\right) \mathrm{N}\right](\mathbf{1 1 4}),{ }^{[50 \mathrm{~b}]}$ which most likely occurs via dimerization of the putative neutral "[U(Tren $\left.\left.{ }^{\mathrm{TIPS}}\right) \mathrm{NH}\right]$ ”. 


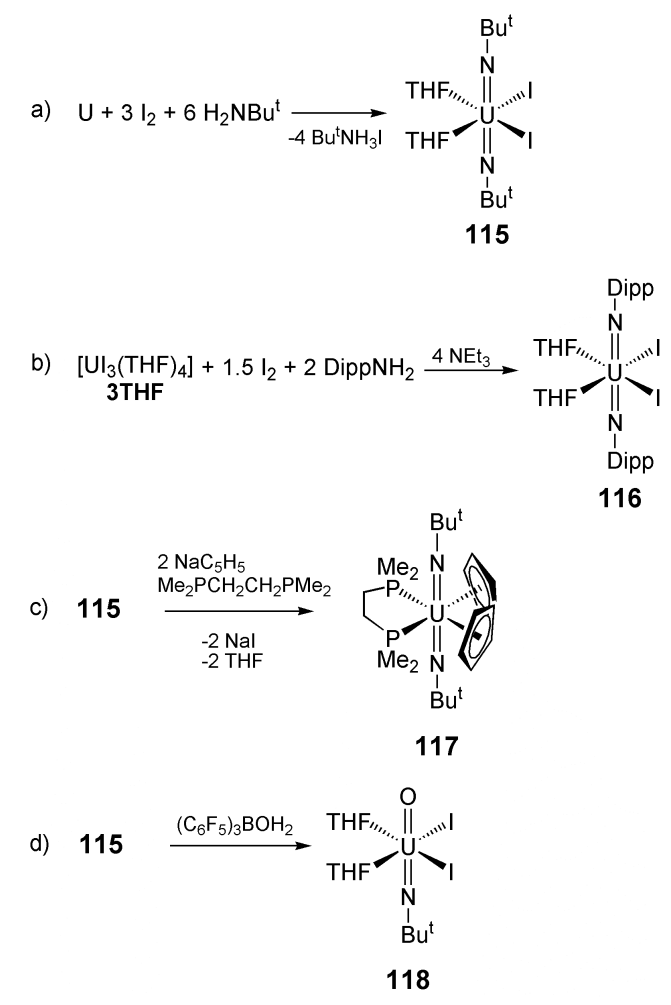

Scheme 24. a) - d): preparation and reactivity of uranium(VI) bis(imido) complexes 115-118.

Returning to bis(imido) uranium chemistry, for 13 years 99 represented the only example of a bis(imido) uranium complex, but a general synthesis of bis(imido) uranyl analogues was reported in 2005. Treatment of uranium metal with iodine and tert-butyl amine produced $\left[\mathrm{UI}_{2}\left(\mathrm{NBu}^{t}\right)_{2}(\mathrm{THF})_{2}\right.$ ] (115) in good yield. ${ }^{[150]}$ This chemistry could be extended to aryl-imidos by reacting 3THF with iodine, an aryl-amine, and the auxiliary-base triethylamine to form, for example, $\left[\mathrm{UI}_{2}(\mathrm{NDipp})_{2}(\mathrm{THF})_{3}\right](\mathbf{1 1 6})$. The $[\mathrm{RN}=\mathrm{U}=\mathrm{NR}]^{2+}$ unit is isoelectronic to uranyl and like uranyl adopts a linear trans arrangement. This method has wide utility and a large range of bis(imido) complexes have now been prepared. Theoretical studies of these bis(imido) complexes reveal a frontier orbital manifold with similarities to uranyl, but the bonding appears to be more covalent for the bis(imidos). Perhaps an indication of this is the fact that with suitable co-ligands $\left[\mathrm{U}\left(\eta^{5}\right.\right.$ $\left.\mathrm{C}_{5} \mathrm{H}_{5}\right)_{2}\left(\mathrm{NBu}^{\mathrm{t}}\right)_{2}\left(\mathrm{Me}_{2} \mathrm{PCH}_{2} \mathrm{CH}_{2} \mathrm{PMe}_{2}\right)$ ] (117) could be prepared by salt elimination whereas such reactions with uranyl would lead to reduction (recall the necessity to prepare $\mathbf{5 2}$ by oxidation of a linear metallocene). ${ }^{[151]}$ Complexes such as $\mathbf{1 1 5}$ were also shown to undergo oxo for imido group metathesis by hydrolysis to give a rare example of a OUNR linkage in $\left[\mathrm{UI}_{2}\left(\mathrm{NBu}^{\mathrm{t}}\right)(\mathrm{O})(\mathrm{THF})_{2}\right](\mathbf{1 1 8})$ that was shown computationally to maintain many of the bonding characteristics of uranyl. ${ }^{[152]}$ 

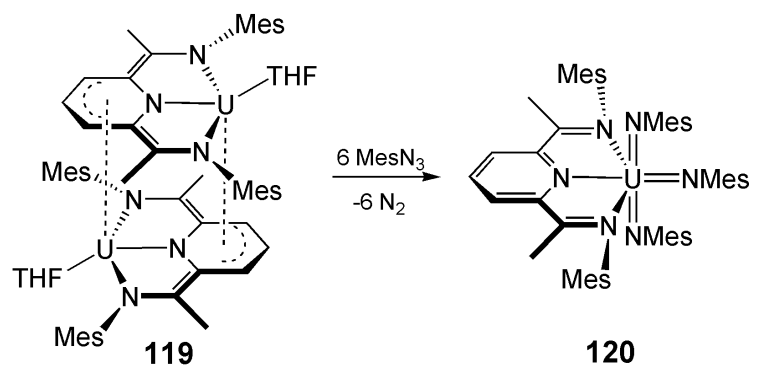

120

Scheme 25. Multi-electron reduction chemistry of 119 to afford the tris(imido) uranium(VI) complex 120.

Having established that the bis(imido) uranium motif is generally available, this raised the question as to whether a tris(imido) complex of uranium could be prepared since this would be isoelectronic to $\mathrm{UO}_{3}$. In 2014, the reducing power of uranium coupled with ligand non-innocence was combined to prepare a uranium tris(imido) complex, Scheme 25. ${ }^{[153]}$ Treatment of $\left[\mathrm{U}\left\{\mathrm{C}_{5} \mathrm{H}_{3} \mathrm{~N}-2,6\right.\right.$ $\left.\left.(\mathrm{CMeNMes})_{2}\right\}(\mathrm{THF})\right]_{2}$ (119), which can be viewed either as a uranium(III)-ligand trianion or a uranium(IV)-ligand tetraanion combination, with six equivalents of $\mathrm{MesN}_{3}$ afforded $\left[\mathrm{U}\left\{\mathrm{C}_{5} \mathrm{H}_{3} \mathrm{~N}-2,6-\right.\right.$ $\left.\left.(\mathrm{CMeNMes})_{2}\right\}(\mathrm{NMes})_{3}\right](\mathbf{1 2 0})$ which features a T-shaped [U(NMes) $\left.)_{3}\right]$ unit. A perhaps surprising conclusion from a theoretical assessment of $\mathbf{1 2 0}$ is that the [U(NMes) $)_{3}$ ] unit exhibits less covalency in the U-N bonds than the U-O bonds in the hypothetical model where the [U(NMes) $)_{3}$ unit is replaced by $\left[\mathrm{UO}_{3}\right]$.

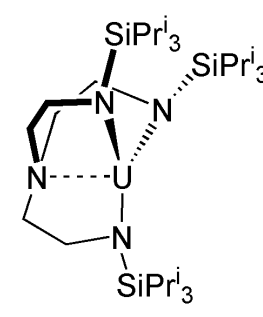

121

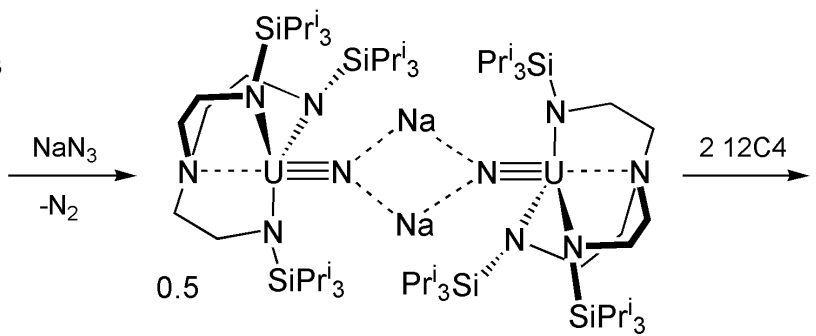

122

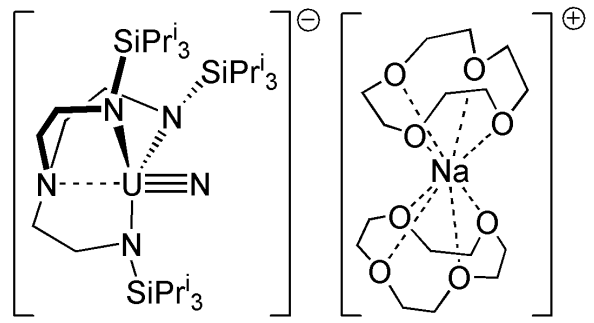

123

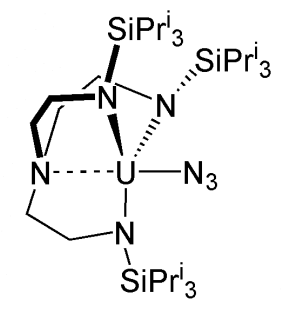

125

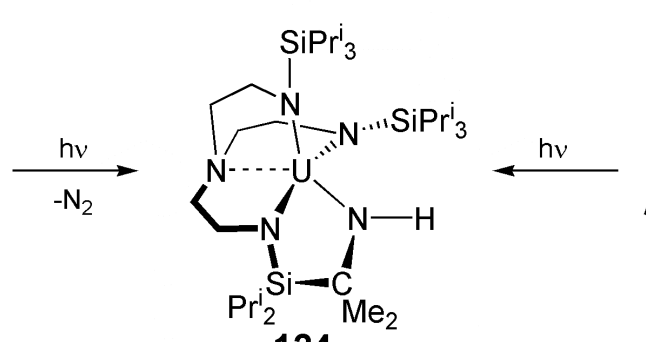

124
$0.5 \mathrm{I}_{2} \downarrow-\left[\mathrm{Na}(12 \mathrm{C} 4)_{2}\right] \mathrm{I}$

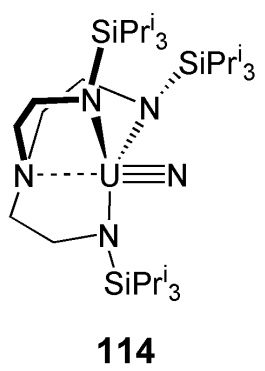

Scheme 26. Synthesis and reactivity of the terminal uranium nitrides $\mathbf{1 2 3}$ and $\mathbf{1 1 4}$.

With the concept that uranium can support multiple bonding to nitrogen well-established, and single (amide) and double (imido, in a formal sense, in reality a triple-bonding interaction is often 
manifested) uranium-nitrogen bonds characterized, the search was on for a terminal uranium-nitride with a covalent triple bond. The synthetic actinide community was given additional impetus to secure this target because molecules such as $\left[\mathrm{F}_{3} \mathrm{U} \equiv \mathrm{N}\right],[\mathrm{U} \equiv \mathrm{N}]$, and $[\mathrm{N} \equiv \mathrm{U} \equiv \mathrm{N}]$ dating back to the 1970 s had been prepared and characterized in argon matrices at ca. $10 \mathrm{~K}^{[154]}$ but the terminal uranium-nitride would remain elusive on a bulk preparative scale for four decades; many elegant attempts resulted in nitrides: i) bridging multiple metal centers; ii) being protected by a covalently bonded borane capping group that is impervious to removal; or iii) being generated photolytically but activating ligand C-H bonds. ${ }^{[155]}$ Finally, in 2012 the synthesis and characterization of a terminal uranium-nitride was achieved on a bulk scale under ambient conditions, Scheme 26. Reaction of $\mathrm{NaN}_{3}$ with trivalent $\left[\mathrm{U}\left(\operatorname{Tren}^{\text {TIPS }}\right)\right]$ (121) afforded the uranium(V)-nitride $\left[\left\{\mathrm{U}\left(\operatorname{Tren}^{\mathrm{TIPS}}\right)(\mathrm{NNa})\right\}_{2}\right](\mathbf{1 2 2}),{ }^{[44 a]}$ which in the solid state exhibits a $\mathrm{U} \equiv \mathrm{N}$ bond length of 1.883(4) $\AA$. The observed ${ }^{14} \mathrm{~N} /{ }^{15} \mathrm{~N}$ isotopomer shift for the $\mathrm{U} \equiv \mathrm{N}$ IR band from 955 to $930 \mathrm{~cm}^{-1}$ (calculated shift $925 \mathrm{~cm}^{-1}$ ), supports the nitride formulation. Abstraction of the sodium cations by $12 \mathrm{C} 4$ from 122 yielded the terminal uranium(V) nitride complex $\left[\mathrm{U}\left(\operatorname{Tren}^{\mathrm{TIPS}}\right)(\mathrm{N})\right]\left[\mathrm{Na}(12 \mathrm{C} 4)_{2}\right](\mathbf{1 2 3}) .{ }^{[44 \mathrm{a}]} \mathrm{An} \mathrm{X}$-ray diffraction study revealed a $\mathrm{U} \equiv \mathrm{N}$ bond length of $1.825(15) \AA$, which is $\sim 0.06 \AA$ shorter than in the bridging species. IR isotopic labelling studies $\left(\mathrm{UN}=936 \mathrm{~cm}^{-1}, \mathrm{U}^{15} \mathrm{~N}=900 \mathrm{~cm}^{-1}\right)$ and other characterization data support the formulation. Theoretical calculations reveal one $\sigma$ - and two $\pi$ components in the $\mathrm{U} \equiv \mathrm{N}$ triple bond and a calculated Mayer bond order of 2.91. Interestingly, the $\sigma$ bond is higher in energy than the two quasi-degenerate $\pi$-bonds as is the case in uranyl. This is ascribed to an antibonding interaction between the nitride $\sigma$-bonding p-orbital and the toroidal lobes of uranium $\mathrm{f}$ - and/or d-orbitals that results from the short $\mathrm{U} \equiv \mathrm{N}$ bond distance.

Although oxidation of 122 results in loss of the nitride linkage, it was reported in 2013 that oxidation of 123 affords the neutral uranium(VI)-nitride [U(Tren $\left.\left.{ }^{T I P S}\right)(N)\right](114)$ with a $U \equiv N$ bond length of $1.799(7) \AA{ }^{[50 b]}$ Scheme 26. The $U-N_{\text {amine }}$ distance is very short at 2.465(5) $\AA$, which suggests the presence of an ITI effect since uranium-amine distances in Tren complexes tend to be $\sim 2.6 \AA$ irrespective of the oxidation state of uranium. Complex 114 is found to be photolytically unstable and decomposes to $\left[\mathrm{U}\left\{\mathrm{N}\left(\mathrm{CH}_{2} \mathrm{CH}_{2} \mathrm{NSiPr}_{3}\right)_{2}\left(\mathrm{CH}_{2} \mathrm{CH}_{2} \mathrm{NSiPr}_{2}^{\mathrm{i}} \mathrm{CMe}_{2} \mathrm{NH}\right\}\right]\right.$ (124), which is the same product obtained from the photolysis of $\left[\mathrm{U}\left(\operatorname{Tren}^{\mathrm{TIPS}}\right)\left(\mathrm{N}_{3}\right)\right](\mathbf{1 2 5})$; this suggests that photolysis of this azide proceeds via a nitride as proposed by uranium-metallocene-azide photolysis chemistry. ${ }^{[155 \mathrm{~h}]}$ A theoretical study of nitrides 123 and 114 suggested that there is appreciable covalency in the $\mathrm{U} \equiv \mathrm{N}$ bond, and surprisingly for uranium(VI) at least as much covalency as in analogous group 6 terminal nitrides. Interesting reactivity of the $\mathrm{U} \equiv \mathrm{N}$ bond is beginning to emerge including reductive homologation by $\mathrm{CO}$ to produce cyanate, which provides a $\mathrm{N}_{3}^{-}$to $\mathrm{N}^{3-}$ to $\mathrm{OCN}^{-}$ synthetic cycle and a rare example of complete nitride $\mathrm{N}$-atom transfer to a substrate. ${ }^{[156]}$ 


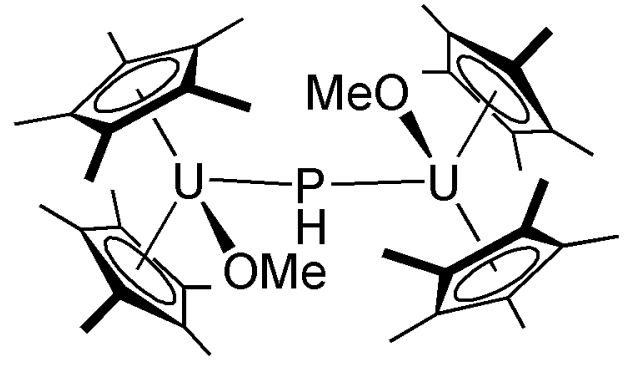

126

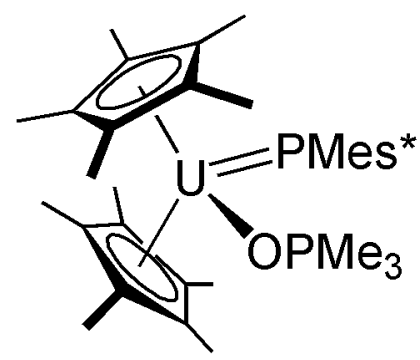

127

Figure 22. Uranium phosphinidiide and phosphinidene complexes 126 and 127.

The majority of reported uranium-pnictide chemistry involves nitrogen derivatives, and there are considerably fewer heavier pnictide complexes reported in terms of covalent U-P bonds. A small number of phospholide complexes are known, ${ }^{[157]}$ and only two phosphide complexes are reported, namely $\left[\mathrm{U}\left(\eta^{5}-\mathrm{C}_{5} \mathrm{Me}_{5}\right)_{2}(\mathrm{Cl})\left\{\mathrm{P}\left(\mathrm{SiMe}_{3}\right)_{2}\right\}\right]$ and $\left[\mathrm{U}\left(\eta^{5}-\mathrm{C}_{5} \mathrm{Me}_{5}\right)_{2}\left(\mathrm{CH}_{2} \mathrm{SiMe}_{2} \mathrm{PSiMe}_{3}\right)\right] .{ }^{[158]}$ Only two terminal phosphinidenes and two bridging phosphinidiides are known. The first bridging phosphinidiide was reported in 1984, where reaction of trimethylphosphite with [U( $\eta^{5}$ $\left.\left.\mathrm{C}_{5} \mathrm{Me}_{5}\right)_{2}(\mathrm{H})_{2}\right]$ induces dealkoxylation to form $\left[\left\{\mathrm{U}\left(\eta^{5}-\mathrm{C}_{5} \mathrm{Me}_{5}\right)_{2}(\mathrm{OMe})\right\}_{2}(\mu-\mathrm{PH})\right](\mathbf{1 2 6}),{ }^{[159]}$ Figure 22, with $\left[\mathrm{U}\left(\eta^{5}-\mathrm{C}_{5} \mathrm{Me}_{5}\right)_{2}(\mathrm{OMe})_{2}\right]$ concomitantly formed as a by-product. In 1996 the first terminal uranium-phosphinidene was reported from the reaction of $\left[\mathrm{U}\left(\eta^{5}-\mathrm{C}_{5} \mathrm{Me}_{5}\right)_{2}(\mathrm{Me})(\mathrm{Cl})\right]$ with $\mathrm{KP}(\mathrm{H}) \mathrm{Mes}^{*}$; in the presence of trimethylphosphine oxide, methane and $\mathrm{KCl}$ are eliminated to produce the uranium(IV) complex $\left[\mathrm{U}\left(\eta^{5}-\mathrm{C}_{5} \mathrm{Me}_{5}\right)_{2}\left(\mathrm{PMes}^{*}\right)\left(\mathrm{OPMe}_{3}\right)\right](\mathbf{1 2 7}),{ }^{[160]}$ Figure 22. The U=P distance was found by X-ray crystallography to be $2.562(3) \AA$ and the U-P-C $C_{i p s o}$ angle of $143.7(3)^{\circ}$ is as expected for the combination of metal and phosphinidene triplet fragments.

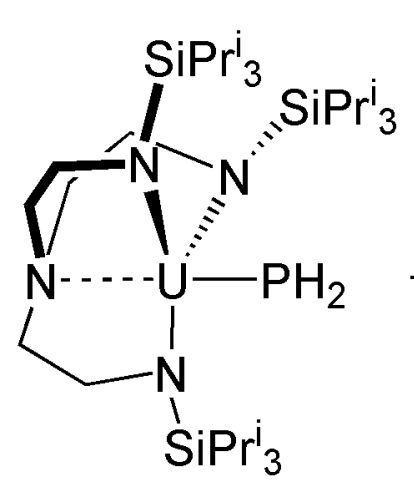

128

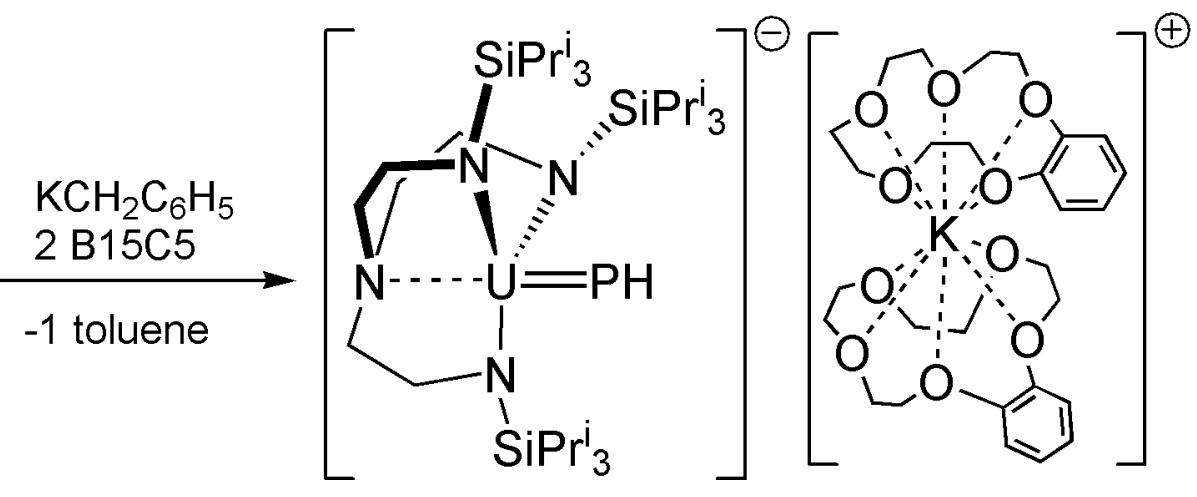

129

Scheme 27. Synthesis of the terminal parent uranium phosphinidene complex 129 from 128. 
Simultaneously to the report of the parent terminal imido complex $\mathbf{1 1 3},{ }^{[149]}$ the preparation of a parent terminal phosphinidene complex of uranium was also reported in 2014, Scheme 27. Analogously to the preparation of 113, treatment of [U(Tren $\left.\left.{ }^{\mathrm{TIS}}\right)\left(\mathrm{PH}_{2}\right)\right](\mathbf{1 2 8})$ with benzyl potassium and two equivalents of B15C5 afforded $\left[\mathrm{U}\left(\operatorname{Tren}^{\mathrm{TIPS}}\right)(\mathrm{PH})\right]\left[\mathrm{K}(\mathrm{B} 15 \mathrm{C} 5)_{2}\right](\mathbf{1 2 9}) .{ }^{[161]}$ The $\mathrm{U}=\mathrm{P}$ distance in 129 was determined to be 2.613(2) $\AA$ by X-ray crystallography and, unlike the U=N-H linkage in 113 which is essentially linear, the $\mathrm{U}=\mathrm{P}-\mathrm{H}$ linkage is bent with an angle of $118.8(9)^{\circ}$, as expected. The report of $\mathbf{1 2 9}$ demonstrates the ability of uranium to stabilize highly reactive parent main group fragments, and, like 113, that bulky stabilizing E-R $(E=N, P)$ groups are not always required.

\subsection{Chalcogenide Donor Atom Ligands}

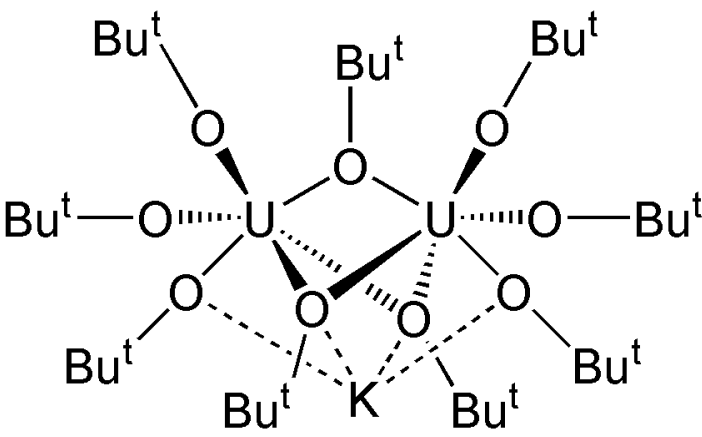

130

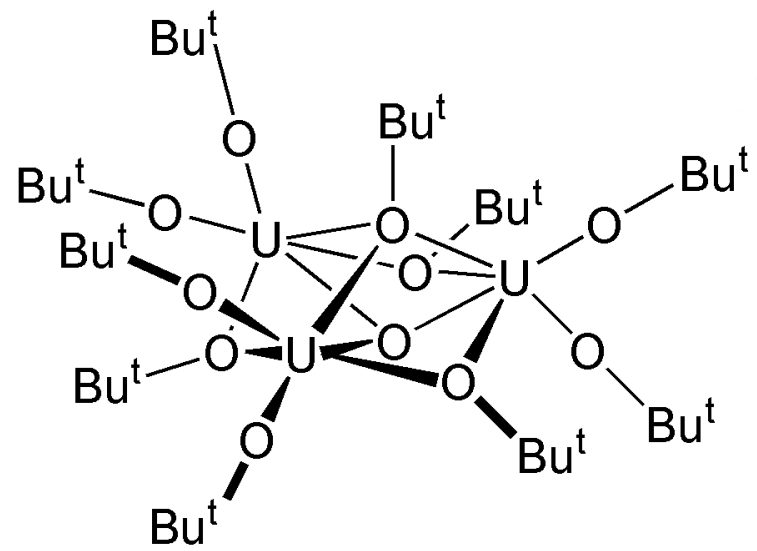

132

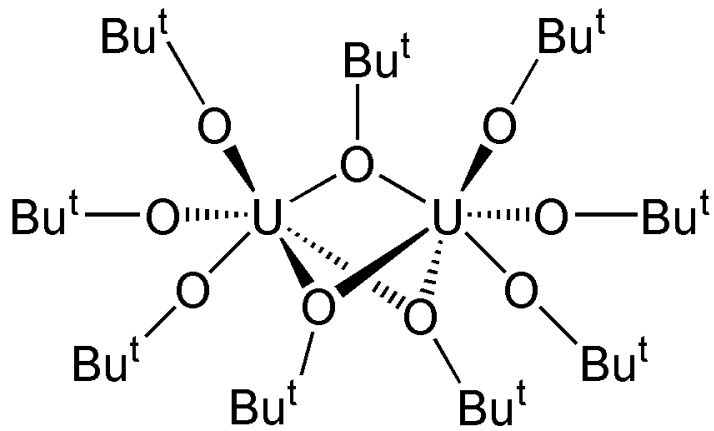

131

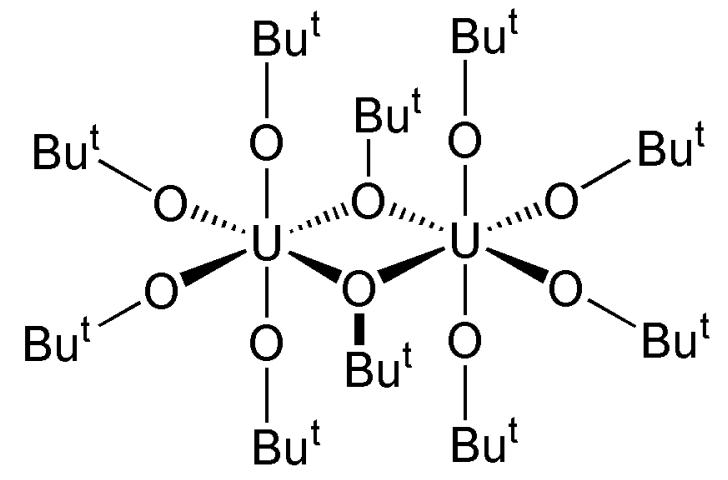

133

Figure 23. Uranium tert-butoxide complexes 130-133.

A significant amount of effort was expended on investigations of uranium alkoxides due to their possible applications in uranium isotope enrichment. This was because of their potential volatility and the fact that alkoxides are, in addition to oxos, imidos, and halides, one of the few ligand sets that can stabilize the hexavalent state of uranium. However, although extensive investigations of homolpetic $\left[\mathrm{U}(\mathrm{OR})_{6}\right]$ complexes $\left(\mathrm{R}=\mathrm{Me}, \mathrm{Et}, \mathrm{Pr}^{\mathrm{i}}, \mathrm{Bu}^{\mathrm{t}}\right)$ were carried out in the 1950s and 1960s, they were only partially characterized by modern-day standards. ${ }^{[162]}$ 


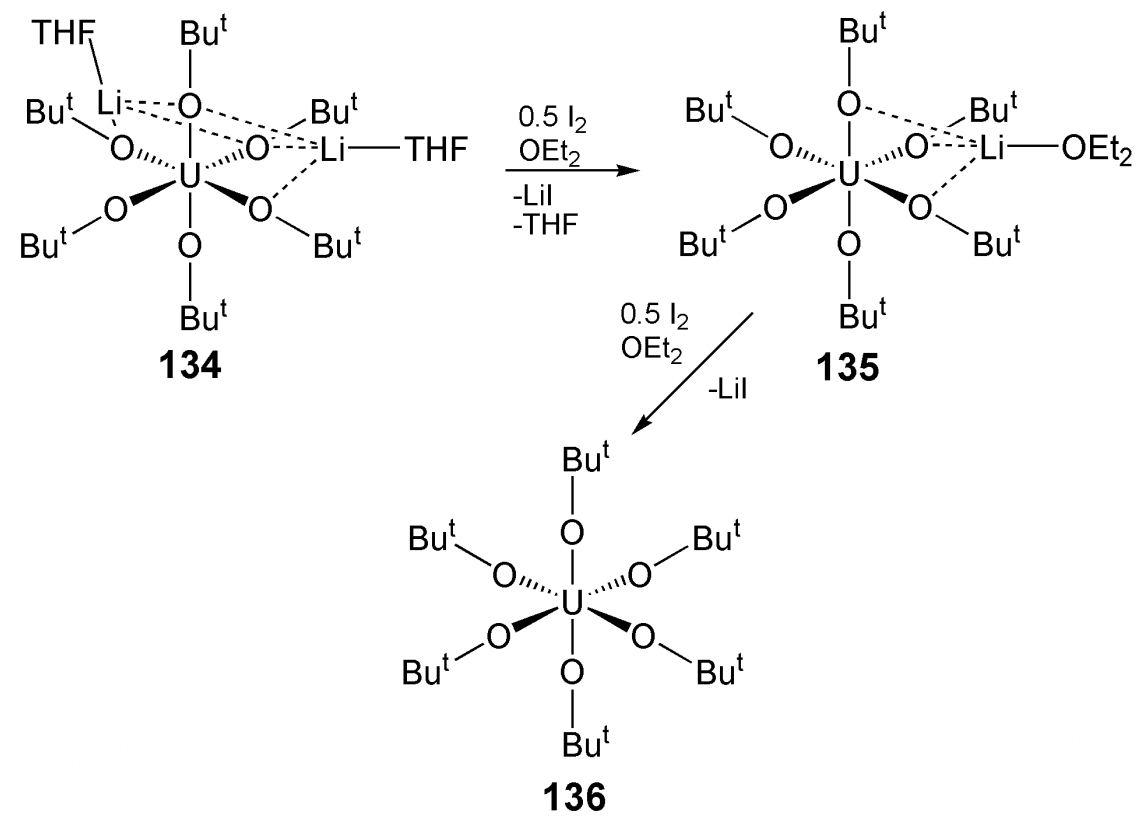

Scheme 28. Synthesis of the homoleptic uranium tert-butoxide 136 from 134 then $\mathbf{1 3 5}$.

A common feature of electropositive metal alkoxide chemistry is that it is frequently more complicated than might be anticipated. For example, studies reported in the 1980s showed that attempts to prepare $\left[\mathrm{U}\left(\mathrm{OBu}^{t}\right)_{4}\right]$ probably resulted in the formation of $\left[\mathrm{U}_{2}\left(\mathrm{OBu}^{\mathrm{t}}\right)_{9} \mathrm{~K}\right](\mathbf{1 3 0})$ and it has been shown that $\mathbf{1 3 0}$ can convert to the mixed-valence complex $\left[\mathrm{U}_{2}\left(\mathrm{OBu}^{\mathrm{t}}\right)_{9}\right](\mathbf{1 3 1})$ or an oxo-capped trinuclear structure $\left[\mathrm{U}_{3}(\mathrm{O})\left(\mathrm{OBu}^{t}\right)_{10}\right](\mathbf{1 3 2})$ depending on reaction conditions, Figure 23. ${ }^{[163]}$ Pentavalent alkoxides are also known, but again often adopt dimeric structures such as $\left[\mathrm{U}_{2}\left(\mathrm{OBu}^{\mathrm{t}}\right)_{10}\right]$ (133), ${ }^{[164]}$ Figure 23. Some of this chemistry was revisited in $2008,{ }^{[165]}$ Scheme 28; treatment of $\mathrm{UCl}_{4}$ with six equivalents of $\mathrm{LiOBu}^{\mathrm{t}}$ results in formation of $\left[\mathrm{U}\left(\mathrm{OBu}^{\mathrm{t}}\right)_{6} \mathrm{Li}_{2}(\mathrm{THF})_{2}\right](\mathbf{1 3 4})$, and this complex can be oxidized with a half or one equivalent (overall) of iodine to produce $\left[\mathrm{U}\left(\mathrm{OBu}^{\mathrm{t}}\right)_{6} \mathrm{Li}\left(\mathrm{OEt}_{2}\right)\right](\mathbf{1 3 5})$ or $\left[\mathrm{U}\left(\mathrm{OBu}^{\mathrm{t}}\right)_{6}\right](\mathbf{1 3 6})$, respectively. Notably, the U(VI/V) redox potential of $-1.12 \mathrm{~V}$ for $136\left(\mathrm{vs} \mathrm{Fc} / \mathrm{Fc}^{+}\right)$contrasts to that of $\mathrm{UF}_{6}\left(2.31 \mathrm{~V} \mathrm{vs} \mathrm{Ag} / \mathrm{Ag}^{+}\right)$; the latter is known to be a strong oxidizing agent, and these observations probably reflect the stronger $\pi$-donating capacity of alkoxides vs halides, which is an effect that has also been observed in group 6 chemistry. 


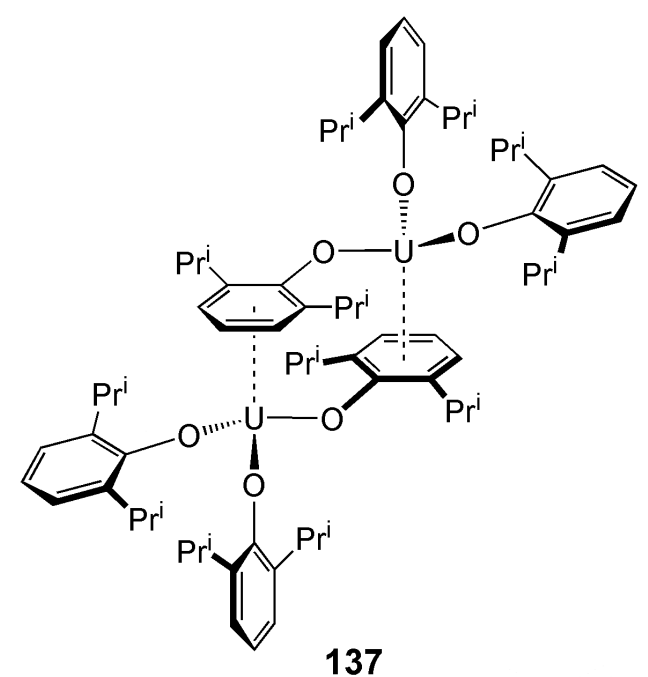

Figure 24. The homoleptic uranium(III) aryloxide complex 137.

Like alkoxides, aryloxides have also found utility in uranium chemistry. The majority of examples include heteroleptic systems where the aryloxide fragment is either one of several co-ligands or is part of a more complicated ligand, e.g. tacn-tris(aryloxides). Where homoleptic variants are concerned there are fewer examples. The first homoleptic uranium(III)-aryloxide was reported in 1988 and utilized a bulky ODipp group. Treatment of $\mathbf{7 5}$ with three equivalents of DippOH afforded $\left[\left\{\mathrm{U}(\mathrm{ODipp})_{3}\right\}_{2}\right](\mathbf{1 3 7})$ as a dimer in the solid state that is held together by $U \cdot \cdots \eta^{6}$-arene interactions, Figure 24. ${ }^{[166]}$ The related complex $\left[\mathrm{U}(\mathrm{ODitb})_{3}\right](\mathbf{1 9}$, see Scheme 6) was reported at the same time, and although a solid state structure was not known then, analysis of the IR spectra suggested it to be monomeric, which was confirmed by a solid state structural determination in 2011. ${ }^{[115]}$ Complex 19 is clearly not totally sterically saturated because the tetravalent analogue $\left[\mathrm{U}(\mathrm{ODitb})_{4}\right]\left(\mathbf{6 3}\right.$, see Scheme 13) can be prepared and is also monomeric. ${ }^{[167]}$

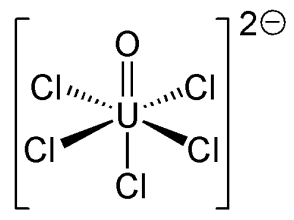

138

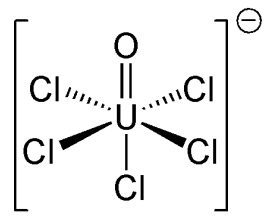

139

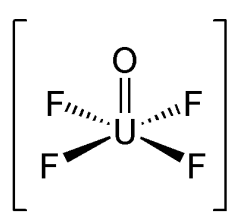

140

Figure 25. Structures of the uranium mono-oxo complexes 138-140.

In recent years there has been a focus on multiply bonded uranium-chalcogen bonds. The field of uranyl coordination chemistry is huge and constitutes nearly half of all structurally characterized uranium complexes in the Cambridge Structural Database. Uranyl chemistry has been extensively reviewed in recent years, both in terms of uranyl(VI) and uranyl(V) chemistry, the latter of which includes clusters that exhibit U-U magnetic coupling, ${ }^{[168]}$ and creative routes to activate and silylate 
the $y l$ oxo $^{[32 \mathrm{e}]}$ and in some cases even functionalization and cleavage of the oxo ligand. ${ }^{[169]}$ An extended discussion of uranyl chemistry is beyond the scope of this article ${ }^{[26 \mathrm{~g}, 27 \mathrm{c}]}$ and therefore, this section focuses principally on complexes with only one chalcogen donor atom.

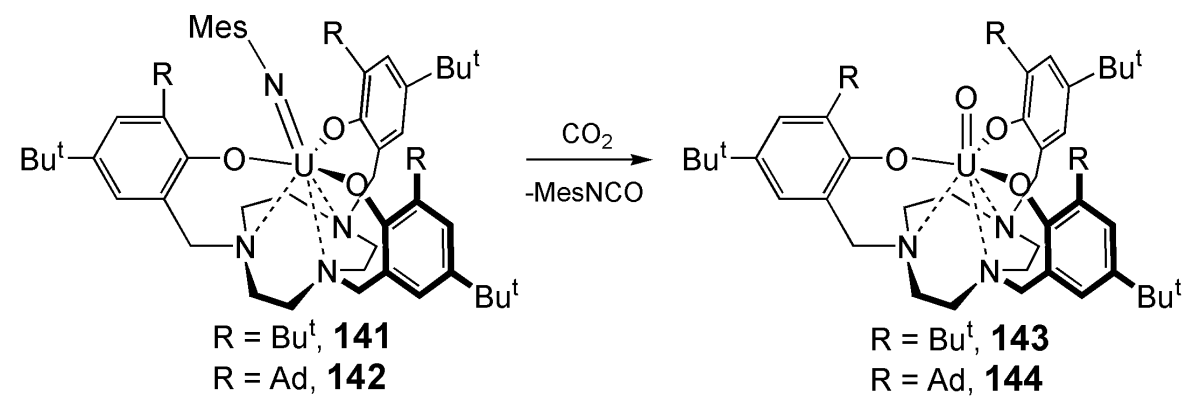

Scheme 29. Bond metathesis of uranium(V) imido complexes to give the terminal uranium(V) mono-oxo complexes 143 and 144.

In addition to the uranium mono-oxo complexes 48, 53, 102, and 105 described in Figure 14 and Schemes 11 and 20, the synthesis of uranium mono-oxos such as $\left[\mathrm{OUCl}_{5}\right]^{2-}(\mathbf{1 3 8}),\left[\mathrm{OUCl}_{5}\right]^{-}(\mathbf{1 3 9})$ and $\left[\mathrm{OUF}_{4}\right](\mathbf{1 4 0})$ can be traced back to the 1970s, Figure 25. ${ }^{[170]}$ More recently, in 2003, it was shown that bond metathesis of imido complexes $\left[\mathrm{U}\left(\operatorname{tacn}\left[\mathrm{CH}_{2} \mathrm{C}_{6} \mathrm{H}_{2}-2-\mathrm{O}-3-\mathrm{R}-5-\mathrm{Bu}^{\mathrm{t}}\right]_{3}(\mathrm{NMes})\right](\mathrm{R}=\right.$ $\mathrm{Bu}^{\mathrm{t}}, 141 ; \mathrm{R}=\mathrm{Ad}, 142$ ) with carbon dioxide produced the terminal mono-oxo uranium complexes $\left[\mathrm{U}\left(\operatorname{tacn}\left[\mathrm{CH}_{2} \mathrm{C}_{6} \mathrm{H}_{2}-2-\mathrm{O}-3-\mathrm{R}-5-\mathrm{Bu}^{\mathrm{t}}\right]_{3}(\mathrm{O})\right]\left(\mathrm{R}=\mathrm{Bu}^{\mathrm{t}}, 1 \mathrm{143} ; \mathrm{R}=\mathrm{Ad}, 144\right)\right.$ with elimination of MesNCO isocyanate as the by-product, Scheme $29 .{ }^{[171]}$

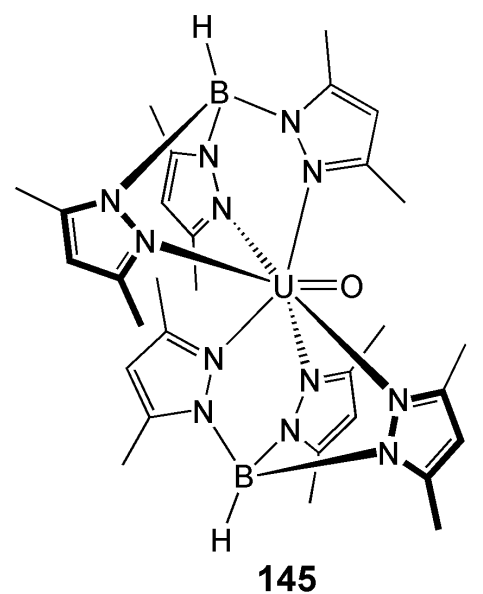

Figure 26. The uranium(IV) terminal mono-oxo complex 145.

Most mono-oxo complexes of uranium involve uranium(V) or (VI). A notable exception is the basefree uranium(IV) terminal oxo species $\left[\mathrm{U}\left\{\mathrm{HB}\left(\mathrm{N}_{2} \mathrm{C}_{3} \mathrm{H}-3,5-\mathrm{Me}_{2}\right\}_{2}(\mathrm{O})\right](\mathbf{1 4 5})\right.$ reported in 2010, Figure 26. ${ }^{[172]}$ Complex 145 was prepared by oxidation of the bipyridine complex $\left[\mathrm{U}\left\{\mathrm{HB}\left(\mathrm{N}_{2} \mathrm{C}_{3} \mathrm{H}-3,5\right.\right.\right.$ $\left.\mathrm{Me}_{2}\right\}_{2}$ (Bipy)] with pyridine- $N$-oxide. Theoretical studies revealed a $\sigma^{2} \pi^{4}$ triple bonding interaction 
between uranium and oxygen and a $\mathrm{U}=\mathrm{O}$ distance of 1.863(4) $\AA$ (ca. $0.1 \AA$ longer than in uranyl derivatives).

a)<smiles>CN(C)[Al](C=P(c1ccccc1)(c1ccccc1)c1ccccc1)(N(C)C)N(C)C</smiles>

$54 \mathrm{H}$

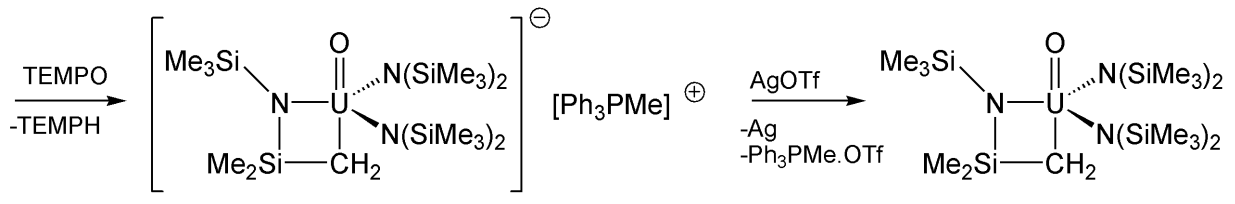

146

147

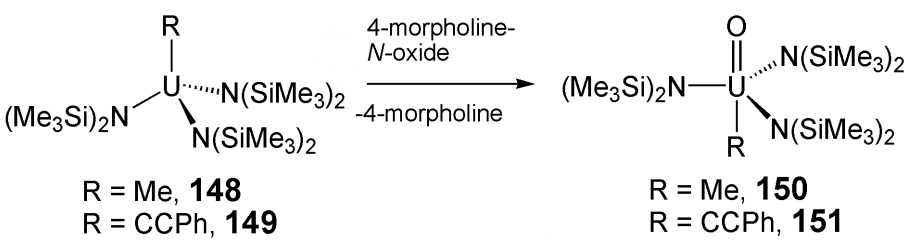

Scheme 30. A) - b): Synthesis of the mono-oxo uranium alkyls 146, 147, 150, and 151.

In 2011 it was shown that oxidation of the trivalent ylide complex $\mathbf{5 4 H}$ with TEMPO affords the uranium(V)-mono-oxo-alkyl complex $\left[\mathrm{U}\left\{\mathrm{N}\left(\mathrm{SiMe}_{3}\right)_{2}\right\}_{2}\left(\mathrm{CH}_{2} \mathrm{SiMe}_{2} \mathrm{NSiMe}_{3}\right)(\mathrm{O})\right]\left[\mathrm{Ph}_{3} \mathrm{PMe}\right](\mathbf{1 4 6}),{ }^{[173]}$ Scheme 30. Complex 146 can be further oxidized with AgOTF to afford $\left[\mathrm{U}\left\{\mathrm{N}\left(\mathrm{SiMe}_{3}\right)_{2}\right\}_{2}\left(\mathrm{CH}_{2} \mathrm{SiMe}_{2} \mathrm{NSiMe} 3\right)(\mathrm{O})\right](\mathbf{1 4 7}) .{ }^{[173]}$ Both complexes represent rare examples of high valent uranium-alkyls. Following a similar strategy, in 2013 it was shown that tetravalent $\left[\mathrm{U}\left\{\mathrm{N}\left(\mathrm{SiMe}_{3}\right)_{2}\right\}_{3}(\mathrm{R})\right](\mathrm{R}=\mathrm{Me}, 148 ; \mathrm{R}=\mathrm{CCPh}, 149)$ could be oxidized by 4-morpholine- $N$-oxide to afford $\left[\mathrm{U}\left\{\mathrm{N}\left(\mathrm{SiMe}_{3}\right)_{2}\right\}_{3}(\mathrm{R})(\mathrm{O})\right](\mathrm{R}=\mathrm{Me}, 150 ; \mathrm{CCPh}, 151)$ which are unusually stable for uranium(VI)-alkyls, ${ }^{[174]}$ Scheme 30 . Theoretical analyses revealed an ITI effect was operating, and together with a range of derivatives where the alkyl was replaced with halides, and theoretically with other co-ligands, it was possible to construct a ligand stability series where it is found that $\sigma$ effects dominate: $\mathrm{CN}^{-}<\mathrm{I}^{-} \sim \mathrm{Br}^{-}<\mathrm{Cl}^{-} \sim \mathrm{SPh}^{-}<\mathrm{PhCC}^{-} \sim \mathrm{F}^{-}<\mathrm{MeO}^{-}<\mathrm{Me}_{2} \mathrm{~N}^{-}<\mathrm{Me}^{-}<\mathrm{H}^{-}$. 


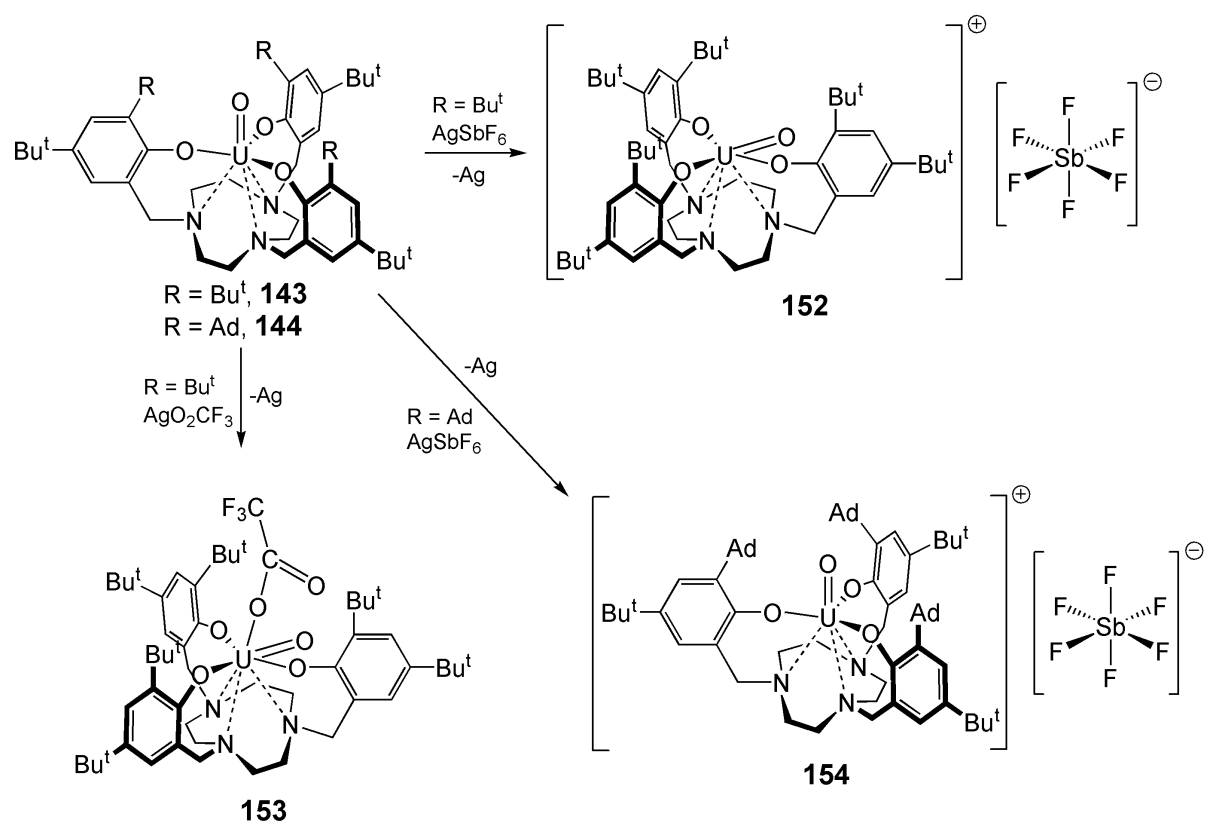

Scheme 31. Synthesis of uranium(VI) mono-oxo complexes 152-154.

Some unusual uranium(VI) mono-oxo complexes that exhibit molecular structure driven by the ITI effect were reported in $2012,{ }^{[175]}$ Scheme 31 . When the uranium(V) complex [U $\left\{\operatorname{tacn}\left(\mathrm{CH}_{2} \mathrm{C}_{6} \mathrm{H}_{2}-2\right.\right.$ $\left.\left.\left.\mathrm{O}-3,5-\mathrm{Bu}_{2}^{\mathrm{t}}\right)_{3}\right\}(\mathrm{O})\right](\mathbf{1 4 3})$ is oxidized by $\mathrm{AgSbF}_{6}$ or $\mathrm{AgO}_{2} \mathrm{CCF}_{3}$ the uranium(VI) complexes $\left[\mathrm{U}\left\{\operatorname{tacn}\left(\mathrm{CH}_{2} \mathrm{C}_{6} \mathrm{H}_{2}-2-\mathrm{O}-3,5-\mathrm{Bu}_{2}^{\mathrm{t}}\right)_{3}\right\}(\mathrm{O})\right]\left[\mathrm{SbF}_{6}\right] \quad(\mathbf{1 5 2}) \quad$ and $\quad\left[\mathrm{U}\left\{\operatorname{tacn}\left(\mathrm{CH}_{2} \mathrm{C}_{6} \mathrm{H}_{2}-2-\mathrm{O}-3,5-\right.\right.\right.$ $\left.\left.\left.\mathrm{Bu}_{2}^{\mathrm{t}}\right)_{3}\right\}(\mathrm{O})\left(\mathrm{O}_{2} \mathrm{CCF}_{3}\right)\right](\mathbf{1 5 3})$ are isolated. In both cases, rather than the oxo group residing in an axial position and the complexes adopting $C_{3}$ geometries, distorted $C_{S}$ geometries are adopted and the oxos reside trans to an aryloxide. In 153 the acetate is coordinated in the axial position whereas in 152 the axial position is vacant. The observation that both complexes adopt equatorial oxo positions shows that the axial site plays no role in driving the geometry, and instead, noting that the trans-oxo exhibits the shortest U-O distance like in the ITI imido complex 110 (Figure 21), it is concluded that it is an ITI effect which drives the geometry. The energetics of this process have been qualitatively bracketed at $\sim 6 \mathrm{kcal} \mathrm{mol}^{-1}$ from theoretical calculations, which is consistent with the fact that such complexes can be forced to adopt axial-oxo geometries using sterically demanding aryloxide substituents that sterically disfavour equatorial binding, as found, for example, in the closely related complex $\left[\mathrm{U}\left\{\operatorname{tacn}\left(\mathrm{CH}_{2} \mathrm{C}_{6} \mathrm{H}_{2}-2-\mathrm{O}-3-\mathrm{Ad}-5-\mathrm{Bu}^{\mathrm{t}}\right)_{3}\right\}(\mathrm{O})\right]\left[\mathrm{SbF}_{6}\right]$ (154).<smiles>CCN(C)[As](=O)N(C)C</smiles>

Figure 27. The uranium(V)-oxo complex 155. 
In 2012, it was reported that oxidation of 75 with TEMPO affords the uranium(V)-oxo complex $\left[\mathrm{U}\left\{\mathrm{N}\left(\mathrm{SiMe}_{3}\right)_{2}\right\}_{3}(\mathrm{O})\right]$ (155) which adopts an unusual trigonal pyramidal geometry rather than tetrahedral, ${ }^{[176]}$ Figure 27 . Theoretical calculations suggest that this geometry is orbital-driven but no second-order Jahn-Teller effect is discernable.
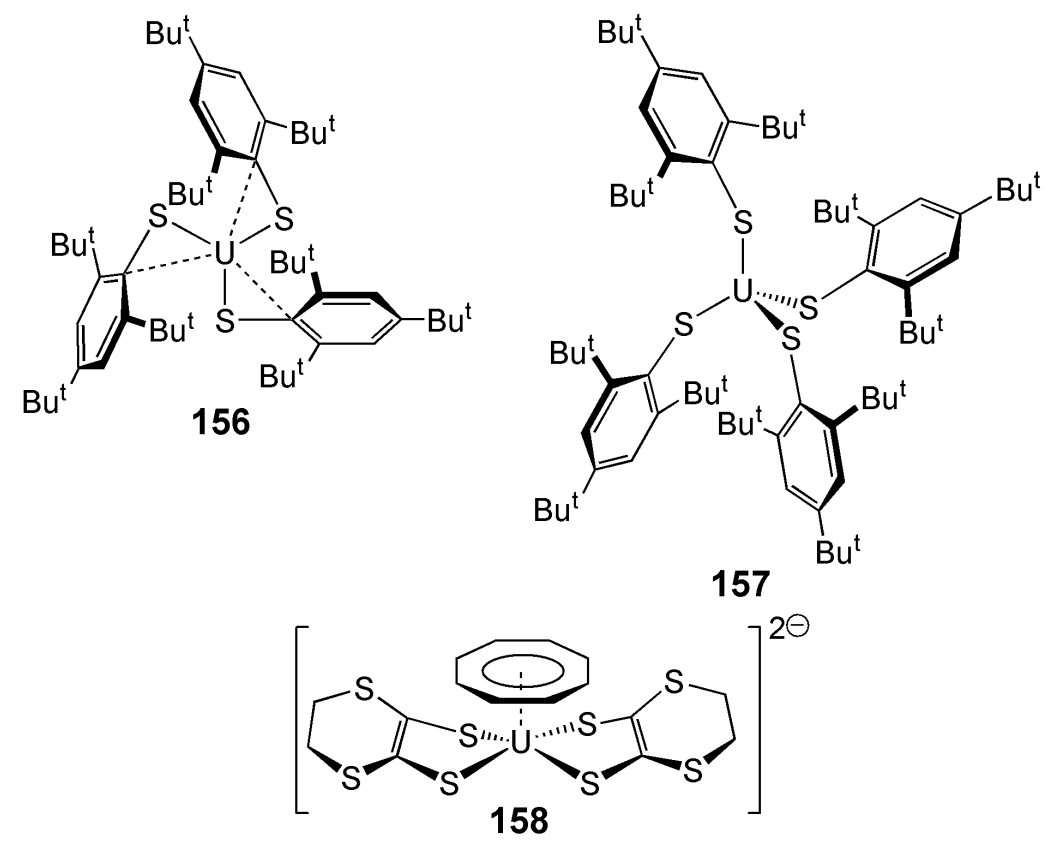

Figure 28. The uranium chalcogenide complexes 156-158.

It was once thought, due to the hard-soft mismatch, that soft S-donor ligands were unsuitable for use with hard actinides. However, over the past two decades this view has been invalidated. A range of uranium-thiolate complexes are now known, including, for example, [U(SMes* $\left.)_{3}\right](\mathbf{1 5 6}){ }^{[177]}$ $\left[\mathrm{U}\left(\mathrm{SMes}^{*}\right)_{4}\right](\mathbf{1 5 7}),{ }^{[177]}$ and dithiolenes such as $\left[\mathrm{U}(\mathrm{COT})\left\{\left(\mathrm{SCSCH}_{2}\right)_{2}\right\}\right]^{2-}(\mathbf{1 5 8}),{ }^{[178]}$ Figure 28 , which once again demonstrates that with suitable ancillary ligands linkages that are a priori thought to be disfavoured can be prepared and isolated. 

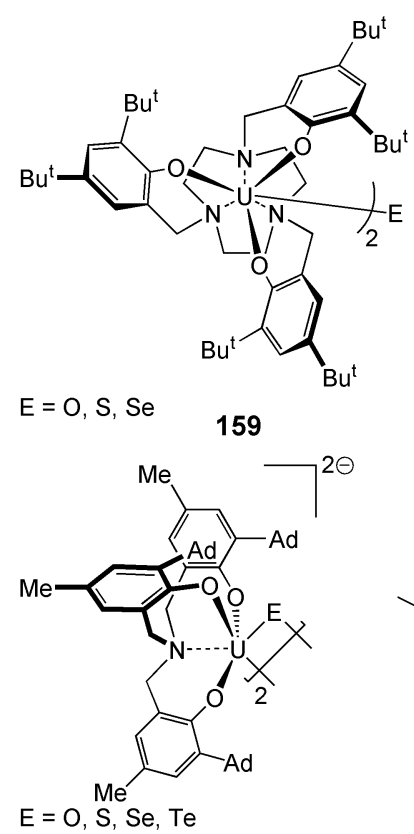

163

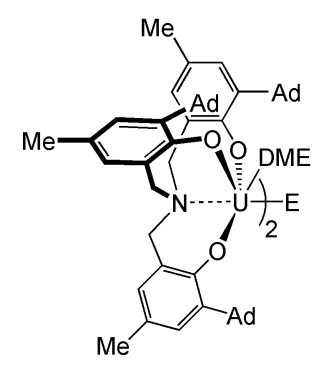

$E=S, S e$

160

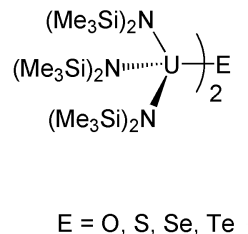

161

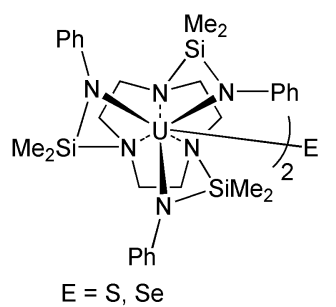

162

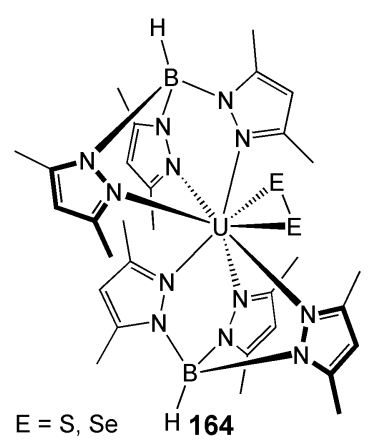

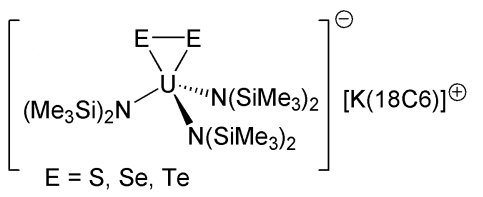

165

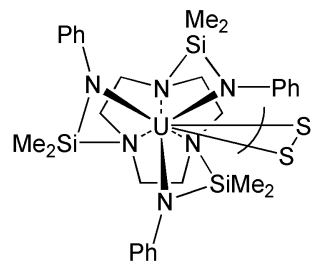

166

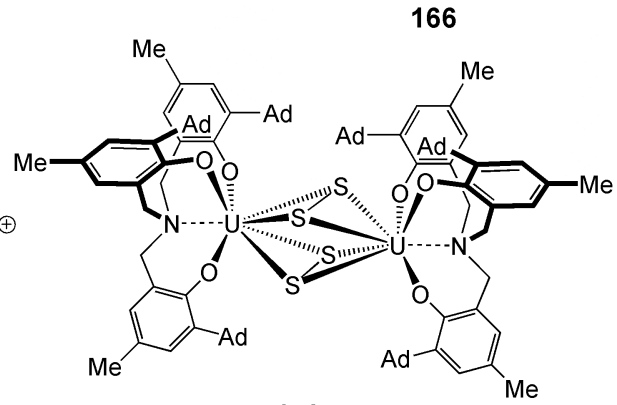

170

Figure 29. Selected uranium chalcogenide complexes 159-170.

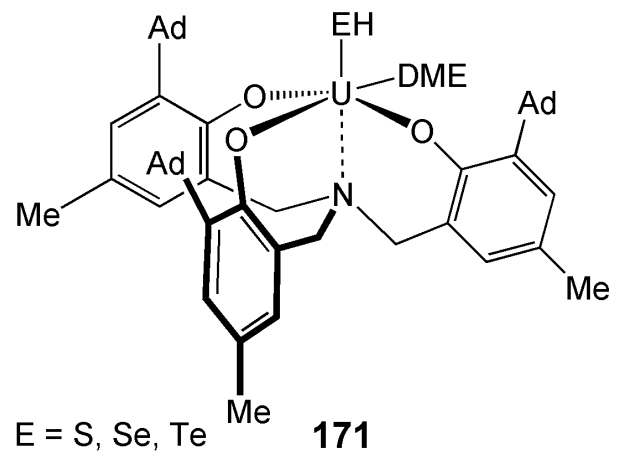

Figure 30. Terminal $\mathrm{EH}(\mathrm{E}=\mathrm{S}, \mathrm{Se}, \mathrm{Te})$ at uranium in complex 171.

Going further still, it has recently been demonstrated that 'naked' chalcogens can be assembled and stabilized at uranium, ${ }^{[179]}$ Figure 29. For example, in the past four years complexes with U-E-U (159-162), $\mathrm{UE}_{2} \mathrm{U}(\mathbf{1 6 3}), \mathrm{U}\left(\mathrm{E}_{2}\right)(\mathrm{E}=\mathrm{S}, \mathrm{Se}, \mathrm{Te}, \mathbf{1 6 4 - 1 6 8})$, and $\mathrm{U}\left(\mathrm{S}_{3}\right)$ (169) fragments were prepared by reaction of the elemental chalcogens with uranium(III) precursors and a selection of representative examples are shown in Figure 29. Some of these complexes have formed the basis for 'stitching together' chalcogens to form $E_{2}$ and $E_{4}$ units, e.g. 170. Also, it was recently disclosed that $\mathrm{EH}_{2}(\mathrm{E}=\mathrm{S}$, Se, Te $)$ react with $\left[\mathrm{U}\left\{\mathrm{N}\left(\mathrm{CH}_{2} \mathrm{C}_{6} \mathrm{H}_{2}-3-\mathrm{Me}-5-\mathrm{Ad}-6-\mathrm{O}\right)_{3}\right\}(\mathrm{DME})\right]$ to afford 
$\left[\mathrm{U}\left\{\mathrm{N}\left(\mathrm{CH}_{2} \mathrm{C}_{6} \mathrm{H}_{2}-3-\mathrm{Me}-5-\mathrm{Ad}-6-\mathrm{O}\right)_{3}\right\}(\mathrm{EH})(\mathrm{DME})\right](\mathbf{1 7 1})$, Figure 30, which contain terminal EH units that are analogous to the parent imido and phosphinidene complexes 113 and 129 (Schemes 23 and 27).

a)

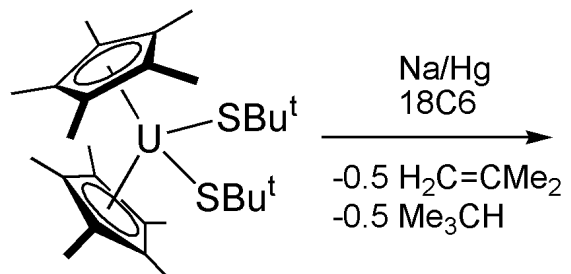

172

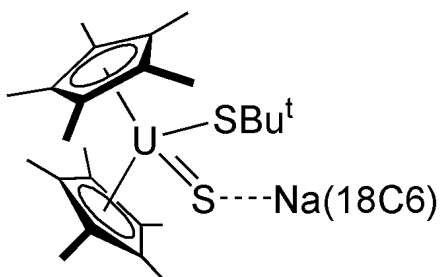

173

b)<smiles>CN(C)[Al](C=P(c1ccccc1)(c1ccccc1)c1ccccc1)(N(C)C)N(C)C</smiles>

$54 \mathrm{H}$

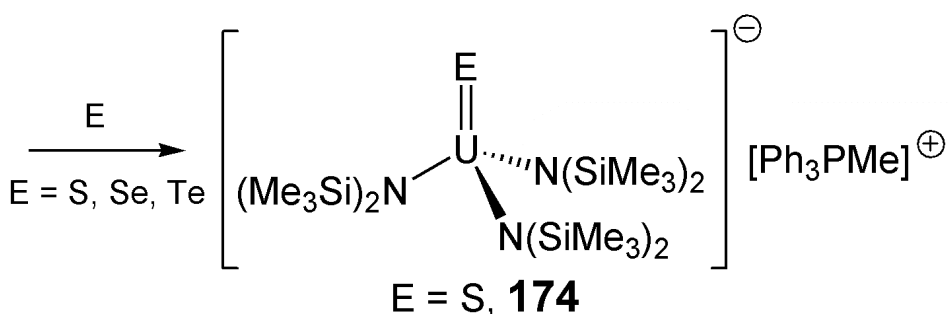
$E=S, 174$ $\mathrm{E}=\mathrm{Se}, 175$ $\mathrm{E}=\mathrm{Te}, 176$

c)
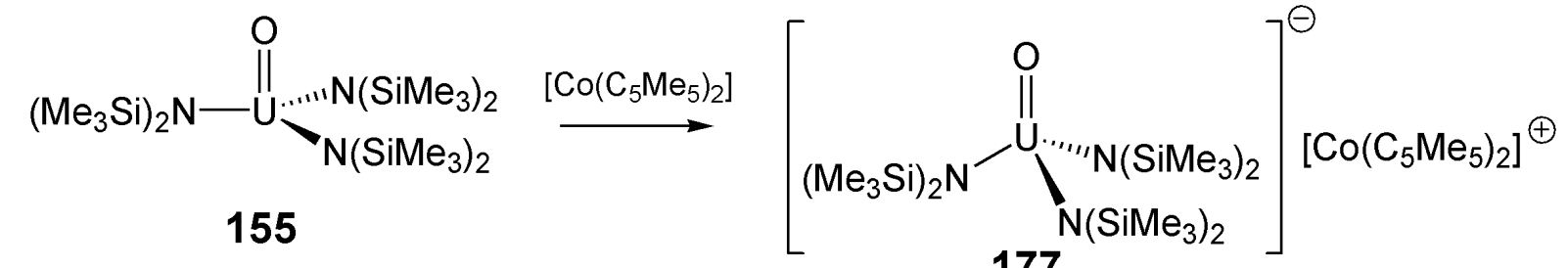
177

Scheme 32. a) - c): Heavier chalcogen uranium multiple bonds in compounds 173-177.

Heavier chalcogens have also been shown to be capable of forming multiple bonds to uranium, though there are few examples. In 1999, it was found that treatment of $\left[\mathrm{U}\left(\eta^{5}-\mathrm{C}_{5} \mathrm{Me}_{5}\right)_{2}\left(\mathrm{SBu}^{\mathrm{t}}\right)_{2}\right](\mathbf{1 7 2})$ with sodium-mercury amalgam resulted in C-S bond homolysis to give $\left[U\left(\eta^{5}\right.\right.$ $\left.\left.\mathrm{C}_{5} \mathrm{Me}_{5}\right)_{2}\left(\mathrm{SBu}^{\mathrm{t}}\right)(\mathrm{S})\right][\mathrm{Na}(18 \mathrm{C} 6)](\mathbf{1 7 3})$ when recrystallized in the presence of $18 \mathrm{C} 6,{ }^{[180]}$ Scheme 32 . In the solid state structure the $\mathrm{U}=\mathrm{S}$ unit is weakly coordinated to the Na center, but the $\mathrm{U}=\mathrm{S}$ bond length of $2.477(2) \AA$ is considerably shorter than the U-S bond distance of 2.744(2) $\AA$, which suggests a $\mathrm{U}=\mathrm{S}$ multiple bond is present. Complex 173 was perhaps ahead of its time because the area fell dormant for over a decade, until in 2012 a series of uranium(IV) chalcogen complexes $\left[\mathrm{U}\left\{\mathrm{N}\left(\mathrm{SiMe}_{3}\right)_{2}\right\}_{3}(\mathrm{E})\right]\left[\mathrm{Ph}_{3} \mathrm{PMe}\right](\mathrm{E}=\mathrm{S}, \mathbf{1 7 4} ; \mathrm{E}=\mathrm{Se}, \mathbf{1 7 5} ; \mathrm{S}=\mathrm{Te}, \mathbf{1 7 6})$ were prepared, ${ }^{[181]}$ Scheme 32. Proving its utility again, the ylide complex $\mathbf{5 4 H}$ is straightforwardly oxidized by elemental chalcogens to give complexes 174-176. To complete the series, complex 155 was reduced with decamethyl cobaltocene to give $\left[\mathrm{U}\left\{\mathrm{N}\left(\mathrm{SiMe}_{3}\right)_{2}\right\}_{3}(\mathrm{O})\right]\left[\mathrm{Co}\left(\eta^{5}-\mathrm{C}_{5} \mathrm{Me}_{5}\right)_{2}\right](\mathbf{1 7 7})$. 


$$
\begin{aligned}
& {\left[\left(\mathrm{Me}_{3} \mathrm{Si}_{2} \mathrm{~N}^{-} \prod_{\mathrm{N}\left(\mathrm{SiMe}_{3}\right)_{2}}^{\mathrm{O}}\right]^{\mathrm{U} \cdots, \ldots, \mathrm{N}\left(\mathrm{SiMe}_{3}\right)_{2}}\right]^{\ominus}\left[\mathrm{Co}\left(\mathrm{C}_{5} \mathrm{Me}_{5}\right)_{2}\right]^{\oplus}} \\
& 177 \\
& \text { E } \\
& {\left[\left(\mathrm{Me}_{3} \mathrm{Si}\right)_{2} \mathrm{~N}-\bigcup_{\mathrm{E}}^{\mathrm{O}} \bigcup_{\mathrm{N}} \mathrm{N}\left(\mathrm{SiMe}_{3}\right)_{2} \mathrm{~N}\left(\mathrm{SiMe}_{3}\right)_{2}\right]^{\Theta}\left[\mathrm{Co}\left(\mathrm{C}_{5} \mathrm{Me}_{5}\right)_{2}\right]^{\oplus}} \\
& E=S, 178 \\
& E=S e, 179
\end{aligned}
$$

Scheme 33. Synthesis of the heavy uranyl analogues 178 and 179.

Heavier chalcogen multiple bonds have also been extended to uranium(VI) to generate heavy uranyl(VI)-analogues. Using 177 as a start-point, oxidation with S or Se afforded the heavy uranyl analogues $\left[\mathrm{U}\left\{\mathrm{N}\left(\mathrm{SiMe}_{3}\right)_{2}\right\}_{3}(\mathrm{O})(\mathrm{S})\right]\left[\mathrm{Co}\left(\eta^{5}-\mathrm{C}_{5} \mathrm{Me}_{5}\right)_{2}\right] \quad(\mathbf{1 7 8})$ and $\left[\mathrm{U}\left\{\mathrm{N}\left(\mathrm{SiMe}_{3}\right)_{2}\right\}_{3}(\mathrm{O})(\mathrm{Se})\right]\left[\mathrm{Co}\left(\eta^{5}-\right.\right.$ $\left.\left.\mathrm{C}_{5} \mathrm{Me}_{5}\right)_{2}\right]\left(\right.$ (179). ${ }^{[182]}$ The tellurium analogue was not accessible by this methodology, presumably because $\mathrm{Te}$ is not sufficiently oxidizing. For completeness, the uranyl(VI) analogue, $\left[\mathrm{UO}_{2}\left\{\mathrm{~N}\left(\mathrm{SiMe}_{3}\right)_{2}\right\}_{3}\right]\left[\mathrm{Co}\left(\eta^{5}-\mathrm{C}_{5} \mathrm{Me}_{5}\right)_{2}\right](\mathbf{1 8 0})$ was prepared and this complex is analogous to 81 (Scheme 17). Theoretical calculations reveal uranyl-type bonding, but as E becomes increasingly heavier the bonding of the U-E unit becomes increasingly localized on E, and thus delocalization across the $[\mathrm{O}=\mathrm{U}=\mathrm{E}]^{2+}$ unit deconvolutes with less mixing as $\mathrm{O}$ is replaced by $\mathrm{S}$ then $\mathrm{Se}$.

\section{Molecular Magnetism}

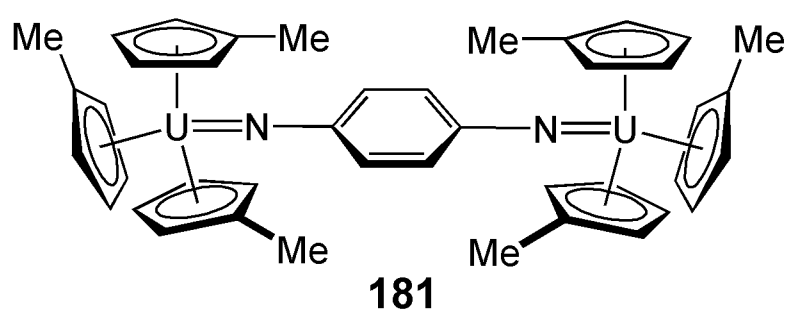

Figure 31. The diuranium(V)-imido complex 181, which exhibits antiferromagnetic U-U coupling.

The basics of static uranium magnetism are reasonably well understood (Section 2.5). However, the area continues to be fascinating because of novel phenomena that are frequently observed such as magnetic coupling and single molecule magnetism. ${ }^{[183]}$ Molecular antiferromagnetic coupling was first observed between uranium(V) centers in $\left[\left\{U\left(\eta^{5}-\mathrm{C}_{5} \mathrm{H}_{4} \mathrm{Me}\right)_{3}\right\}\left(1,4-\mathrm{NC}_{6} \mathrm{H}_{4} \mathrm{~N}\right)\right](\mathbf{1 8 1})$, Figure 31, in 1990 and rationalized on the basis of superexchange. ${ }^{[184]}$ Further examples of unusual and notable 
uranium(V)-uranium(V) coupling involve a pentavalent bis(imido) uranium dimer, ${ }^{[185]}$ diuranium(V)-dioxo diamond cores, ${ }^{[186]}$ which can exhibit Neél temperatures up to $70 \mathrm{~K}$ that are surpassed only by a Neél temperature of $110 \mathrm{~K}$ for the diuranium(III) arene-dianion complex 57, and pentavalent uranyl-uranyl coupling. ${ }^{[168]}$ As expected for the more ionic uranium(IV), examples of uranium(IV)-uranium(IV) coupling are far fewer, and are limited to two examples, ${ }^{[179 a, 187]}$ both of which are mediated by chalcogen bridges. However, examples of uranium(IV)-copper(II) and nickel(II) coupling are known. ${ }^{[188]}$

\subsection{Single molecule magnetism of uranium(III)}
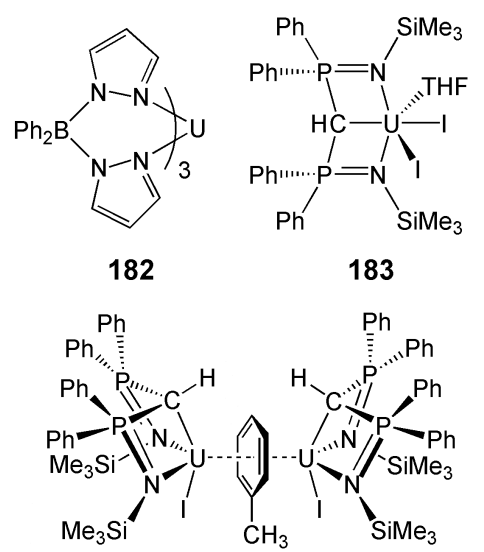

184

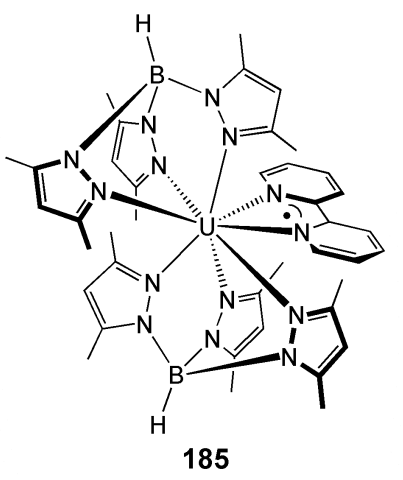

Figure 32. Selected uranium(III) single molecule magnets 182-185.

In the arena of dynamic magnetism, it was first shown in 2009 that uranium(III) can exhibit SMM behaviour. ${ }^{[189]}$ Throughout this section we provide energy barriers $\left(U_{\text {eff }}\right)$ in units of $\mathrm{cm}^{-1}$ with $\mathrm{K}$ values in parentheses for accessibility. The complex $\left[\mathrm{U}\left\{\mathrm{Ph}_{2} \mathrm{~B}\left(\mathrm{~N}_{2} \mathrm{C}_{3} \mathrm{H}_{3}\right)_{2}\right\}_{3}\right]$ (182), Figure 32, exhibits frequency dependent maxima in the out-of-phase $\left(\chi^{\prime \prime}\right)$ ac susceptibility, which is indicative of slow magnetic relaxation. In the thermally activated regime an energy barrier of $U_{\text {eff }}=$ $20 \mathrm{~cm}^{-1}(29 \mathrm{~K})$ was extracted, but at low temperature quantum tunnelling occurs which bypasses the thermal barrier to relaxation. Since 2009 a number of uranium(III) SMMs have been reported, ${ }^{[127,190]}$ which are mainly supported by pyrazolyl borate ligands. Interestingly, however, studies of 3THF, 75, 76 and $\left[\mathrm{U}\left(\mathrm{BIPM}^{\mathrm{TMS}} \mathrm{H}\right)(\mathrm{I})_{2}(\mathrm{THF})\right]$ (183), Figure 32, have shown SMM 
behaviour, and, despite the fact their symmetries at uranium are different, they present remarkably similar $U_{\text {eff }}$ values of $12.9(18.6 \mathrm{~K}), 21.5(31 \mathrm{~K}), 21.4(31 \mathrm{~K})$, and $16.3(23.4 \mathrm{~K}) \mathrm{cm}^{-1}{ }^{[191]}$ As stated above, one inverted sandwich diuranium(III) arene-dianion complex uniquely exhibits SMM behaviour. Specifically, $\left[\left\{\mathrm{U}\left(\mathrm{BIPM}^{\mathrm{TMS}} \mathrm{H}\right)(\mathrm{I})\right\}_{2}\left(\mu-\eta^{6}: \eta^{6}-\mathrm{C}_{6} \mathrm{H}_{5} \mathrm{Me}\right)\right](\mathbf{1 8 4})$ was reported in 2011 , $^{[192]}$ Figure 32, and this complex exhibits slow relaxation as evidenced by frequency-dependent maxima in $\chi^{\prime \prime}$ м plots. Complex 184 exhibits hysteresis which collapses at zero-field to give a butterfly shaped curve, which is a common phenomena for uranium(III) SMMs, i.e uranium SMMs are often field-induced. Unfortunately an energy barrier to the reversal of the magnetization could not be obtained, but this compound suggests promise for constructing polyuranium complexes with improved SMM characteristics. Quantum tunnelling allows complexes to relax via much lower energy barriers than a purely thermal regime would suggest. One way to potentially avoid this is to force the $m_{\mathrm{J}}$ levels of opposite sign away from degeneracy by using a small external magnetic local field. One way to do this is with a neighbouring spin, and this effect, called exchange bias, could be effected a number of ways, but introducing an open-shell ligand radical is an attractive approach reported recently. Complex 185, ${ }^{[193]}$ Figure 32, shows clear signs of antiferromagnetic coupling at low temperature, but even in zero-field SMM behaviour is exhibited suggesting that quantum tunnelling has been supressed by the ligand radical which holds promise for the design of uranium(III) SMMs with higher blocking temperatures in the future.

\subsection{Single molecule magnetism of uranium(V)}



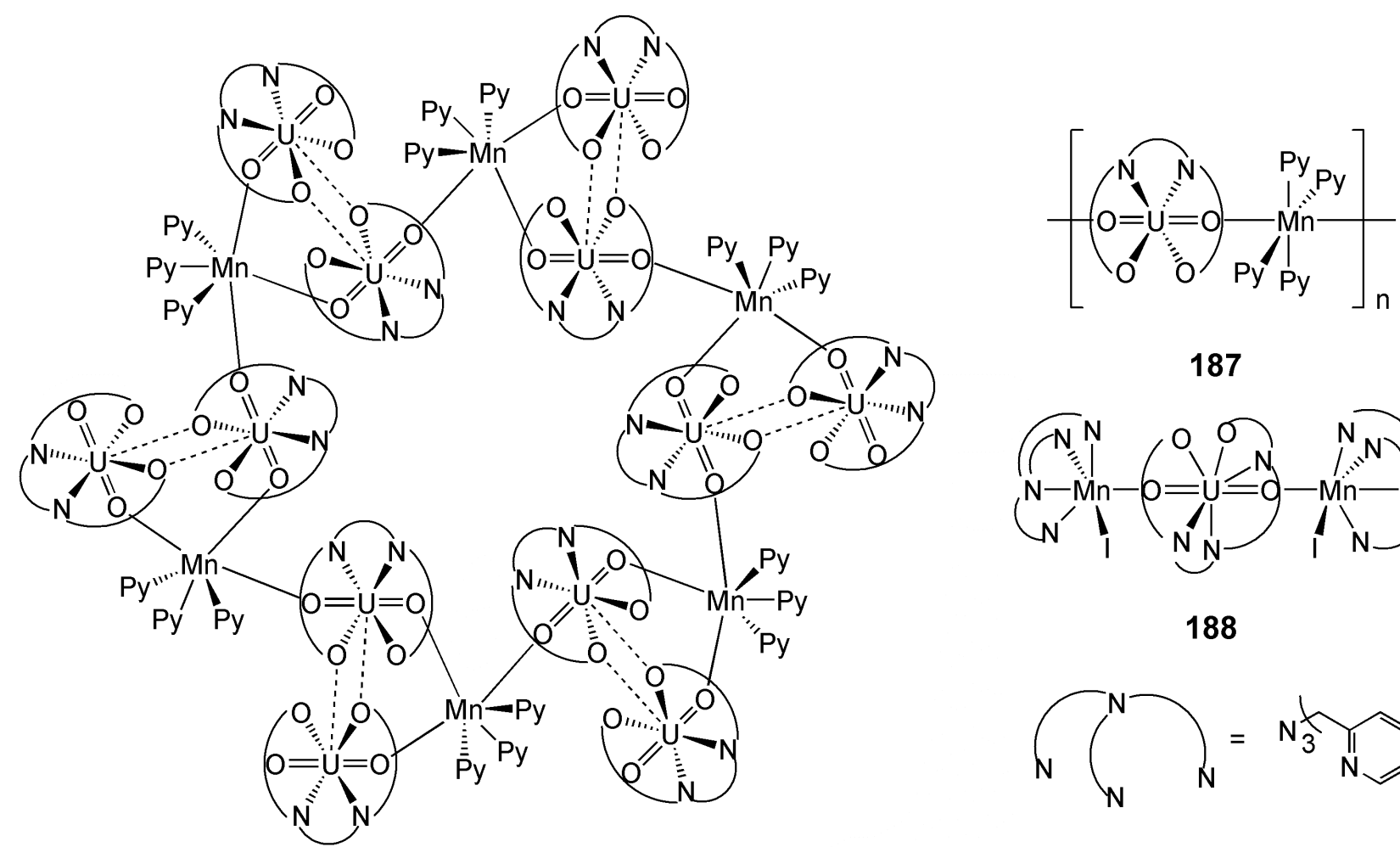

187

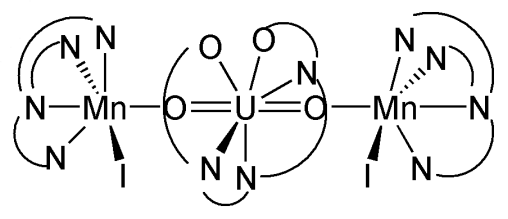

188

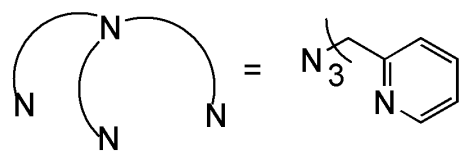

186
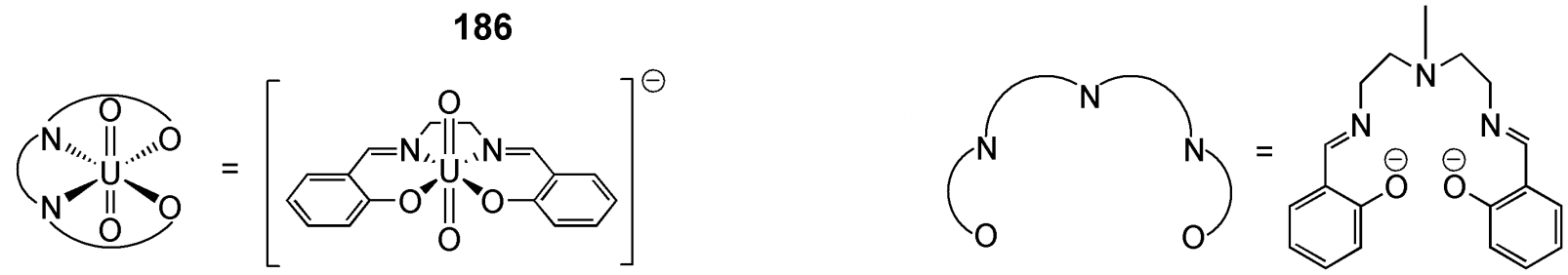

Figure 33. Uranyl(V) single molecule magnets 186-188.

At first, all examples of uranium SMMs contained formally trivalent uranium ions. This changed in 2012 with the report of an aesthetically pleasing nanometer-scale wheel containing twelve uranyl(V) and six manganese(II) centers in the complex $\left[\left\{\left(\mathrm{UO}_{2}\left[\left(\mathrm{CH}_{2} \mathrm{NCHC}_{6} \mathrm{H}_{4}-2-\right.\right.\right.\right.\right.$ $\left.\left.\left.\left.\mathrm{O}_{2}\right]\right)_{2}\left(\mathrm{Mn}[\mathrm{Py}]_{3}\right)\right\}_{6}\right]$ (186), ${ }^{[194]}$ Figure 33. In complex 186 uranyl-salen anion fragments dimerize via bridging aryloxide units, and each dimer coordinates via yl-oxos to a Mn center which in turn bonds to one yl-oxo of the next unit. The dc susceptibility measurements are indicative of significant magnetic interactions between the uranyl(V) and manganese(II) ions. In the thermally activated regime of magnetic relaxation an energy barrier of $98.7 \mathrm{~cm}^{-1}(142 \mathrm{~K})$ was determined. Since the manganese(II) centers might not have a sizeable anisotropy of their own, the uranyl(V) ions may play a significant role in the magnetization dynamics, but their relationship is not fully resolved since a variant with a non-magnetic metal(II) ion to isolate the uranyl(V) contribution is not currently available. This complex exhibits coercivity at $2.25 \mathrm{~K}$ with a coercive field of $\sim 1.5 \mathrm{~T}$. Quantum tunneling could be observed in hysteresis loops as step-like features. The strength of the mixed uranyl-3d approach was underlined by reports in 2014 of a uranyl(V)-manganese(II) single chain magnet (187), with an energy barrier of $93 \mathrm{~cm}^{-1}(134 \mathrm{~K})$, and a uranyl(V)-bis(manganese(II)) 
complex $(\mathbf{1 8 8})$ with a relaxation barrier of $56.3 \mathrm{~cm}^{-1}(81 \mathrm{~K}) .{ }^{[195]}$ The latter barrier is the largest for any discrete single uranium ion SMM and in both systems the hysteresis loops remain open at zero field. In these latter two systems, the effective energy barrier depends on the magnetic coupling strengths as well as on the single-ion anisotropies.

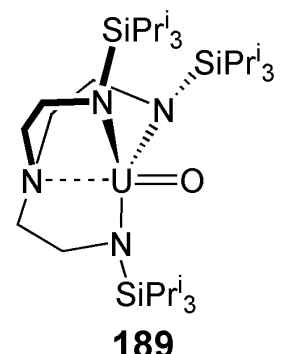

Figure 34. The single ion uranium(V) single molecule magnet 189.

In 2013, the synthesis of a terminal uranium(V)-mono-oxo complex supported by a Tren ligand was reported, ${ }^{[196]}$ Figure 34. Specifically, oxidation of 121 with $\mathrm{Me}_{3} \mathrm{NO}$ afforded $\left[\mathrm{U}\left(\operatorname{Tren}^{\mathrm{TIPS}}\right)(\mathrm{O})\right](\mathbf{1 8 9})$. This complex is notable for three reasons. Firstly, there appears to be an ITI effect in this molecule, like in the uranium(VI)-nitride analogue 114 (Scheme 26) where the amine trans to the oxo bonds to uranium at an unusually close distance of 2.482(6) $\AA$. Secondly, 189 is the first example of a monometallic $\mathrm{f}^{1}$ SMM. Lastly, 189 unambiguously demonstrates the important principle that in a strong axial crystal field uranium(V) can exhibit SMM behavior. Complex 189 possesses a strong axial ligand field from the amine and oxo groups, and whilst the energy barrier of this complex to relaxation of the magnetization breaks no records at $15.3 \mathrm{~cm}^{-1}(22 \mathrm{~K})$ it does exhibit slow relaxation up to a blocking temperature of $3.5 \mathrm{~K}$ and at scanning frequencies as low as $10 \mathrm{~Hz}$.

\section{Small Molecule Activation}

The binding and activation of small molecules at uranium has received intense interest over the past 15 years and the area has been comprehensively reviewed recently. ${ }^{[25 \mathrm{a}, \mathrm{e}, \mathrm{f}, 30 \mathrm{j}, 31 \mathrm{~b}]}$ Therefore, and since various examples have been covered above, the following section describes some of the more notable advances to provide a flavour of the novel small molecule activation chemistry that uranium is capable of effecting. These examples usually have no counter-parts in the d- or p-blocks.

\subsection{Carbon Monoxide}




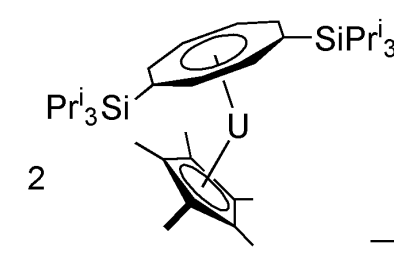

190

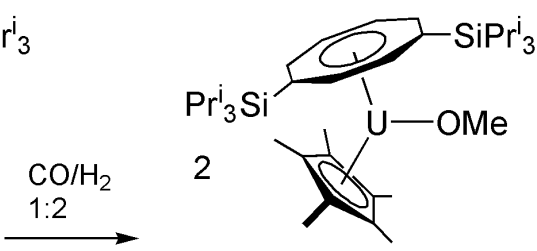

192
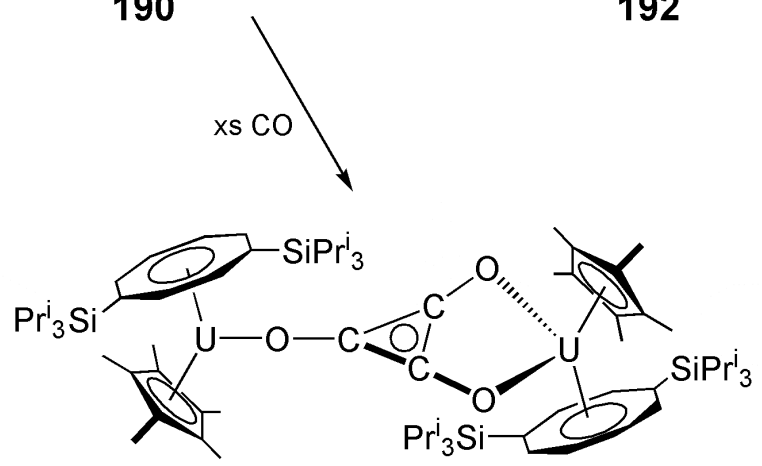

191

Scheme 34. Reactivity of the organouranium(III) complex with $\mathrm{CO}$ and $\mathrm{CO} / \mathrm{H}_{2}$ gases to produce 191 and 192.

A major step forward in the reductive homologation of CO was reported in $2006{ }^{[197]}$ Reaction of $\mathrm{CO}$ with the solvent-free organouranium(III) complex $\left[\mathrm{U}\left\{\eta^{8}-\mathrm{C}_{8} \mathrm{H}_{6}-1,4-\left(\mathrm{SiPr}_{3}^{\mathrm{i}}\right)_{2}\right\}\left(\eta^{5}-\mathrm{C}_{5} \mathrm{Me}_{5}\right)\right](\mathbf{1 9 0})$ affords the cyclotrimerized product $\left[\left\{\mathrm{U}\left(\eta^{8}-\mathrm{C}_{8} \mathrm{H}_{6}-1,4-\left[\mathrm{SiPr}_{3}^{\mathrm{i}}\right]_{2}\right)\left(\eta^{5}-\mathrm{C}_{5} \mathrm{Me}_{5}\right)\right\}_{2}\left(\kappa^{1}: \kappa^{2}-\mathrm{C}_{3} \mathrm{O}_{3}\right)\right]$ (191), Scheme 34. Subsequent studies have shown that a terminal CO adduct is first formed which then couples in a 'zig-zag' complex in a process that is promoted by the reduction. It was also found that varying the steric demands of the cyclopentadienyl ligand modulates the oligomerization of $\mathrm{CO}$ to produce squarate $\left(\mathrm{C}_{4} \mathrm{O}_{4}\right)^{2-}$ or ethyne-diolate $\left(\mathrm{C}_{2} \mathrm{O}_{2}\right)^{2-} \cdot{ }^{2}{ }^{198]}$ When this reaction is carried out in the presence of two equivalents of hydrogen a remarkable hydrogenation reaction occurs to give the methoxide complex $\left[\left\{\mathrm{U}\left(\eta^{8}-\mathrm{C}_{8} \mathrm{H}_{6}-1,4-\left[\mathrm{SiPr}_{3}^{\mathrm{i}}\right]_{2}\right)\left(\eta^{5}-\mathrm{C}_{5} \mathrm{Me}_{5}\right)\right\}_{2}(\mathrm{OMe})\right] \quad(\mathbf{1 9 2})$, Scheme 34 ; the methoxide can be extricated as its silyl ether and the resulting uranium triflate can be reduced back to $\mathbf{1 9 0}$ to close the reaction cycle. ${ }^{[199]}$ 


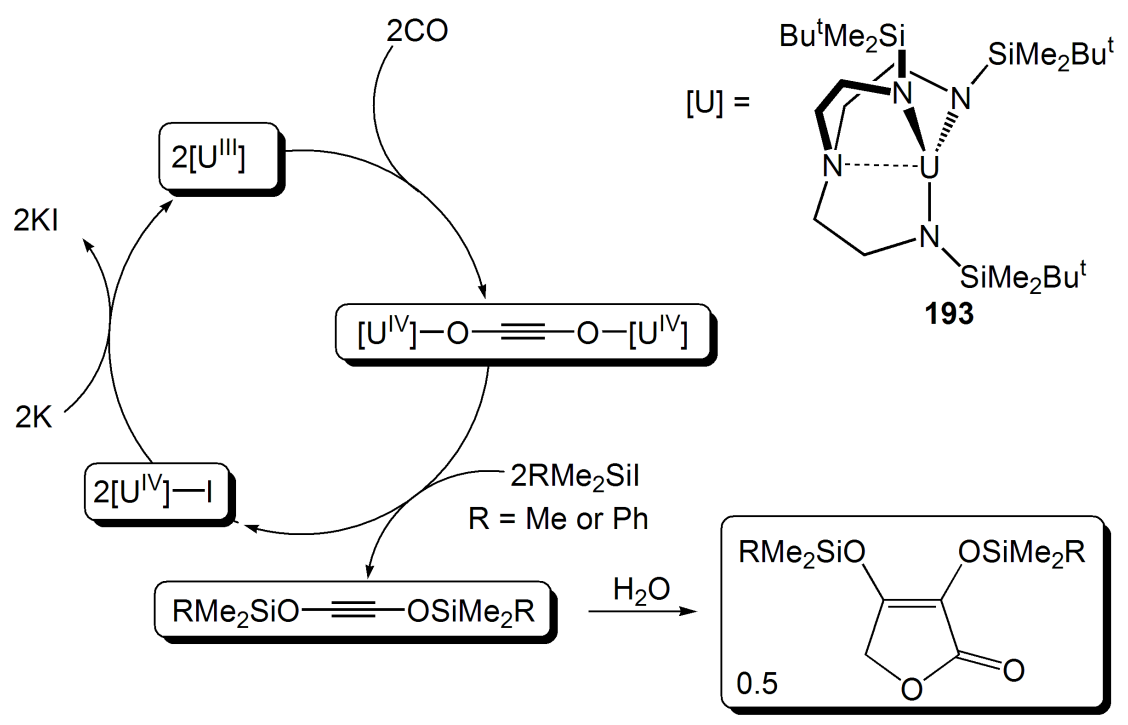

Scheme 35. Reductive homologation of CO to give a furanone in a synthetic cycle promoted by 193.

With the exception of 192, reductive CO-homologation usually resists further steps beyond the initial coupling because of the formation of strong U-O bonds. However, for example, it was shown in 2011 that $\left(\mathrm{C}_{2} \mathrm{O}_{2}\right)^{2-}$ can be formed when coupled by $\mathbf{7 5}$ and functionalized by activation of a ligand C-H bond. ${ }^{[200]}$ Subsequently, in 2012 it was demonstrated that with certain reagents $\left(\mathrm{C}_{2} \mathrm{O}_{2}\right)^{2-}$ can be liberated as its silyl ether to give closed synthetic cycles when the chemistry is supported by $\left[\mathrm{U}\left(\operatorname{Tren}^{\mathrm{DMBS}}\right)\right]\left[\mathbf{1 9 3}\right.$, Tren $\left.^{\mathrm{DMBS}}=\mathrm{N}\left(\mathrm{CH}_{2} \mathrm{CH}_{2} \mathrm{NSiMe}_{2} \mathrm{Bu}^{\mathrm{t}}\right)_{3}\right]$, Scheme 35. ${ }^{[187]}$

\subsection{Carbon Dioxide}

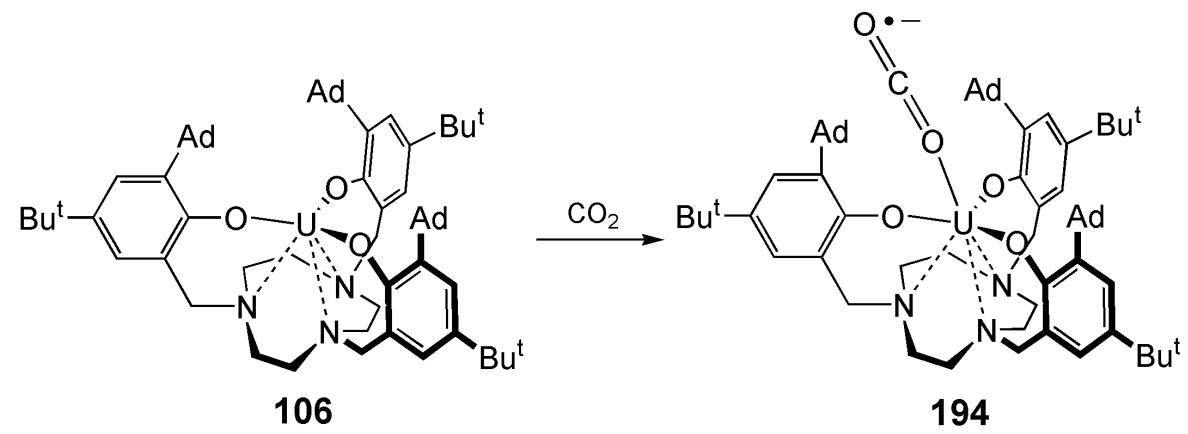

Scheme 36. Reaction of $\mathbf{1 0 6}$ with $\mathrm{CO}_{2}$ to give the radical anion complex 194.

The potential for uranium(III) to reductively activate $\mathrm{CO}_{2}$ was demonstrated in 2004. Addition of $\mathrm{CO}_{2}$ to $\mathbf{1 0 6}$ afforded the end-on coordinated complex [ $\mathrm{U}\left\{\operatorname{tacn}\left(\mathrm{CH}_{2} \mathrm{C}_{6} \mathrm{H}_{2}-2-\mathrm{O}-3-\mathrm{Ad}-5\right.\right.$ $\left.\left.\left.\mathrm{Bu}^{\mathrm{t}}\right)_{3}\right\}\{\mathrm{OCO}\}\right]$ (194), ${ }^{[201]}$ Scheme 36. The coordination mode of $\mathrm{CO}_{2}$ was unprecedented and results from the cylindrical cavity to uranium formed from the three Ad-groups. Although characterization data are consistent with a reduced radical anion uranium(IV) formulation, further reactivity has not 
been reported, perhaps because the sterics required to stabilize this novel linkage may suppress subsequent reactivity.

a)

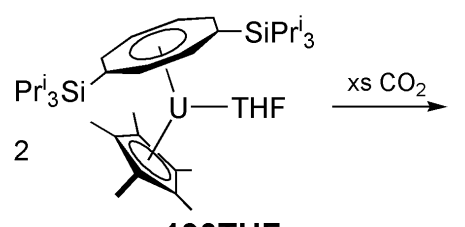

190THF

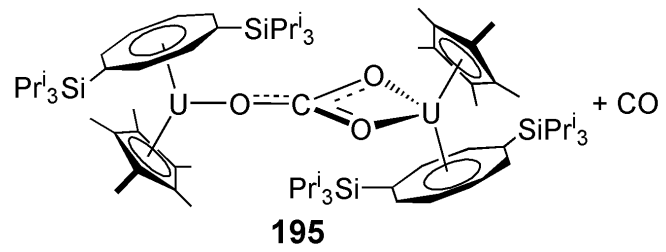

195

b)

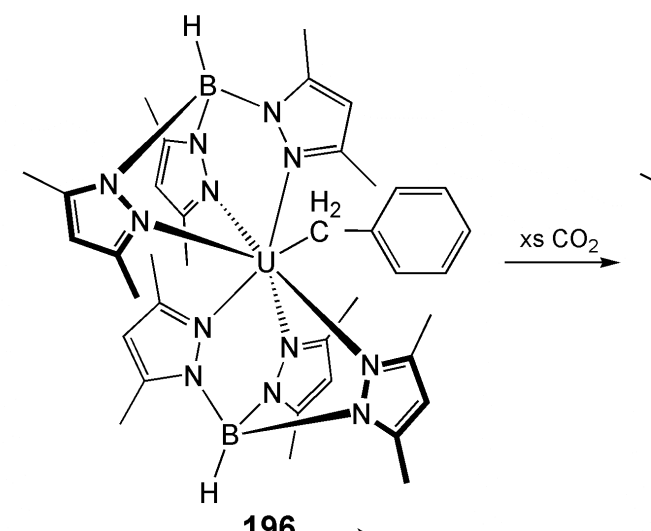

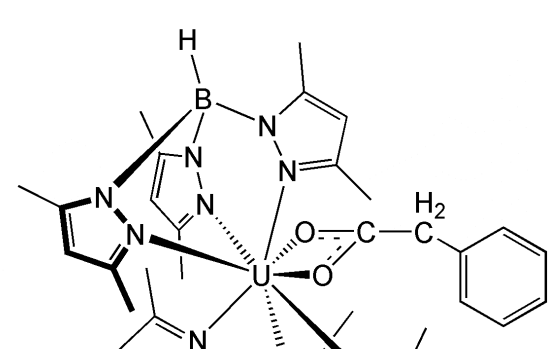

196
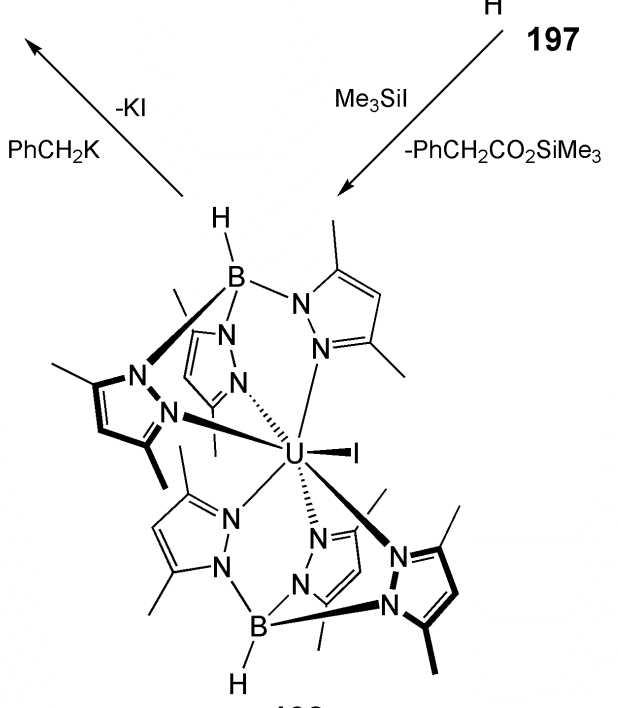

198

Scheme 37. a) Reductive disproportionation of $\mathrm{CO}_{2}$ by uranium(III) to give 195. b) Insertion of $\mathrm{CO}_{2}$ into a uranium-benzyl to give 197.

Where sterically less demanding complexes are employed a rich redox chemistry with $\mathrm{CO}_{2}$ has been uncovered, usually involving reductive disproportionation to give carbonate derivatives. For example, the THF adduct of 190 (190THF) reacts with $\mathrm{CO}_{2}$ to give the carbonate 195 and CO, Scheme 37. A number of uranium(III) complexes are now known to promote this reaction and studies have shown that in some cases a bridging oxo is formed which reacts with $\mathrm{CO}_{2}$ to give carbonate. ${ }^{[19 a, 203]}$ Insertion reactivity of $\mathrm{CO}_{2}$ into polar uranium-ligand bonds is also known in a wider context. ${ }^{[204]}$ For example, insertion of $\mathrm{CO}_{2}$ into the uranium-benzyl bond of 196 gives $\mathbf{1 9 7}$, 
Scheme 37; treatment of 197 with $\mathrm{Me}_{3} \mathrm{SiI}$ produces the silyl ether $\mathrm{PhCH}_{2} \mathrm{C}(\mathrm{O}) \mathrm{OSiMe}_{3}$ along with the uranium iodide 198 which is a precursor to 196. A synthetic cycle for the production of silyl ethers could be continued over three [re]cycles. ${ }^{[205]}$

\subsection{Dinitrogen}

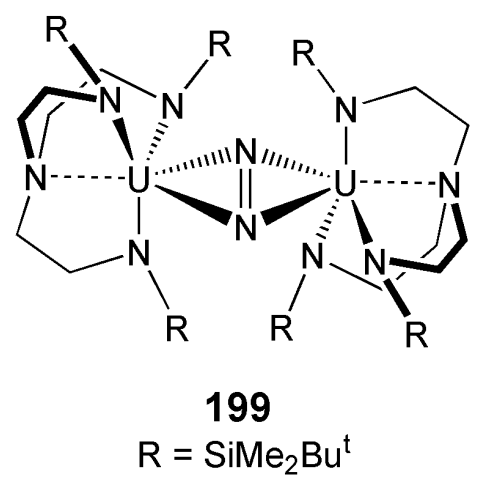

Figure 35. The side-on bound bridging uranium dinitrogen complex 199.

The activation of dinitrogen is of considerable interest and importance and uranium has shown promise in this field (recall the utility of uranium in the Haber Bosch patent, Section 1). Nevertheless, compared to the extensive dinitrogen chemistry of transition metals that of uranium is underdeveloped. The first dinitrogen complex of uranium was published in 1998. Exposure of a pentane solution of 193 to an atmosphere of dinitrogen gave $\left[\left\{U\left(\operatorname{Tren}^{\text {DMBS }}\right)\right\}_{2}\left(\mu-\eta^{2}: \eta^{2}-N_{2}\right)\right](199)$ in which the dinitrogen is bound in a side-on manner, ${ }^{[206]}$ Figure 35 . The N-N bond of 1.109(7) $\AA$ is essentially unchanged compared to free $\mathrm{N}_{2}(1.0975 \AA)$. A full understanding of the bonding in the $\mathrm{U}\left(\mathrm{N}_{2}\right) \mathrm{U}$ unit of $\mathbf{1 9 9}$ had to wait until theoretical methods were sufficiently advanced, but over a decade later the weight of opinion, after initial analyses suggested that a $\pi_{\mathrm{p}} \sigma$-type bond might be more favourable than a $\sigma_{\mathrm{p}}$ orbital, is now that uranium engages in back-bonding to the $\pi^{*}$ of $\mathrm{N}_{2}{ }^{[207]}$ The original bonding model was based on the knowledge that 199 easily converts back to 193 and free $\mathrm{N}_{2}$, but it seems now that this reflects the weak nature of the back-bond, and the apparently small lengthening of the N-N bond that is most likely due to an underestimation by the X-ray diffraction experiment which locates electron density and not atomic positions. 


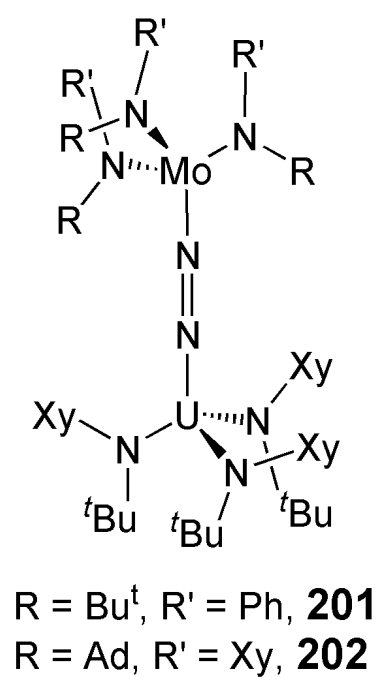

Figure 36. The end-on bound bridging heterobimetallic uranium molybdenum dinitrogen complexes 201 and 202.

Shortly after the report of side-on bound dinitrogen, two end-on variants were reported. Mixing the uranium(III) complex $\left[\mathrm{U}\left\{\mathrm{N}\left(\mathrm{Bu}^{\mathrm{t}}\right)(\mathrm{Xy})\right\}_{3}(\mathrm{THF})\right]$ (200), prepared from $\mathrm{Na} / \mathrm{Hg}$ reduction of $\left[\mathrm{U}\left\{\mathrm{N}\left(\mathrm{Bu}^{\mathrm{t}}\right)(\mathrm{Xy})\right\}_{3}(\mathrm{I})\right](\mathbf{5 6 B u})$, with the $\mathrm{Mo}(\mathrm{III})$ tris (amide) complexes $\left[\mathrm{Mo}\left\{\mathrm{N}(\mathrm{R})\left(\mathrm{R}^{\prime}\right)\right\}_{3}\right]\left(\mathrm{R}=\mathrm{Bu}^{\mathrm{t}}, \mathrm{R}^{\prime}\right.$ $\left.=\mathrm{Ph} ; \mathrm{R}=\mathrm{Xy}, \mathrm{R}^{\prime}=\mathrm{Ad}\right)$ was reported to afford $\left[\mathrm{U}\left\{\operatorname{Ar}\left(\mathrm{Bu}^{\mathrm{t}}\right) \mathrm{N}\right\}_{3}\left(\mu-\eta^{1}: \eta^{1}-\mathrm{N}_{2}\right) \mathrm{Mo}\{\mathrm{N}(\mathrm{R}) \mathrm{Ph}\}_{3}\right]\left(\mathrm{R}=\mathrm{Bu} u^{\mathrm{t}}\right.$, $\left.\mathrm{R}^{\prime}=\mathrm{Ph}, 201 ; \mathrm{R}=\mathrm{Ad}, \mathrm{R}^{\prime}=\mathrm{Xy}, \mathbf{2 0 2}\right),{ }^{[208]}$ Figure 36. X-ray diffraction studies revealed evidence for the reduction of $\mathrm{N}_{2}$, indicated by an $\mathrm{N}-\mathrm{N}$ distance of $1.232(11) \AA$ in $201(0.13 \AA$ longer than that in free $\mathrm{N}_{2}$ ) and $\mathrm{U}-\mathrm{N}$ distances that are characteristic of uranium(IV). It was noted that the putative Mo-dinitrogen complex $\left[\left\{\mathrm{Mo}\left(\mathrm{N}(\mathrm{R})\left(\mathrm{R}^{\prime}\right)\right\}_{3}\left(\mathrm{~N}_{2}\right)\right]\right.$ is more efficiently trapped by $\left[\mathrm{U}\left\{\mathrm{N}\left(\mathrm{Bu}^{\mathrm{t}}\right)(\mathrm{Xy})\right\}_{3}\right]$ than by $\left[\mathrm{Mo}\left(\mathrm{N}(\mathrm{R})\left(\mathrm{R}^{\prime}\right)\right\}_{3}\right]$, leading to the observed product, which is a consequence of the strong Lewis acidity of $U$ ions. The formal oxidation state of +4 was assigned for both metal centers, with molybdenum acting as the more effective $\pi$-donor to the complexed diazenide ligand.
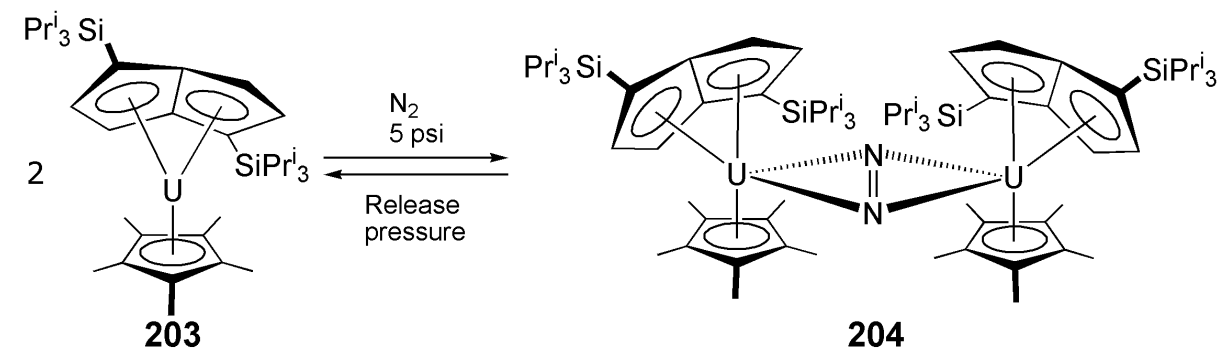

Scheme 38. Formation of the side-on bound bridging uranium dinitrogen complex 204 from 203.

The mixed-sandwich uranium(III) complex $\left[\mathrm{U}\left(\eta^{5}-\mathrm{C}_{5} \mathrm{Me}_{5}\right)\left\{\eta^{8}-1,4-\left(\mathrm{SiPr}_{3}^{\mathrm{i}}\right)_{2} \mathrm{C}_{8} \mathrm{H}_{4}\right\}\right]$ (203) was reported in 2002 to reversibly bind and reduce dinitrogen to afford a dinuclear uranium(IV) complex $\left[\left\{\mathrm{U}\left(\eta^{5}-\mathrm{C}_{5} \mathrm{Me}_{5}\right)\left[\eta^{8}-1,4-\left(\mathrm{SiPr}_{3}^{\mathrm{i}}\right)_{2} \mathrm{C}_{8} \mathrm{H}_{4}\right]\right\}_{2}\left(\mu-\eta^{2}: \eta^{2}-\mathrm{N}_{2}\right)\right]$ (204), ${ }^{[209]}$ containing a bridging, 
sideways-bound $\mathrm{N}_{2}{ }^{2-}$ ligand, Scheme 38 . An overpressure of dinitrogen (5 psi) was required to keep the dinitrogen bound to uranium, despite its formal reduction. An X-ray diffraction study of 204 revealed an $\mathrm{N}-\mathrm{N}$ bond length of 1.232(10) $\AA$, consistent with an $\mathrm{N}=\mathrm{N}$ double bond.

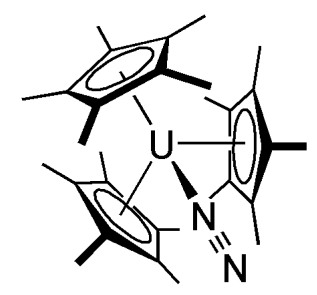

205

Figure 37. The end-on bound terminal dinitrogen uranium complex 205.

In 2003 it was shown that $\left[\mathrm{U}\left(\eta^{5}-\mathrm{C}_{5} \mathrm{Me}_{5}\right)_{3}\left(\eta^{1}-\mathrm{N}_{2}\right)\right](\mathbf{2 0 5})$ could be prepared from 29, and the former exhibits a remarkable $\eta^{1}$-coordinated dinitrogen ligand. ${ }^{[210]}$ However, a pressure of 80 psi $\mathrm{N}_{2}$ was required to stabilize the complex and when the over-pressure is released, solutions of 205 release $\mathrm{N}_{2}$, regenerating 29. The dinitrogen binding to uranium in $\mathbf{2 0 5}$ is thus reversible and weak as emphasized by an X-ray diffraction study showing virtually no change in the $\left[\mathrm{U}\left(\eta^{5}-\mathrm{C}_{5} \mathrm{Me}_{5}\right)_{3}\right]$ fragment upon complexation of dinitrogen. The N-N distance in $\mathbf{2 0 5}$ is indistinguishable from that of free dinitrogen, but as stated above X-ray crystallography may not be the best method to probe this metric.

\section{4. $P_{4}$}

Alongside the activation of dinitrogen, there has been considerable interest in the activation of white phosphorus to access organophosphorus species directly to avoid the intermediate chlorination step. ${ }^{[211]}$ The highly strained $\mathrm{P}_{4}$ tetrahedron is primed for rupture and reduction, and a significant amount of activity regarding transition metal- and main group-mediated activation of $\mathrm{P}_{4}$ has emerged in recent years. ${ }^{[11]}$ However, examples of $\mathrm{P}_{4}$ activation by uranium remains rare. 


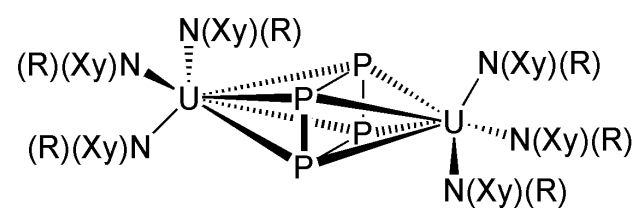

$\mathrm{R}=\mathrm{Bu}^{\mathrm{t}}, 206 \mathrm{Bu}$

$\mathrm{R}=\mathrm{Ad}, 206 \mathrm{Ad}$

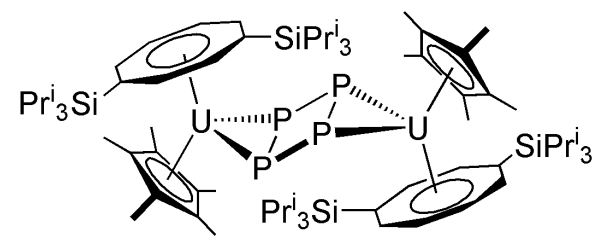

207

Figure 38. The $\left[\mathrm{P}_{4}\right]^{2-}$ complexes of uranium 206Bu/Ad and 207.

In 2004 it was reported in a MIT Thesis that treatment of 56Bu/Ad with $\mathrm{P}_{4}$ resulted in the isolation of an orange-brown solid. Recrystallization and determination of the structures by X-ray diffraction revealed the compounds to be $\left[\left\{\mathrm{U}(\mathrm{N}[\mathrm{Xy}] \mathrm{R})_{3}\right\}_{2}\left(\mu-\eta^{4}: \eta^{4}-\mathrm{P}_{4}\right)\right]\left(\mathrm{R}=\mathrm{Bu}^{\mathrm{t}}, \mathbf{2 0 6} \mathrm{Bu} ; \mathrm{R}=\mathrm{Ad}, \mathbf{2 0 6} \mathrm{Ad}\right)$ where two edges of the $\mathrm{P}_{4}$ tetrahedron have been cleaved to produce a planar $\left[\mathrm{P}_{4}\right]^{2-}$ square, ${ }^{[212]}$ Figure 38. A similar activation of $\mathrm{P}_{4}$ in an organometallic context was reported in 2011. Treatment of 190THF with $\mathrm{P}_{4}$ resulted in cleavage of two $\mathrm{P}-\mathrm{P}$ bonds to give a $\left[\mathrm{P}_{4}\right]^{2-}$ planar square in $\left[\left\{\mathrm{U}\left(\eta^{5}-\right.\right.\right.$ $\left.\left.\left.\mathrm{C}_{5} \mathrm{Me}_{5}\right)\left[\eta^{8}-1,4-\left(\mathrm{SiPr}_{3}^{\mathrm{i}}\right)_{2} \mathrm{C}_{8} \mathrm{H}_{4}\right]\right\}_{2}\left(\mu-\eta^{2}: \eta^{2}-\mathrm{P}_{4}\right)\right](\mathbf{2 0 7}),{ }^{[213]}$ Figure 38 . However, the $\left[\mathrm{P}_{4}\right]^{2-}$ square in 207 is not bonded $\eta^{4}$ to each uranium, and rather the $\left[\mathrm{P}_{4}\right]^{2-}$ unit 'slips' to bind $\eta^{2}$ to each uranium. Theoretical calculations suggest that by adopting an $\eta^{2}$ coordination mode to each uranium ion the $\left[\mathrm{P}_{4}\right]^{2-}$ square can engage in $\sigma$ and $\pi$ bonding, however it is likely this 'slipped' coordination mode results from best steric fit into the wedge shape of the $\left[U\left(\eta^{5}-C_{5} M_{5}\right)\left\{\eta^{8}-1,4-\left(\operatorname{SiPr}_{3}{ }_{2}\right)_{2} \mathrm{C}_{8} \mathrm{H}_{4}\right\}\right]$ unit. 


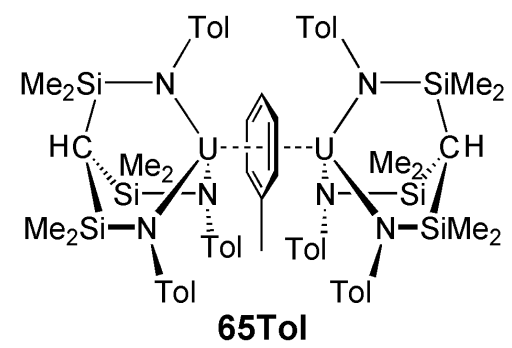

1.1 $\mathrm{P}_{4} \downarrow$-Toluene

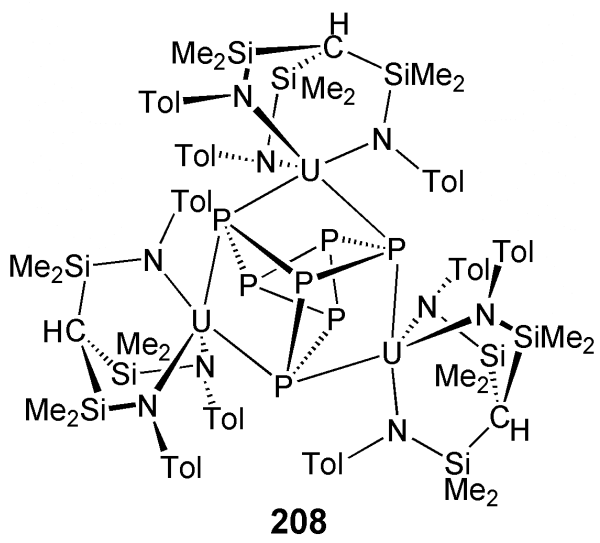

Scheme 39. Reaction of 65Tol with white phosphorus to produce the Zintl complex 208.

In the two examples above cleavage of two $\mathrm{P}-\mathrm{P}$ bonds of $\mathrm{P}_{4}$ occurs along with two-electron reduction. However, in 2013 the activation of $\mathrm{P}_{4}$ by $\mathbf{6 5 T o l}$ to give the first actinide Zintl $\left[\mathrm{P}_{7}\right]^{3-}$ cluster $\left[\left\{\mathrm{U}\left(\mathrm{HC}\left[\mathrm{SiMe}_{2} \mathrm{NAr}\right]_{3}\right)\right\}_{3}\left(\mu_{3}-\eta^{2}: \eta^{2}: \eta^{2}-\mathrm{P}_{7}\right)\right](\mathbf{2 0 8}, \mathrm{Ar}=\mathrm{Tol})$ was reported, ${ }^{[118]}$ Scheme 39. This example is unusual since wholesale reorganization of $\mathrm{P}_{4}$ occurs with catenation to generate the $\left[\mathrm{P}_{7}\right]^{3-}$, which in a wider context is a generally rare occurrence, and binary uranium-phosphides do not form. It was shown that $\mathbf{2 0 8}$ could be treated with electrophiles to liberate $\left[\mathrm{P}_{7} \mathrm{R}_{3}\right]\left[\mathrm{R}=\mathrm{SiMe}_{3}\right.$, $\mathrm{Me}, \mathrm{Ph}, \mathrm{Li}(\mathrm{tmeda})]$ and so a synthetic cycle is closed that could be operated over two turn-overs in preliminary experiments.

\subsection{Alkanes}

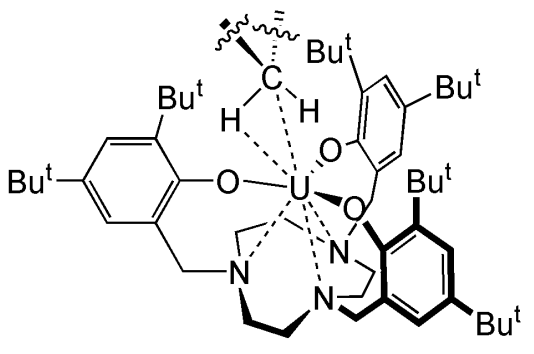

Alkane $=$ cyclohexane cyclopentane methylcyclohexane methylcyclopentane neohexane

Figure 39. The $\sigma$-alkane complex of uranium 209. 
There is intense interest in the study of $\sigma$-alkane complexes of transition metals because of the implications for $\mathrm{C}-\mathrm{H}$ activation reactions. Perhaps reflecting the limited capacity for orbital involvement in agostic-type bonding to one of the poorest donors ligand types, it is perhaps of no surprise to note that examples of genuine, unsupported $\sigma$-alkane complexes of uranium are almost unheard of. $^{[32 \mathrm{e}, 214]}$ However, in $2003 \sigma$-alkane complexes of uranium were reported. Utilizing a sterically demanding tris(aryloxide)tacn ligand, it was possible to engender a pocket of just the right size to kinetically stabilize an $\eta^{2}$-bound alkane, as determined by X-ray diffraction, at uranium(III) in $\left[\mathrm{U}\left\{\operatorname{tacn}\left(\mathrm{CH}_{2} \mathrm{C}_{6} \mathrm{H}_{2}-2-\mathrm{O}-3,5-\mathrm{Bu}_{2}^{\mathrm{t}}\right)_{3}\right\}(\right.$ alkane) $]$ (209, alkane = cyclohexane, cyclopentane, methylcyclohexane, methylcyclopentane, neohexane), ${ }^{[215]}$ Figure 39. A DFT study also suggests an $\eta^{2}$-bound alkane with a $\sigma$-type $U-R$ interaction involving a uranium $\mathrm{f}_{\mathrm{z}}$ orbital.

\section{Summary and Outlook}

With recent advances in techniques, methodologies, and analytical equipment the pace of advances has certainly quickened in recent years. Many new examples of the major uranium-ligand classes of alkyls, aryls, arenes, carbenes, amides, imidos, alkoxides, aryloxides, and oxos have been delivered, and several novel uranium-ligand linkages including terminal nitrides and heavier chalcogenides have now been achieved. Small molecule activation studies have revealed a diverse and truly unique array of novel reactivity, and many new molecules are exhibiting fascinating magnetic phenomena including single molecule magnetism. Given that sufficient numbers of well characterized compounds have now become available for further study, advances in spectroscopic and computational techniques are providing unprecedented opportunities to fully understand the complex electronic structure of non-aqueous uranium complexes. Considering the unique availability of frontier orbitals which uranium has at its disposal, many exciting advances are almost certainly just around the corner.

Looking to the future, the area is hardly begging for 'grand challenges'. Despite major advances in uranium-pnictide and -chalcogenide multiply bonded derivatives, a uranium-alkylidene and carbyne are targets still prominent by their absence under ambient conditions. ${ }^{[216]}$ Given the increasing recognition that an ITI might be beneficial to stabilizing multiply bonded linkages at uranium, perhaps such linkages can be realized by exploiting the ITI effect. The recent experimental reports of terminal uranium-nitride triple bonds suggest that with suitable supporting ligands terminal UE triple bonds $(\mathrm{E}=\mathrm{P}, \mathrm{As}, \mathrm{Sb}, \mathrm{Bi})$ could be accessible. With two examples of uranium(II) now reported, and even thorium(II) now known, ${ }^{[217]}$ it is tempting to speculate that molecular uranium(I) and (0) complexes might be isolable. Although uranium-metal bonds have not been discussed in this review, ${ }^{[26 e, h, 29 a, e]}$ and only a few examples are known, ${ }^{[218]}$ a uranium-uranium 
bond is unknown under 'normal' conditions, but would be of significant interest given the prevalence of group 6-group 6 metal-metal bonds. ${ }^{[219]}$ The isolation of a monomeric cis-uranyl and/or heavier chalcogen analogues would be of major interest in terms of assessing the magnitude of the ITI as well as providing comparison to cis(dioxo) complexes of group 6 metals. Much of the impressive small molecule activation chemistry of uranium hinges on the fact that uranium is highly reducing when low-valent; however, the 'sting in the tail' becomes evident when trying to return uranium to this state after activating a substrate to close reactivity cycles - high reactivity can be a double-edged sword. A challenge here would be to better balance reactivity cycles to make them catalytic. In this regard, no genuine single metal two-electron oxidative addition has yet been reported, reductive elimination remains incredibly rare, and the two have not been coupled together at uranium. Lastly, perhaps the biggest 'grand challenge' is to marry the synthesis and electronic structure characterization of non-aqueous uranium complexes in a complete framework, in order to realise routine, experimentally calibrated determinations of the nature and extent of covalency in the chemical bonding of uranium, and to relate this directly to reactivity and magnetism in an accurate and predictive capacity.

The Author is grateful for continued and generous support from the Royal Society, European Research Council, Engineering and Physical Sciences Research Council, European Union, University of Nottingham, UK National Nuclear Laboratory, and COST. Dr Benedict Gardner (University of Nottingham) is thanked for producing Figure 2.

\section{References}

[1] a) M. Tsutsui, N. Ely and R. Dubois, Acc. Chem. Res. 1976, 9, 217; b) T. J. Marks, Acc. Chem. Res. 1976, 9, 223.

[2] H. H. Dam, D. N. Reinhoudt, W. Verboom, Chem. Soc. Rev. 2007, 36, 367.

[3] a) The Chemistry of the Actinide and Transactinide Elements, $3^{\text {rd }}$ Ed. L. R. Morss, N. M. Edelstein, J. Fuger, J. J. Katz, Eds, Springer, Dordrecht, The Netherlands, 2006; b) M. J. Monreal, P. L. Diaconescu, Nat. Chem. 2010, 2, 424.

[4] a) The felements, N. Kaltsoyannis, P. Scott Eds, Oxford University Press, Oxford, UK, 1999; Lanthanide and Actinide Chemistry, S. Cotton Ed, John Wiley \& Sons Ltd, Chichester, England, 2006.

[5] a) P. B. Iveson, C. Rivière, D. Guillaneux, M. Nierlich, P. Thuéry, M. Ephritikhine, C. Madic, Chem. Commun. 2001, 1512; b) T. Mehdoui, J. -C. Berthet, P. Thuéry, M. Ephritikhine, Chem. Commun. 2005, 2860; c) Z. Kolarik, Chem. Rev. 2008, 108, 4208; d) M. B. Jones, A. J. Gaunt, J. C. Gordon, N. Kaltsoyannis, M. P. Neu, B. L. Scott, Chem. Sci. 2013, 4, 1189; e) P. 
J. Panak, A. Geist, Chem. Rev. 2013, 113, 1199.

[6] F. Haber, Ger. Pat. 1909, DE229126.

[7] F. H. Allen, Acta Cryst. Sect. B 2002, 58, 380.

[8] A. E. Comyns, Chem. Rev. 1960, 60, 115.

[9] K. W. Bagnall, Coord. Chem. Rev. 1967, 2, 145.

[10] J. Selbin, J. D. Ortego, Chem. Rev. 1969, 69, 657.

[11] U. Casellato, M. Vidali, P. A. Vigato, Coord. Chem. Rev. 1979, $28,231$.

[12] W. G. Van der Sluys, A. P. Sattelberger, Chem. Rev. 1990, 90, 1027.

[13] a) M. Pepper, B. E. Bursten, Chem. Rev. 1991, 91, 719; B. E. Bursten, R. J. Strittmatter, Angew. Chem. Int. Ed. Engl. 1991, 30, 1069.

[14] a) U. Kilimann, F. T. Edelmann, Coord. Chem. Rev. 1995, 141, 1; b) V. Alexander, Chem. Rev. 1995, 95, 273.

[15] a) Y. K. Gonko, F. T. Edelmann, Coord. Chem. Rev. 1996, 156, 1; b) J. Richter, F. T. Edelmann, Coord. Chem. Rev. 1996, 147, 373.

[16] F. T. Edelmann, Y. K. Gun'ko Coord. Chem. Rev. 1997, 165, 163.

[17] a) F. Nief, Coord. Chem. Rev. 1998, 178-180, 13; b) J. -C. Berthet, M. Ephritikhine, Coord. Chem. Rev. 1998, 178-180, 83.

[18] F. T. Edelmann, V. Lorenz, Coord. Chem. Rev. 2000, 209, 99.

[19] J. L. Sessler, A. E. Vivian, D. Seidel, A. K. Burrell, M. Hoehner, T. D. Mody, A. Gebauer, S. J. Weghorn, V. Lynch, Coord. Chem. Rev. 2001, 216-217, 411.

[20] a) W. J. Evans, B. L. Davis, Chem. Rev. 2002, 102, 2119; b) W. J. Evans, J. Organomet. Chem. 2002, 647, 2; c) W. J. Evans, J. Organomet. Chem. 2002, 652, 61.

[21] a) F. T. Edelmann, Coord. Chem. Rev. 2003, 247, 21; b) J. -Y. Hyeon, F. T. Edelmann, Coord. Chem. Rev. 2003, 241, 249.

[22] a) J. Drozdzynski, Coord. Chem. Rev. 2005, 249, 21; b) J. Gottfriedsen, F. T. Edelmann, Coord. Chem. Rev. 2005, 249, 919; c) J. -Y. Hyeon, J. Gottfriedsen, F. T. Edelmann, Coord. Chem. Rev. 2005, 249, 2787.

[23] a) J. Gottfriedsen, F. T. Edelmann, Coord. Chem. Rev. 2006, 250, 2347; b) F. T. Edelmann, Coord. Chem. Rev. 2006, 250, 2511; c) M. A. Denecke, Coord. Chem. Rev. 2006, 250, 730; d) J. K. Gibson, J. Marçalo, Coord. Chem. Rev. 2006, 250, 776; e) J. L. Sessler, P. J. Melfi, G. D. Pantos, Coord. Chem. Rev. 2006, 250, 816; f) W. J. Evans, S. A. Kozimor, Coord. Chem. Rev. 2006, 250, 911; g) I. Castro-Rodríguez, K. Meyer, Chem. Commun. 2006, 1353; h) P. L. Arnold, S. T. Liddle, Chem. Commun. 2006, 3959; i) M. Ephritikhine, Dalton Trans. 2006, 2501.

[24] a) J. Gottfriedsen, F. T. Edelmann, Coord. Chem. Rev. 2007, 251, 142; b) S. T. Liddle, I. S. 
Edworthy, P. L. Arnold, Chem. Soc. Rev. 2007, 36, 1732; c) W. J. Evans, Inorg. Chem. 2007, 46, 3435.

[25] a) A. R. Fox, S. C. Bart, K. Meyer, C. C. Cummins, Nature 2008, 455, 341; b) S. Mishra, Coord. Chem. Rev. 2008, 252, 1996; c) M. Sharma, M. S. Eisen, Struct. Bonding (Berlin) 2008, 127, 1; d) O. T. Summerscales, F. G. N. Cloke, Struct. Bonding (Berlin) 2008, 127, 87; e) S. C. Bart, K. Meyer, Struct. Bonding (Berlin) 2008, 127, 119; f) T. Andrea, M. S. Eisen, Chem. Soc. Rev. 2008, 37, 550.

[26] a) F. T. Edelmann, Coord. Chem. Rev. 2009, 253, 343; b) F. T. Edelmann, Coord. Chem. Rev. 2009, 253, 2515; c) O. P. Lam, C. Anthon, K. Meyer, Dalton Trans. 2009, 9677; d) P. L. Arnold, I. J. Casely, Chem. Rev. 2009, 109, 3599; e) S. T. Liddle, Phil. Trans. R. Soc. A. 2009, 465, 1673; f) C. R. Graves, J. L. Kiplinger, Chem. Commun. 2009, 3831; g) P. L. Arnold, J. B. Love, D. Patel, Coord. Chem. Rev. 2009, 253, 1973; h) S. T. Liddle, D. P. Mills, Dalton Trans. 2009, 5569.

[27] a) T. W. Hayton, Dalton Trans. 2010, 39, 1145; b) S. T. Liddle, D. P. Mills, A. J. Wooles, Organomet. Chem. 2010, 36, 29; c) S. Fortier, T. W. Hayton, Coord. Chem. Rev. 2010, 254, 197.

[28] a) S. T. Liddle, D. P. Mills, A. J. Wooles, Chem. Soc. Rev. 2011, 40, 2164; b) F. T. Edelmann, Coord. Chem. Rev. 2011, 255, 1834.

[29] a) M. V. Butovski, R. Kempe, Chem. E. J. 2012, 18, 13566; b) O. P. Lam, K. Meyer, Polyhedron 2012, 32, 1; c) R. J. Baker, Coord. Chem. Rev. 2012, 256, 2843; d) L. S. Natrajan, Coord. Chem. Rev. 2012, 256, 1583; e) D. Patel, S. T. Liddle, Rev. Inorg. Chem. 2012, 32, 1; f) F. T. Edelmann, Coord. Chem. Rev. 2012, 256, 1151; g) F. T. Edelmann, Coord. Chem. Rev. 2012, 256, 2641.

[30] a) F. T. Edelmann, Coord. Chem. Rev. 2013, 257, 1122; b) H. S. La Pierre, K. Meyer, Inorg. Chem. 2013, 52, 529; c) M. Ephritikhine, Organometallics 2013, 32, 2464; d) L. A. Seaman, J. R. Walensky, G. Wu, T. W. Hayton, Inorg. Chem. 2013, 52, 3556; e) T. W. Hayton, Chem. Commun. 2013, 49, 2956; f) M. B. Jones, A. J. Gaunt, Chem. Rev. 2013, 113, 1137; g) M. Ephritikhine, Comptes Rendu Chimie 2013, 16, 391; h) M. L. Neidig, D. L. Clark, R. L. Martin, Coord. Chem. Rev. 2013, 257, 394; i) N. Kaltsoyannis, Inorg. Chem. 2013, 52, 3407; j) B. M. Gardner, S. T. Liddle, Eur. J. Inorg. Chem. 2013, 3753.

[31] a) F. T. Edelmann, Coord. Chem. Rev. 2014, 261, 73; b) H. S. La Pierre, K. Meyer, Prog. Inorg. Chem. 2014, 58, 303; c) D. R. Kindra, W. J. Evans, Chem. Rev. 2014, 114, 8865; d) D. M. King, S. T. Liddle, Coord. Chem. Rev. 2014, 266-267, 2; e) M. J. Polinski, E. M. Villa, T. E. Albrecht-Schmitt, Coord. Chem. Rev. 2014, 266-267, 16; f) F. Abraham, B. Arab-Chapelet, M. Rivenet, C. Tamain, S. Grandjean, Coord. Chem. Rev. 2014, 266-267, 28; g) T. Loiseau, I. 
Mihalcea, N. Henry, C. Volkringer, Coord. Chem. Rev. 2014, 266-267, 69; h) R. J. Baker, Coord. Chem. Rev. 2014, 266-267, 123; i) J. -P. Dognon, Coord. Chem. Rev. 2014, 266-267, 110; j) R. J. Baker, Coord. Chem. Rev. 2014, 266-267, 123; k) B. L. Scott, J. J. Joyce, T. D. Durakiewicz, R. L. Martin, T. M. McCleskey, E. Bauer, H. Luo, Q. Jia, Coord. Chem. Rev. 2014, 266-267, 137; 1) C. E. Hayes, D. B. Leznoff, Coord. Chem. Rev. 2014, 266-267, 155; m) L. S. Natrajan, A. N. Swinburne, M. B. Andrews, S. Randall, S. L. Heath, Coord. Chem. Rev. 2014, 266-267, 171.

[32] a) F. T. Edelmann, Coord. Chem. Rev. 2015, 284, 124; b) S. A. Johnson, S. C. Bart, Dalton Trans. 2015, 44, in press; c) S. T. Liddle, Coord. Chem. Rev. 2015, in press; d) K. R. Meihaus, J. R. Long, Dalton Trans. 2015, in press; e) P. L. Arnold, M. W. McMullon, J. Rieb, F. E. Kühn, Angew. Chem. Int. Ed. 2015, in press.

[33] a) K. E. Knope, L. Soderholm, Chem. Rev. 2013, 113, 944; b) C. Walther, M. A. Denecke, Chem. Rev. 2013, 113, 995; c) X. -D. Wen, R. L. Martin, T. M. Henderson, G. E. Scuseria, Chem. Rev. 2013, 113, 1063; d) J. Qiu, P. C. Burns, Chem. Rev. 2013, 113, 1097; M. B. Andrews, C. L. Cahill, Chem. Rev. 2013, 113, 1121.

[34] a) V. A. Cocalia, K. E. Gutowski, R. D. Rodgers, Coord. Chem. Rev. 2006, 250, 755; b) K. Binnemans, Chem. Rev. 2007, 107, 2592; c) X. Sun, H. Luo, S. Dai, Chem. Rev. 2012, 112, 2100 .

[35] C. J. Jones, $d$ - and f-Block Chemistry, Polestar Wheatons Ltd., Exeter, UK, 2001.

[36] A. Vértes, S. Nagy, Z. Klencsár, Handbook of Nuclear Chemistry, Volume 2, Kluwer Academic Publishers, Dordrecht, Amsterdam, 2003.

[37] a) J. Blaise, J.-F. Wyatt, International Tables of Selected Constants, Vol. 20, 1992; b)W. J. Liu,W. Kuchle, M. Dolg, Phys. Rev. A 1998, 58, 1103; c) X. Y. Cao, M. Dolg, Mol. Phys. 2003, 101, 961; d) B. A. Palmer, R. Engleman, J. Opt. Soc. Am. 1984, 1, 609.

[38] B. E. Bursten, L. F. Rhodes, R. J. Strittmatter, J. Am. Chem. Soc. 1989, 111, 2756.

[39] M. R. MacDonald, M. E. Fieser, J. E. Bates, J. W. Ziller, F. Furche, W. J. Evans, J. Am. Chem. Soc. 2013, 135, 13310.

[40] H. S. La Pierre, A. Scheurer, F. W. Heinemann, W. Hieringer, K. Meyer, Angew. Chem. Int. Ed. 2014, 53, 7158 .

[41] a) D. E. Morris, R. E. Da Re, K. C. Jantunen, I. Castro-Rodriguez, J. L. Kiplinger, Organometallics 2004, 23, 5142; b) C. R. Graves, P. Yang, S. A. Kozimor, A. E. Vaughn, D.

L. Clark, S. D. Conradson, E. J. Schelter, B. L. Scott, J. D. Thompson, P. J. Hay, D. E. Morris, J. L. Kiplinger, J. L. J. Am. Chem. Soc. 2008, 130, 5272.

[42] N. Edelstein, D. Brown, B. Whittaker, Inorg. Chem. 1974, 13, 563.

[43] J. L. Ryan, J. Inorg. Nucl. Chem. 1971, 33, 153. 
[44] a) D. M. King, F. Tuna, E. J. L. McInnes, J. McMaster, W. Lewis, A. J. Blake, S. T. Liddle, Science 2012, 337, 717 ; b) O. J. Cooper, D. P. Mills, J. McMaster, F. Tuna, E. J. L. McInnes, W. Lewis, A. J. Blake, S. T. Liddle, Chem. Eur. J. 2013, 19, 7071.

[45] D. P. Halter, H. S. La Pierre, F. W. Heinemann, K. Meyer, Inorg. Chem. 2014, 53, 8418.

[46] J. W. Bruno, H. A. Stecher, L. R. Morss, D. C. Sonnenberger, T. J. Marks, J. Am. Chem. Soc. 1986, 108,7275 .

[47] a) S. A. Kozimor, P. Yang, E. R. Batista, K. S. Boland, C. J. Burns, D. L. Clark, S. D. Conradson, R. L. Martin, M. P. Wilkerson, L. E. Wolfsberg, J. Am. Chem. Soc. 2009, 131, 12125; b) S. G. Minasian, J. M. Keith, E. R. Batista, K. S. Boland, D. L. Clark, S. D. Conradson, S. A. Kozimor, R. L. Martin, D. E. Schwarz, D. K. Shuh, G. L. Wagner, M. P. Wilkerson, L. E. Wolfsberg, P. Yang, J. Am. Chem. Soc. 2012, 134, 5586; c) L. P. Spencer, P. Yang, S. G. Minasian, R. E. Jilek, E. R. Batista, K. S. Boland, J. M. Boncella, S. D. Conradson, D. L. Clark, T. W. Hayton, S. A. Kozimor, R. L. Martin, M. M. MacInnes, A. C. Olson, B. L. Scott, D. K. Shuh, M. P. Wilkerson, J. Am. Chem. Soc. 2013, 135, 2279; d) S. G. Minasian, J. M. Keith, E. R. Batista, K. S. Boland, D. L. Clark, S. A. Kozimor, R. L. Martin, D. K. Shuh, T. Tyliszczak, Chem. Sci. 2014, 5, 351.

[48] A. Streitwieser Jnr, U. Müller-Westerhoff, J. Am. Chem. Soc. 1968, 90, 7364.

[49] a) R. G. Denning, Struct. Bonding (Berlin) 1992, 79, 215; b) E. O’Grady, N. Kaltsoyannis, J. Chem. Soc. Dalton Trans. 2002, 1233; c) R. G. Denning, J. Phys. Chem. A 2007, 111, 4125.

[50] a) O. P. Lam, S. M. Franke, H. Nakai, F. W. Heinemann, W. Hieringer, K. Meyer, Inorg. Chem. 2012, 51, 6190; b) D. M. King, F. Tuna, E. J. L. McInnes, J. McMaster, W. Lewis, A. J. Blake, S. T. Liddle, Nat. Chem. 2013, 5, 482; c) D. M. King, F. Tuna, J. McMaster, W. Lewis, A. J. Blake, E. J. L. McInnes, S. T. Liddle, Angew. Chem. Int. Ed. 2013, 52, 4921; d) A. J. Lewis, K. C. Mullane, E. Nakamaru-Ogiso, P. J. Carroll, E. J. Schelter, Inorg. Chem. 2014, 53, 6944.

[51] T. J. Marks, Science, 1982, 217, 989.

[52] a) A. M. Seyam, Inorg. Chim. Acta 1982, 58, 71; b) S. J. Kraft, P. E. Fanwick, S. C. Bart, J. Am. Chem. Soc. 2012, 134, 6160.

[53] a) R. G. Finke, Y. Hirose, G. Gaughan, J. Chem. Soc. Chem. Comm. 1981, 232; b) R. G. Finke, D. A. Schiraldi, Y. Hirose, J. Am. Chem. Soc. 1981, 103, 1875; c) P. J. Fagan, J. M. Manriquez, T. J. Marks, C. S. Day, S. H. Vollmer, V. W. Day, Organometallics 1982, 1, 170; d) C. Villiers, M. Ephritikhine, J. Organomet. Chem. 1990, 393, 339; e) R. Adam, C. Villiers, M. Ephritikhine, M. Lance, M. Nierlich, J. Vigner, J. Organomet. Chem. 1993, 445, 99; f) L. P. Spencer, P. Yang, B. L. Scott, E. R. Batista, J. M. Boncella, Inorg. Chem. 2009, 48, 11615; g) S. J. Kraft, U. J. Williams, S. R. Daly, E. J. Schelter, S. A. Kozimor, K. S. Boland, J. M. 
Kikkawa, W. P. Forrest, C. N. Christensen, D. E. Schwarz, P. E. Fanwick, D. L. Clark, S. D. Conradson, S. C. Bart, Inorg. Chem. 2011, 50, 9838; h) E. M. Matson, S. R. Opperwall, P. E. Fanwick, S. C. Bart, Inorg. Chem. 2013, 52, 7295; i) W. J. Evans, K. A. Miller, S. A. Kozimor, J. W. Ziller, A. G. DiPasquale, A. L. Rheingold, Organometallics 2007, 26, 3568; j) W. J. Evans, E. Montalvo, S. A. Kozimor, K. A. Miller, J. Am. Chem. Soc. 2008, 130, 12258.

[54] a) J. D. Corbett, Inorg. Synth. 1983, 22, 31; b) F. G. N. Cloke, P. B. Hitchcock, J. Am. Chem. Soc. 2002, 124, 9352.

[55] W. J. Evans, S. A. Kozimor, J. W. Ziller, A. A. Fagin, M. N. Bochkarev, Inorg. Chem. 2005, 44, 3993.

[56] a) D. L. Clark, A. P. Sattelberger, S. G. Bott, R. N. Vrtis, Inorg. Chem. 1989, 28, 1771; b) L. R. Avens, S. G. Bott, D. L. Clark, A. P. Sattelberger, J. G. Watkin, B. D. Zwick, Inorg. Chem. 1994, 33, 2248.

[57] C. D. Carmichael, N. A. Jones, P. L. Arnold, Inorg. Chem. 2008, 47, 8577.

[58] M. J. Monreal, R. K. Thomson, T. Cantat, N. E. Travia, B. L. Scott, J. L. Kiplinger, Organometallics 2011, 30, 2031.

[59] D. C. Moody, J. D. Odom, J. Inorg. Nucl. Chem. 1979, 41, 533.

[60] H. S. La Pierre, F. W. Heinemann, K. Meyer, Chem. Commun. 2014, 50, 3962.

[61] a) J. A. Hermann, J. F. Suttle, Inorg. Synth. 1957, 5, 143; b) E. Uhlemann, W. Fischbach, Z. Chem. 1963, 3, 431; c) I. A. Khan, H. S. Ahuja, Inorg. Synth. 1982, 21, 187; d) J. L. Kiplinger, D. E. Morris, B. L. Scott, C. J. Burns, Organometallics 2002, 21, 5978.

[62] W. G. van der Sluys, J. M. berg, D. Barnhardt, N. N. Sauer, Inorg. Chim. Acta 1993, 204, 251.

[63] D. D. Schnaars, G. Wu, T. W. Hayton, Dalton Trans. 2008, 6121.

[64] K. W. Bagnall, D. Brown, P. J. Jones, J. G. H. du Preez, J. Chem. Soc. 1965, 350.

[65] a) J. -C. Berthet, P. Thuéry, M. Ephritikhine, Inorg. Chem. 2005, 44, 1142; b) A. E. Enriquez, B. L. Scott, M. P. Neu, Inorg. Chem. 2005, 44, 7403.

[66] G. Nocton, J. Pécaut, M. Mazzanti, Angew. Chem. Int. Ed. 2008, 47, 3040.

[67] H. J. Sherrill, D. G. Durret, J. Selbin, Inorg. Synth. 1974, 15, 243.

[68] M. P. Wilkerson, C. J. Burns, R. T. Paine, B. L. Scott, Inorg. Chem. 1999, 38, 4156.

[69] a) J. Rebizant, G. van den Bossche, M. R. Spirlet, J. Goffart, Acta Cryst. Sect C 1987, 43, 1298; b) J. -C. Berthet, M. Nierlich, M. Ephritikhine, Chem. Commun. 2004, 870; c) J. -C Berthet, G. Siffredi, P. Thuéry, M. Ephritikhine, Dalton Trans. 2009, 3478.

[70] a) J. -C. Berthet, M. Lance, M. Nierlich, M. Ephritikhine, Eur. J. Inorg. Chem. 2000, 1969;

b) S. M. Oldham, B. L. Scott, W. J. Oldham Jnr, Appl. Organomet. Chem. 2006, 20, 39.

[71] L. Natrajan, F. Burdet, J. P. Pécaut, M. Mazzanti, J. Am. Chem. Soc. 2006, 128, 7152.

[72] a) L. T. Reynolds, G. Wilkinson, J. Inorg. Nucl. Chem. 1956, 2, 246; b) C. -H. Wong, T. -M. 
Yen, T. -Y. Lee, Acta Cryst. 1965, 18, 340.

[73] E. O. Fischer, Y. Hristidu, Z. Naturforsch. 1962, 17, 275.

[74] B. Kanellakopulos, E. O. Fischer, E. Dornberger, F. Baumgärtner, J. Organomet. Chem. 1970, $24,507$.

[75] a) A. Streitwieser Jnr, U. Müller-Westerhoff, J. Am. Chem. Soc. 1968, 90, 7364; b) A. Zalkin, K. N. Raymond, J. Am. Chem. Soc. 1969, 91, 5667.

[76] T. J. Marks, A. M. Seyam, J. R. Kolb, J. Am. Chem. Soc. 1973, 95, 5529.

[77] P. G. Edwards, R. A. Andersen, A. Zalkin, Organometallics 1984, 3, 293.

[78] B. M. Gardner, P. A. Cleaves, C. E. Kefalidis, J. Fang, L. Maron, W. Lewis, A. J. Blake, S. T. Liddle, Chem. Sci. 2014, 5, 2489.

[79] W. G. van der Sluys, C. J. Burns, A. P. Sattelberger, Organometallics 1990, 8, 855.

[80] a) S. Fortier, B. C. Melot, G. Wu, T. W. Hayton, J. Am. Chem. Soc. 2009, 131, 15512; b) S. Fortier, J. Walensky, G. Wu, T. W. Hayton, J. Am. Chem. Soc. 2011, 133, 11732.

[81] L. A. Seaman, P. Hrobárik, M. F. Schettini, S. Fortier, M. Kaupp, T. W. Hayton, Angew. Chem. Int. Ed. 2013, 52, 3259.

[82] L. A. Seaman, E. A. Pedrick, T. Tsuchiya, G. Wu, E. Jakubikova, T. W. Hayton, Angew. Chem. Int. Ed. 2013, 52, 10589.

[83] a) W. J. Evans, J. R. Walensky, J.W. Ziller, A. L. Rheingold, Organometallics 2009, 28, 3350; b) P. J. Fagan, J. M. Manriquez, E. A. Maatta, A. M. Seyam, T. J. Marks, J. Am. Chem. Soc. 1981, 103, 6650 .

[84] W. J. Evans, K. J. Forrestal, J. W. Ziller, J. Am. Chem. Soc. 1997, 36, 774.

[85] W. J. Evans, T. J. Mueller, J. W. Ziller, Chem. Eur. J. 2010, 16, 964.

[86] a) C. R. Graves, B. L. Scott, D. E. Morris, J. L. Kiplinger, J. Am. Chem. Soc. 2007, 129, 11914; b) C. R. Graves, P. Yang, S. A. Kozimor, A. E. Vaughn, D. L. Clark, S. D. Conradson, E. J. Schelter, B. L. Scott, J. D. Thompson, P. J. Hay, D. E. Morris, J. L. Kiplinger, J. Am. Chem. Soc. 2008, 130, 5272; c) C. R. Graves, A. E. Vaughn, E. J. Schelter, B. L. Scott, J. D. Thompson, D. E. Morris, J. L. Kiplinger, Inorg. Chem. 2008, 47, 11879.

[87] a) J. Maynadié, J. -C. Berthet, P. Thuéry, M. Ephritikhine, J. Am. Chem. Soc. 2006, 128, 1082; b) J. Maynadié, J. -C. Berthet, P. Thuéry, M. Ephritikhine, Organometallics 2006, 25, 5603; c) J. Maynadié, N. Barros, J. -C. Berthet, P. Thuéry, L. Maron, M. Ephritikhine, Angew. Chem. Int. Ed. 2007, 46, 2010.

[88] J. -C. Berthet, P. Thuéry, M. Ephritikhine, Organometallics 2008, 27, 1664.

[89] J. -C. Berthet, P. Thuéry, N. Garin, J. -P. Dognon, T. Cantat, M. Ephritikhine, J. Am. Chem. Soc. 2013, 135, 10003.

[90] R. K. Sheline, J. L. Slater, Angew. Chem. Int. Ed. 1975, 14, 309. 
[91] J. G. Brennan, R. A. Andersen, J. L. Robbins, J. Am. Chem. Soc. 1986, 108, 335.

[92] J. Parry, E. Carmona, S. Coles, M. Hursthouse, J. Am. Chem. Soc. 1995, 117, 2649.

[93] W. J. Evans, S. A. Kozimor, G. W. Nyce, J. W. Ziller, J. Am. Chem. Soc. 2003, 125, 13831.

[94] I. Castro-Rodriguez, K. Meyer, J. Am. Chem. Soc. 2005, 127, 11242.

[95] L. Maron, O. Eisenstein, R. A. Andersen, Organometallics 2009, 28, 3629.

[96] W. J. Oldham Jnr, S. M. Oldham, B. L. Scott, K. D. Abney, W. H. Smith, D. A. Costa, Chem. Commun. 2001, 1348.

[97] H. Nakai, X. Hu, L. N. Zakharov, A. L. Rheingold, K. Meyer, Inorg. Chem. 2004, 43, 855.

[98] P. L. Arnold, A. J. Blake, C. Wilson, Chem. Eur. J. 2005, 11, 6095.

[99] R. E. Cramer, R. B. Maynard, J. C. Paw, J. W. Gilje, J. Am. Chem. Soc. 1981, 103, 3589.

[100] J. W. Gilje, R. E. Cramer, Inorg. Chim. Acta 1987, 139, 177.

[101] O. J. Cooper, D. P. Mills, J. McMaster, F. Moro, E. S. Davies, W. Lewis, A. J. Blake, S. T. Liddle, Angew. Chem. Int. Ed. 2011, 50, 2383.

[102] D. P. Mills, O. J. Cooper, F. Tuna, E. J. L. McInnes, E. S. Davies, J. McMaster, F. Moro, W. Lewis, A. J. Blake, S. T. Liddle, J. Am. Chem. Soc. 2012, 134, 10047.

[103] a) D. P. Mills, L. Soutar, W. Lewis, A. J. Blake, S. T. Liddle, J. Am. Chem. Soc. 2010, 132, 14379; b) M. Gregson, E. Lu, J. McMaster, W. Lewis, A. J. Blake, and S. T. Liddle, Angew. Chem. Int. Ed. 2013, 52, 13016.

[104] a) T. Cantat, T. Arliguie, A. Noël, P. Thuéry, M. Ephritikhine, P. Le Floch, N. Mézailles, J. Am. Chem. Soc. 2009, 131, 963; b) J. -C. Tourneux, J. -C. Berthet, T. Cantat, P. Thuéry, N. Mézailles, P. Le Floch, M. Ephritikhine, Organometallics 2011, 30, 2957.

[105] J.-C. Tourneaux, J.-C. Berthet, T. Cantat, P. Thuéry, N. Mézailles, M. Ephritikhine, J. Am. Chem. Soc. 2011, 133, 6162.

[106] a) M. J. Sarsfield, M. Helliwell, D. Collison, Chem. Commun. 2002, 2264; b) M. J. Sarsfield, H. Steele, M. Helliwell, S. J. Teat, Dalton Trans. 2003, 3443; c) J. -C. Berthet, P. Thuéry, M. Ephritikhine, Chem. Commun. 2007, 604.

[107] J. Maynadié, J. -C. Berthet, P. Thuéry, M. Ephritikhine, Chem. Commun. 2007, 486.

[108] E. Lu, O. J. Cooper, J. McMaster, F. Tuna, E. J. L. McInnes, W. Lewis, A. J. Blake, S. T. Liddle, Angew. Chem. Int. Ed. 2014, 53, 6696.

[109] S. Fortier, J. R. Walensky, G. Wu, T. W. Hayton, J. Am. Chem. Soc. 2011, 133, 6894.

[110] a) M. Zhou, L. Andrews, J. Li, B. E. Bursten, J. Am. Chem. Soc. 1999, 121, 9712; b) J. Li, B.

E. Bursten, B. Liang, L. Andrews, Science 2002, 295, 2242; c) L. Andrews, B. Liang, J. Li, B.

E. Bursten, J. Am. Chem. Soc. 2003, 125, 3126.

[111] M. Cesari, U. Pedretti, A. Zazetta, G. Lugli, W. Marconi, Inorg. Chim. Acta 1971, 5, 439.

[112] P. L. Diaconescu, P. L. Arnold, T. A. Baker, D. J. Mindiola, C. C. Cummins, J. Am. Chem. 
Soc. 2000, 122, 6108.

[113] P. L. Diaconescu, C. C. Cummins, J. Am. Chem. Soc. 2002, 124, 7660.

[114] W. J. Evans, S. A. Kozimor, J. W. Ziller, N. Kaltsoyannis, J. Am. Chem. Soc. 2004, 126, 14533.

[115] P. L. Arnold, S. M. Mansell, L. Maron, D. McKay, Nat. Chem. 2012, 4, 668.

[116] a) D. Patel, F. Moro, J. McMaster, W. Lewis, A. J. Blake, S. T. Liddle, Angew. Chem. Int. Ed. 2011, 50, 10388; b) D. Patel, F. Tuna, E. J. L. McInnes, J. McMaster, W. Lewis, A. J. Blake, S. T. Liddle, Dalton Trans. 2013, 42, 5224.

[117] D. Patel, J. McMaster, W. Lewis, A. J. Blake, S. T. Liddle, Nat. Commun. 2013, 4:2323, doi:10.1038/ncomms3323.

[118] a) D. Patel, F. Tuna, E. J. L. McInnes, W. Lewis, A. J. Blake, S. T. Liddle, Angew. Chem. Int. Ed. 2013, 52, 13334.

[119] a) V. Mougel, C. Camp, J. Pécaut, C. Copéret, L. Maron, C. E. Kefalidis, M. Mazzanti, Angew. Chem. Int. Ed. 2012, 51, 12280; b) C. Camp, V. Mougel, J. Pécaut, L. Maron, M. Mazzanti, Chem. Eur. J. 2013, 19, 17528.

[120] M. L. H. Green, D. K. P. Ng, Chem. Rev. 1995, 95, 439.

[121] a) T. Arliguie, M. Lance, M. Nierlich, J. Vigner, M. Ephritikhine, J. Chem. Soc. Chem. Commun. 1994, 847; b) T. Arliguie, M. Lance, M. Nierlich, J. Vigner, M. Ephritikhine, J. Chem. Soc. Chem. Commun. 1995, 183.

[122] J. Li, B. E. Bursten, J. Am. Chem. Soc. 1997, 119, 9021.

[123] N. A. Siladke, K. R. Meihaus, J. W. Ziller, M. Fang, F. Furche, J. R. Long, W. J. Evans, J. Am. Chem. Soc. 2012, 134, 1243.

[124] B. E. Bursten, L. F. Rhodes, R. J. Strittmatter, J. Am. Chem. Soc. 1989, 111, 2758.

[125] a) R. A. Andersen, A. Zalkin, D. H. Templeton, Inorg. Chem. 1981, 20, 622; b) J. L. Stewart, R. A. Andersen, Polyhedron 1988, 17, 953; c) S. M. Mansell, B. F. Perandones, P. L. Arnold, J. Organomet. Chem. 2010, 695, 2814.

[126] K. C. Mullane, A. J. Lewis, H. Yin, P. J. Carroll, E. J. Schelter, Inorg. Chem. 2014, 53, 9129.

[127] C. A. P. Goodwin, F. Tuna, E. J. L. McInnes, S. T. Liddle, J. McMaster, I. J. VitoricaYrezabal, D. P. Mills, Chem. Eur. J. 2014, 20, 14579.

[128] W. J. Evans, D. S. Lee, D. B. Rego, J. M. Perotti, S. A. Kozimor, E. K. Moore, J. W. Ziller, J. Am. Chem. Soc. 2004, 126, 14574.

[129] a) S. J. Simpson, H. W. Turner, R. A. Andersen, Inorg. Chem. 1981, 20, 2991; b) A. Dormond, A. El Bouadili, A. Aaliti, C. Moise, J. Organomet. Chem. 1985, 288, C1; c) O. Bénaud, J. -C. Berthet, P. Thuéry, M. Ephritikhine, Inorg. Chem. 2010, 49, 8117.

[130] A. J. Lewis, U. J. Williams, P. J. Carroll, E. J. Schelter, Inorg. Chem. 2013, 52, 7326. 
[131] R. A. Andersen, Inorg. Chem. 1979, 18, 209.

[132] D. M. Barnhart, C. J. Burns, N. N. Sauer, J. G. Watkin, Inorg. Chem. 1995, 34, 4079.

[133] C. J. Burns, D. L. Clark, R. J. Donohoe, P. B. Duval, B. L. Scott, C. D. Tait, Inorg. Chem. 2000, 39, 5464.

[134] a) R. G. Jones, G. Karmas, G. A. Martin Jnr, H. Gilman, J. Am. Chem. Soc. 1956, 78, 4285; b) J. G. Reynolds, A. Zalkin, D. H. Templeton, N. M. Edelstein, L. K. Templeton, Inorg. Chem. 1976, 15, 2498.

[135] J. G. Reynolds, A. Zalkin, D. H. Templeton, N. M. Edelstein, Inorg. Chem. 1977, 16, 1090.

[136] H. Yin, A. J. Lewis, U. J. Williams, P. J. Carroll, E. J. Schelter, Chem. Sci. 2013, 4, 798.

[137] K. Meyer, D. J. Mindiola, T. A. Baker, W. M. Davis, C. C. Cummins, Angew. Chem. Int. Ed. 2000, 39, 3063.

[138] L. A. Seaman, S. Fortier, G. Wu, T. W. Hayton, Inorg. Chem. 2011, 50, 636.

[139] L. A. Seaman, G. Wu, N. M. Edelstein, W. W. Lukens, N. Magnani, T. W. Hayton, J. Am. Chem. Soc. 2012, 134, 4931.

[140] R. E. Cramer, K. Panchanatheswaran, J. W. Gilje, J. Am. Chem. Soc. 1984, 106, 1853.

[141] J. G. Brennan, R. A. Andersen, J. Am. Chem. Soc. 1985, 107, 514.

[142] A. Zalkin, J. G. Brennan, R. A. Andersen, Acta Cryst. Sect. C 1988, 44, 1553.

[143] C. J. Burns, W. H. Smith, J. C. Huffman, A. P. Sattelberger, J. Am. Chem. Soc. 1990, 112, 3237.

[144] a) D. S. J. Arney, C. J. Burns, D. C. Smith, J. Am. Chem. Soc. 1992, 114, 10068; b) D. S. J. Arney, C. J. Burns, J. Am. Chem. Soc. 1995, 117, 9448.

[145] D. J. S. Arney, C. J. Burns, J. Am. Chem. Soc. 1993, 115, 9840.

[146] P. B. Duval, C. J. Burns, W. E. Buschmann, D. L. Clark, D. E. Morris, B. L. Scott, Inorg. Chem. 2001, 40, 5491.

[147] I. Castro-Rodríguez, H. Nakai, K. Meyer, Angew. Chem. Int. Ed. 2006, 45, 2389.

[148] R. E. Jilek, L. P. Spencer, D. L. Kuiper, B. L. Scott, U. J. Williams, J. M. Kikkawa, E. J. Schelter, J. M. Boncella, Inorg. Chem. 2011, 50, 4235.

[149] D. M. King, J. McMaster, F. Tuna, E. J. L. McInnes, W. Lewis, A. J. Blake, and S. T. Liddle, J. Am. Chem. Soc., 2014, 136, 5619.

[150] a) T. W. Hayton, J. M. Boncella, B. L. Scott, P. D. Palmer, E. R. Batista, P. J. Hay, Science 2005, 310, 1941; b) T. W. Hayton, J. M. Boncella, B. L. Scott, E. R. Batista, P. J. Hay, J. Am. Chem. Soc. 2006, 128, 10549.

[151] L. P. Spencer, R. L. Gdula, T. W. Hayton, B. L. Scott, J. M. Boncella, Chem. Commun. 2008, 4986.

[152] T. W. Hayton, J. M. Boncella, B. L. Scott, E. R. Batista, J. Am. Chem. Soc. 2006, 128, 12622. 
[153] N. H. Anderson, S. O. Odoh, Y. Yao, U. J. Williams, B. A. Schaefer, J. J. Kiernicki, A. J. Lewis, M. D. Goshert, P. E. Fanwick, E. J. Schelter, J. R. Walensky, L. Gagliardi, S. C. Bart, Nat. Chem. 2014, 6, 919.

[154] a) D. W. Green, G. T. Reedy, J. Chem. Phys. 1976, 65, 2921; b) R. D. Hunt, J. T. Yustein, L. Andrews, J. Chem. Phys. 1993, 98, 6070; c) P. Pyykkö, J. Li, N. Runeberg, J. Phys. Chem. 1994, 98, 4809; d) C. Heinemann, H. Schwarz, Chem. Eur. J. 1995, 1, 7; e) M. Zhou, L. Andrews, J. Chem. Phys. 1999, 111, 11044; f) N. Kaltsoyannis, Inorg. Chem. 2000, 39, 6009; g) L. Andrews, X. Wang, R. Lindh, B. O. Roos, C. J. Marsden, Angew. Chem. Int. Ed. 2008, 47, 5366; h) D. J. Matthew, M. D. Morse, J. Chem. Phys. 2013, 138, 184303; i) L. Andrews, X. Wang, Y. Gong, B. Vlaisavljevich, L. Gagliardi, Inorg. Chem. 2013, 52, 9989.

[155] (a) I. Korobkov, S. Gambarotta, G. P. A. Yap, Angew. Chem. Int. Ed. 2002, 41, 3433); b) W. J. Evans, S. A. Kozimor, J. W. Ziller, Science 2005, 309, 1835; c) W. J. Evans, K. A. Miller, J. W. Ziller, J. Greaves, Inorg. Chem. 2007, 46, 8008; d) A. R. Fox, C. C. Cummins, J. Am. Chem. Soc. 2009, 131, 5716; e) A. R. Fox, P. L. Arnold, C. C. Cummins, J. Am. Chem. Soc. 2010, 132, 3250; f) S. Fortier, G. Wu, T. W. Hayton, J. Am. Chem. Soc. 2010, 132, 6888; g) T. K. Todorova, L. Gagliardi, J. R. Walensky, K. A. Miller, W. J. Evans, J. Am. Chem. Soc. 2010, 132, 12397; h) R. K. Thomson, T. Cantat, B. L. Scott, D. E. Morris, E. R. Batista, J. L. Kiplinger, Nat. Chem. 2010, 2, 723; i) C. Camp, J. Pécaut, M. Mazzanti, J. Am. Chem. Soc. 2013, 135, 12101.

[156] P. A. Cleaves, D. M. King, C. E. Kefalidis, L. Maron, F. Tuna, E. J. L. McInnes, J. McMaster, W. Lewis, A. J. Blake, S. T. Liddle, Angew. Chem. Int. Ed. 2014, 53, 10412.

[157] D. Baudry, M. Ephritikhine, F. Nief, L. Ricard, F. Mathey, Angew. Chem. Int. Ed. 1990, 29, 1485.

[158] S. W. Hall, J. C. Huffman, M. M. Miller, L. R. Avens, C. J. Burns, D. S. J. Arney, A. F. England, A. P. Sattelberger, Organometallics 1993, 12, 752.

[159] M. R. Duttera, V. W. Day, T. J. Marks, J. Am. Chem. Soc. 1984, 106, 2907.

[160] D. S. J. Arney, R. C. Schnabel, B. C. Scott, C. J. Burns, J. Am. Chem. Soc. 1996, 118, 6780.

[161] B. M. Gardner, G. Balázs, M. Scheer, F. Tuna, E. J. L. McInnes, J. McMaster, W. Lewis, A. J. Blake, S. T. Liddle, Angew. Chem. Int. Ed. 2014, 53, 4484.

[162] D. C. Bradley, A. K. Chatterjee, A. K. Chatterjee, J. Inorg. Nucl. Chem. 1959, 12, 71.

[163] F. A. Cotton, D. O. Marler, W. Schwotzer, Inorg. Chem. 1984, 23, 4211.

[164] P. G. Eller, P. J. Vergamini, Inorg. Chem. 1983, 22, 3184.

[165] S. Fortier, G. Wu, T. W. Hayton, Inorg. Chem. 2008, 47, 4752.

[166] W. G. van der Sluys, C. J. Burns, J. C. Huffman, A. P. Sattelberger, J. Am. Chem. Soc. 1988, 110, 5924. 
[167] W. G. van der Sluys, A. P. Sattelberger, W. E. Streib, J. C. Huffman, Polyhedron 1989, 8, 1247.

[168] a) G. Nocton, P. Horeglad, J. Pécaut, M. Mazzanti, J. Am. Chem. Soc. 2008, 130, 16633; b) V. Mougel, P. Horeglad, G. Nocton, J. Pécaut, M. Mazzanti, Angew. Chem. Int. Ed. 2009, 48, 8477; c) L. Chatelain, V. Mougel, J. Pécaut, M. Mazzanti, Chem. Sci. 2012, 3, 1075.

[169] a) D. D. Schnaars, G. Wu, T. W. Hayton, J. Am. Chem. Soc. 2009, 131, 17532; b) J. L. Brown, G. Wu, T. W. Hayton, J. Am. Chem. Soc. 2010, 132, 7248; c) E. A. Pedrick, G. Wu, N. Kaltsoyannis, T. W. Hayton, Chem. Sci. 2014, 5, 3204.

[170] a) E. Jacob, W. Polligkeit, Z. Naturforsch 1973, B28, 120; b) K. W. Bagnall, J. G. H. du Preez, B. J. Gellatly, J. Chem. Soc. Dalton Trans. 1975, 1963; c) J. F. de Wet, J. G. H. du Preez, J. Chem. Soc. Dalton Trans. 1978, 592.

[171] S. C. Bart, C. Anthon, F. W. Heinemann, E. Bill, N. M. Edelstein, K. Meyer, J. Am. Chem. Soc. 2008, 130, 12536.

[172] S. J. Kraft, J. Walensky, P. E. Fanwick, M. B. Hall, S. C. Bart, Inorg. Chem. 2010, 49, 7620.

[173] S. Fortier, N. Kaltsoyannis, G. Wu, T. W. Hayton, J. Am. Chem. Soc. 2011, 133, 14224.

[174] a) A. J. Lewis, P. J. Carroll, E. J. Schelter, J. Am. Chem. Soc. 2013, 135, 511; b) A. J. Lewis, P. J. Carroll, E. J. Schelter, J. Am. Chem. Soc. 2013, 135, 13185.

[175] B. Kosog, H. S. La Pierre, F. W. Heinemann, S. T. Liddle, K. Meyer, J. Am. Chem. Soc., 2012, 134, 5284.

[176] S. Fortier, J. L. Brown, N. Kaltsoyannis, G. Wu, T. W. Hayton, Inorg. Chem. 2012, 51, 1625.

[177] M. Roger, N. Barros, T. Arliguie, P. Thuéry, L. Maron, M. Ephritikhine, J. Am. Chem. Soc. 2006, 128, 8790.

[178] L. Belkhiri, T. Arliguie, P. Thuéry, M. Fourmigue, A. Boucekkine, M. Ephritikhine, Organometallics 2006, 25, 2782.

[179] a) O. P. Lam, F. W. Heinemann, K. Meyer, Chem. Sci. 2011, 2, 1538; b) J. L. Brown, G. Wu, T. W. Hayton, Organometallics 2013, 32, 1193; c) E. M. Matson, M. D. Goshert, J. J. Kiernicki, B. S. Newell, P. E. Fanwick, M. P. Shores, J. R. Walensky, S. C. Bart, Chem. Eur. J. 2013, 19, 16176; d) S. M. Franke, F. W. Heinemann, K. Meyer, Chem. Sci. 2014, 5, 942; e) D. E. Smiles, G. Wu, T. W. Hayton, Inorg. Chem. 2014, 53, 10240; f) C. Camp, M. A. Antunes, G. García, I. Ciofini, I. C. Santos, J. Pécaut, M. Almeida, J. Marçalo, M. Mazzanti, Chem. Sci. 2014, 5, 841; g) S. M. Franke, M. W. Rosenzweig, F. W. Heinemann, K. Meyer, Chem. Sci. 2015, 6, 275; h) D. E. Smiles, G. Wu, T. W. Hayton, Inorg. Chem. 2015, in press. [180] L. Ventelon, C. Lescop, T. Arliguie, P. C. Leverd, M. Lance, M. Nierlich, M. Ephritikhine, Chem. Commun. 1999, 659.

[181] a) J. L. Brown, S. Fortier, R. A. Lewis, G. Wu, T. W. Hayton, J. Am. Chem. Soc. 2012, 134, 
15468; b) D. E. Smiles, G. Wu, T. W. Hayton, J. Am. Chem. Soc. 2014, 136, 96.

[182] J. L. Brown, S. Fortier, G. Wu, N. Kaltsoyannis, T. W. Hayton, J. Am. Chem. Soc. 2013, 135, 5352.

[183] a) J. D. Rinehart, T. D. Harris, S. A. Kozimor, B. M. Bartlett, J. R. Long, Inorg. Chem. 2009, 48, 3382; b) B. S. Newell, A. K. Rappé, M. P. Shores, Inorg. Chem. 2010, 49, 1595.

[184] R. K. Rosen, R. A. Andersen, N. M. Edelstein, J. Am. Chem. Soc. 1990, 112, 4588.

[185] L. P. Spencer, E. J. Schelter, P. Yang, R. L. Gdula, B. L. Scott, J. D. Thompson, J. L. Kiplinger, E. R. Batista, J. M. Boncella, Angew. Chem. Int. Ed. 2009, 48, 3795.

[186] a) P. L. Arnold, D. Patel, C. Wilson, J. B. Love, Nature, 2008, 451, 315; b) P. L. Arnold, A. F. Pecharman, E. Hollis, A. Yahia, L. Maron, S. Parsons, J. B. Love, Nat. Chem. 2010, 2, 1056; c) P. L. Arnold, E. Hollis, F. J. White, N. Magnani, R. Caciuffo, J. B. Love, Angew. Chem. Int. Ed. 2011, 50, 887; d) P. L. Arnold, G. M. Jones, S. O. Odoh, G. Schreckenbach, N. Magnani, J. B. Love, Nat. Chem. 2012, 4, 221; e) P. L. Arnold, E. Hollis, G. S. Nichol, J. B. Love, J. -C. Griveau, R. Caciuffo, N. Magnani, L. Maron, L. Castro, A. Yahia, S. O. Odoh, G. Schreckenbach, J. Am. Chem. Soc. 2013, 135, 3841; f) A. -C. Schmidt, F. W. Heinemann, W. W. Lukens Jnr, K. Meyer, J. Am. Chem. Soc. 2014, 136, 11980.

[187] B. M. Gardner, J. C. Stewart, A. L. Davis, J. McMaster, W. Lewis, A. J. Blake, S. T. Liddle, Proc. Natl. Acad. Sci. USA, 2012, 109, 9265.

[188] a) L. Salmon, P. Thuéry, E. Rivière J. -J. Girerd, M. Ephritikhine, Chem. Commun. 2003, 762; b) S. A. Kozimor, B. M. Bartlett, J. D. Rinehart, J. R. Long, J. Am. Chem. Soc. 2007, 129, 10672.

[189] a) J. D. Rinehart, J. R. Long, J. Am. Chem. Soc. 2009, 131, 12558; b) J. D. Rinehart, K. R. Meihaus, J. R. Long, J. Am. Chem. Soc. 2010, 132, 7572.

[190] a) K. R. Meihaus, J. D. Rinehart, J. R. Long, Inorg. Chem. 2011, 50, 8484; b) M. A. Antunes, L. C. J. Pereira, I. C. Santos, M. Mazzanti, J. Marçalo, M. Almeida, Inorg. Chem. 2011, 50, 9915; c) J. T. Coutinho, M. A. Antunes, L. C. J. Pereira, H. Bolvin, J. Marcalo, M. Mazzanti, M. Almeida, Dalton Trans. 2012, 41, 13568; d) J. D. Rinehart, J. R. Long, Dalton Trans. 2012, 41, 13572; e) K. R. Meihaus, S. G. Minasian, W. W. Lukens Jnr, S. A. Kozimor, D. K. Shuh, T. Tyliszczak, J. R. Long, J. Am. Chem. Soc. 2014, 136, 6056.

[191] F. Moro, D. P. Mills, S. T. Liddle, J. van Slageren, Angew. Chem. Int. Ed. 2013, 52, 3430.

[192] D. P. Mills, F. Moro, J. McMaster, J. van Slageren, W. Lewis, A. J. Blake, S. T. Liddle, Nat. Chem. 2011, 3, 454.

[193] J. T. Coutinho, M. A. Antunes, L. C. J. Pereira, J. Marçalo, M. Almeida, Chem. Commun. 2014, 50, 10262.

[194] V. Mougel, L. Chatelain, J. Pécaut, R. Caciuffo, E. Colineau, J. -C. Griveau, M. Mazzanti, 
Nature Chem. 2012, 4, 1011.

[195] a) V. Mougel, L. Chatelain, J. Hermle, R. Caciuffo, E. Colineau, F. Tuna, N. Magnani, A. de Geyer, J. Pécaut, M. Mazzanti, Angew. Chem. Int. Ed. 2014, 53, 819; b) L. Chatelain, J. P. S. Walsh, J. Pécaut, F. Tuna, M. Mazzanti, Angew. Chem. Int. Ed. 2014, 53, 13434.

[196] D. M. King, F. Tuna, J. McMaster, W. Lewis, A. J. Blake, E. J. L. McInnes, and S. T. Liddle, Angew. Chem. Int. Ed., 2013, 52, 4921.

[197] O. T. Summerscales, F. G. N. Cloke, P. B. Hitchcock, J. C. Green, N. Hazari, Science 2006, $311,829$.

[198] a) O. T. Summerscales, F. G. N. Cloke, P. B. Hitchcock, J. C. Green, N. Hazari, J. Am. Chem. Soc. 2006, 128, 9602; b) A. S. P. Frey, F. G. N. Cloke, P. B. Hitchcock, I. J. Day, J. C. Green, G. Aitken, J. Am. Chem. Soc. 2008, 130, 13816.

[199] A. S. P. Frey, F. G. N. Cloke, M. P. Coles, L. Maron, T. Davin, Angew. Chem. Int. Ed. 2011, 50,6881 .

[200] P. L. Arnold, Z. R. Turner, R. M. Bellabarba, R. P. Tooze, Chem. Sci. 2011, $2,77$.

[201] I. Castro-Rodriguez, H. Nakai, L. N. Zakharov, A. L. Rheingold, K. Meyer, Science 2004, 305, 1757.

[202] O. T. Summerscales, A. S. P. Frey, F. Geoffrey, N. Cloke, P. B. Hitchcock, Chem. Commun. 2009, 198.

[203] a) O. P. Lam, S. C. Bart, H. Kameo, F. W. Heinemann, K. Meyer, Chem. Commun. 2010, 46, 3137; b) A. -C. Schmidt, A. V. Nizovtsev, A. Scheurer, F. W. Heinemann, K. Meyer, Chem. Commun. 2012, 48, 8634.

[204] a) S. J. Zuend, O. P. Lam, F. W. Heinemann, K. Meyer, Angew. Chem. Int. Ed. 2011, 50, 10626; b) O. P. Lam, S. M. Franke, F. W. Heinemann, K. Meyer, J. Am. Chem. Soc. 2012, $134,16877$.

[205] E. M. Matson, W. P. Forrest, P. E. Fanwick, S. C. Bart, J. Am. Chem. Soc. 2011, 133, 4948.

[206] P. Roussel, P. Scott, J. Am. Chem. Soc. 1998, 120, 1070.

[207] S. M. Mansell, N. Kaltsoyannis, P. L. Arnold, J. Am. Chem. Soc. 2011, 133, 9036.

[208] A. L. Odom, P. L. Arnold, C. C. Cummins, J. Am. Chem. Soc. 1998, 120, 5836.

[209] F. G. N. Cloke, P. B. Hitchcock, J. Am. Chem. Soc. 2002, 124, 9352.

[210] W. J. Evans, S. A. Kozimor, J. W. Ziller, J. Am. Chem. Soc. 2003, 125, 14264.

[211] B. M. Cossairt, N. A. Piro, C. C. Cummins, Chem. Rev. 2010, 110, 4164.

[212] F. H. Stephens, Ph.D. Thesis, Massachusetts Institute of Technology, Cambridge, 2004.

[213] A. S. P. Frey, F. G. N. Cloke, P. B. Hitchcock, J. C. Green, New. J. Chem. 2011, 35, 2022. 
[214] a) M. J. Monreal, S. Khan, P. L. Diaconescu, Angew. Chem. Int. Ed. 2009, 48, 8352; b) M. J. Monreal, P. L. Diaconescu, J. Am. Chem. Soc. 2010, 132, 7676; c) C. Camp, V. Mougel, P. Horeglad, J. Pécaut, M. Mazzanti, J. Am. Chem. Soc. 2010, 132, 17374.

[215] I. Castro-Rodríguez, H. Nakai, P. Gantzel, L. N. Zakharov, A. L. Rheingold, K. Meyer, J. Am. Chem. Soc. 2003, 125, 15734.

[216] A UC triple bond has been observed in matrix isolation: J. T. Lyon, H. -S. Hu, L. Andrews, J. Li, Proc. Natl. Acad. Sci. USA 2007, 104, 18919.

[217] R. R. Langeslay, M. E. Fieser, J. W. Ziller, F. Furche, W. J. Evans, Chem. Sci. 2015, 6, 517.

[218] (a) S. P. Nolan, M. Porchia, T. J. Marks, J. Am. Chem. Soc. 1991, 10, 1450; (b) R. S. Sternal, T. J. Marks, J. Am. Chem. Soc. 1987, 6, 2621; c) S. G. Minasian, J. L. Krinsky, V. A. Williams, J. Arnold, J. Am. Chem. Soc. 2008, 130, 10086; d) S. T. Liddle, J. McMaster, D. P. Mills, A. J. Blake, C. Jones, W. D. Woodul, Angew. Chem. Int. Ed. 2009, 48, 1077; e) B. M. Gardner, J. McMaster, W. Lewis, S. T. Liddle, Chem. Commun. 2009, 2851; f) B. M. Gardner, J. McMaster, W. Lewis, A. J. Blake, S. T. Liddle, J. Am. Chem. Soc. 2009, 131, 10388; g) D. Patel, D. M. King, B. M. Gardner, J. McMaster, W. Lewis, A. J. Blake, S. T. Liddle, Chem. Commun. 2011, 47, 295; h) B. M. Gardner, J. McMaster, F. Moro, W. Lewis, A. J. Blake, S. T. Liddle, Chem. Eur. J. 2011, 17, 6909; i) B. M. Gardner, D. Patel, A. D. Cornish, J. McMaster, W. Lewis, A. J. Blake, S. T. Liddle, Chem. Eur. J. 2011, 17, 11266; j) B. M. Gardner, D. Patel, W. Lewis, A. J. Blake, S. T. Liddle, Angew. Chem. Int. Ed. 2011, 50, 10440.

[219] L. Gagliardi, B. O. Roos, Nature 2005, 433, 848.

\section{Author Biography and Picture}

Stephen T. Liddle was born in Sunderland in the North East of England in 1974. He obtained his BSc (Hons) in 1997 and $\mathrm{PhD}$ in 2000, both from Newcastle University. After postdoctoral fellowships at the Universities of Edinburgh, Newcastle, and Nottingham, he took up a Royal Society University Research Fellowship at Nottingham where he is currently a Professor of Inorganic Chemistry. His research interests include metal-ligand multiple bonding, metal-metal bonds, small molecule activation, and single molecule magnetism of the f-block elements, with a particular focus on uranium. 


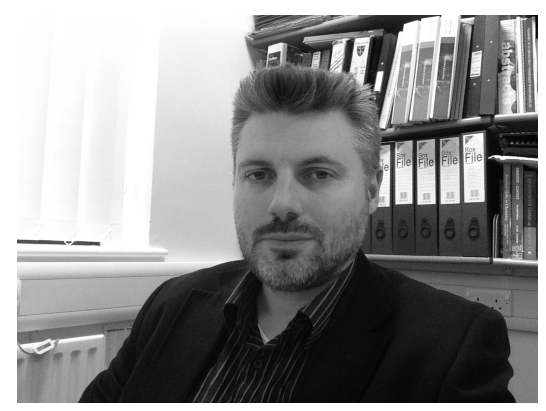

ToC Graphic

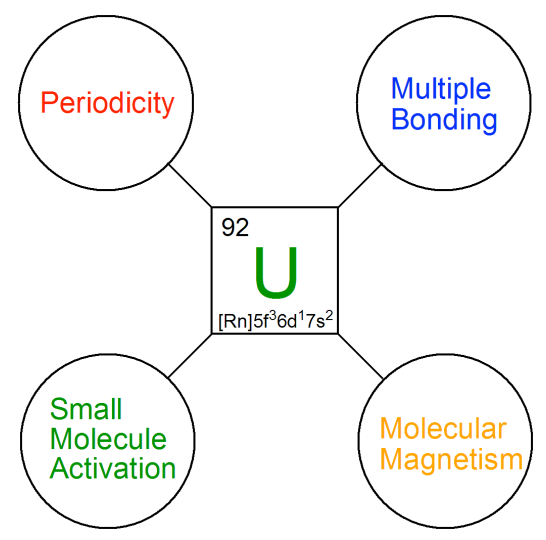

